\title{
Receipt of Overactive Bladder Drugs and Incident Dementia: a Population-Based Case-Control Study
}

\author{
by
}

\author{
Rano Matta
}

A thesis submitted in conformity with the requirements

for the degree of Master's of Science in Clinical Epidemiology and Healthcare Research

Institute of Health Policy, Management and Evaluation University of Toronto

(C) Copyright by Rano Matta 2019 


\title{
Receipt of Overactive Bladder Drugs and Incident Dementia: a Population-Based Case-Control Study
}

\author{
Rano Matta \\ Master's of Science in Clinical Epidemiology and Health Care Research \\ Institute of Health Policy, Management and Evaluation \\ University of Toronto
}

2019

\begin{abstract}
Second-line treatment for overactive bladder $(\mathrm{OAB})$, consists of muscarinic antagonists or $\beta-3$ agonists. There is limited knowledge about the differential risk of incident dementia associated with receiving the various $\mathrm{OAB}$ drugs available.
\end{abstract}

We conducted a population-based case-control study, where cases with incident dementia were age- and sex-matched to controls from the general population. We performed multivariate conditional logistic regression to estimate the odds of incident dementia associated with receiving individual $\mathrm{OAB}$ antimuscarinics, relative to a $\beta-3$ agonist, mirabegron.

Patients had an increased odds of incident dementia associated with receiving antimuscarinic drugs, solifenacin (OR 1.24; 95\% CI 1.08-1.43) and darifenacin (OR 1.30; 95\% CI 1.08-1.56), compared to those receiving mirabegron, in the six months prior to diagnosis. In the six months to one year prior to diagnosis, receipt of any OAB antimuscarinic was associated with increased odds of incident dementia (OR 1.29; 95\% CI 1.09-1.54), compared to receipt of mirabegron. 


\section{Acknowledgments}

A sincere thank you to all the members of my thesis committee. Many thanks to Dr. Tara Gomes and Dr. David Juurlink who went above and beyond their roles as committee members to provide clinical and methodological expertise in all aspects of designing and executing this study. Special thanks to Dr. Nick Daneman and Dr. Keith Jarvi as reviewers for my thesis, who provided valuable insights that have served to enhance the quality and rigor of this research.

Dr. Robert Nam has been an excellent research mentor and role model for me since beginning my Master's studies. It was his encouragement that led me to pursue this degree. His impact on my development as both a health services researcher and urologist is immeasurable. He has truly been an outstanding research supervisor.

I would also like to thank Dr. Sender Herschorn, whose guidance and mentorship has been instrumental to my development as a researcher and clinician. Dr. Herschorn has played an outsized role in my short time as an investigator and urology resident. Importantly, Dr. Herschorn's unwavering enthusiasm for functional urology and unparalleled capability to collaborate are qualities I hope to carry with me going forward.

Many thanks to other members of the Division of Urology who were supportive throughout my time as a resident in the Surgeon Scientist Training Program: Dr. Ronald Kodama, Dr. Robert Stewart, Dr. Jason Lee, and Dr. Neil Fleshner. I am also grateful to the Department of Surgery, University of Toronto, Surgeon Scientist Training Program for salary support through my graduate studies. This thesis was supported in part by a Canada Graduate Scholarship from the Canadian Institute for Health Research.

Lastly, to my wife Donna for her unending support and encouragement during my graduate studies and residency. Without her this would not have been possible. 


\section{Table of Contents}

\section{Contents}

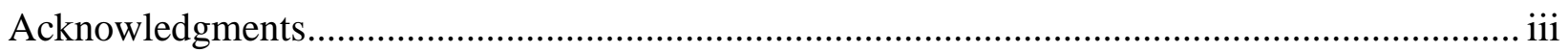

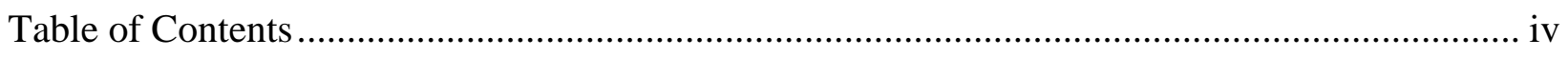

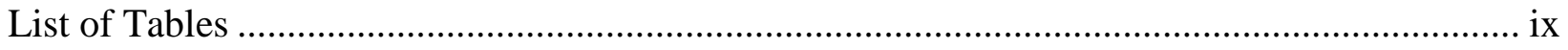

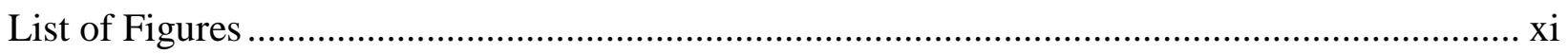

Chapter 1 Introduction and Study Objectives ................................................................................

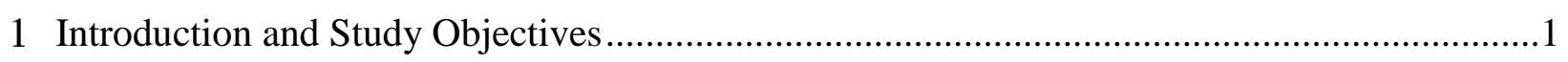

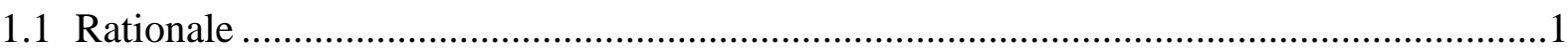

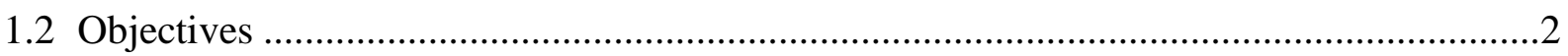

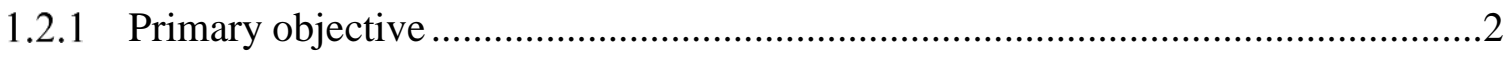

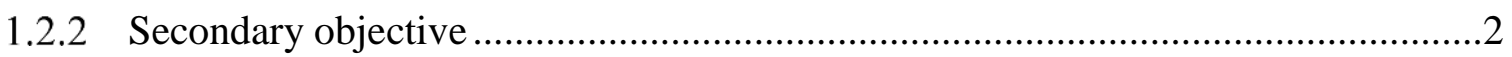

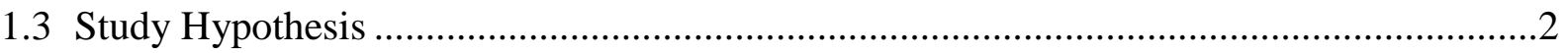

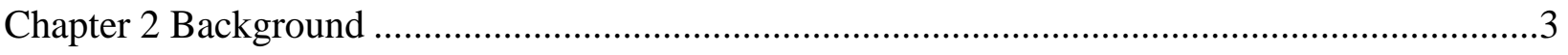

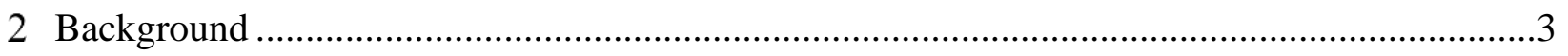

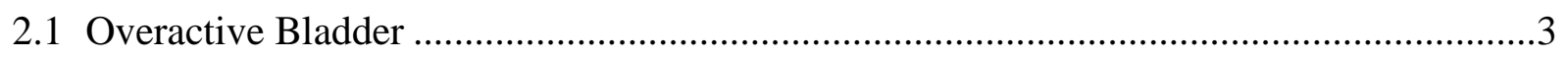

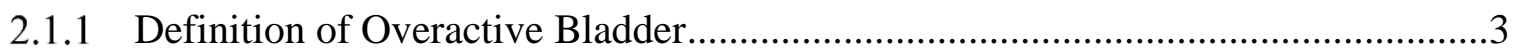

2.1.2 Epidemiology of Overactive Bladder ……………..............................................

2.1.3 Physiology of micturition and urinary storage ........................................................

2.1.4 Pathophysiology and mechanisms of $\mathrm{OAB}$......................................................10

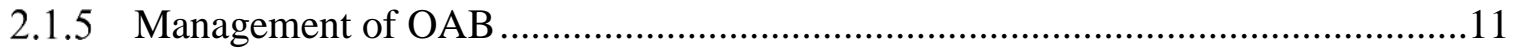

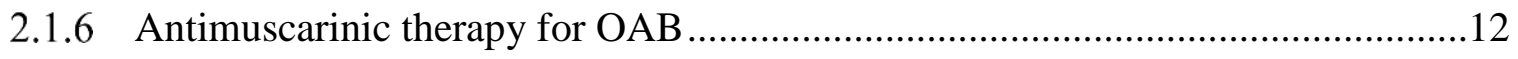

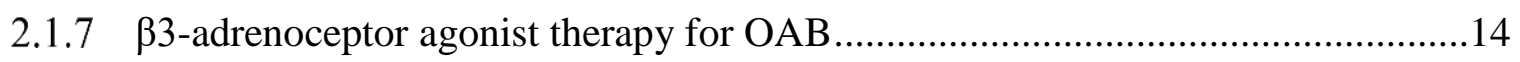

2.1.8 $\mathrm{OAB}$ Antimuscarinics and anticholinergic burden .............................................15

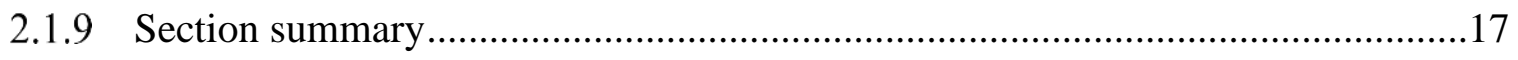




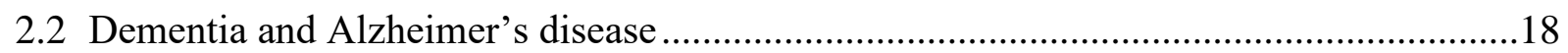

2.2.1 Definition and Epidemiology ............................................................................18

2.2.2 Pathophysiology of Alzheimer's disease ..........................................................20

2.2.3 Section summary ..........................................................................................21

2.3 The cognitive effects of antimuscarinic overactive bladder drugs ....................................21

2.3.1 Cognitive effects of oxybutynin in clinical trials................................................21

2.3.2 Cognitive effects of darifenacin in clinical trials ..............................................22

2.3.3 Cognitive effects of fesoterodine in clinical trials ...........................................22

2.3.4 Cognitive effects of solifenacin in clinical trials ...............................................22

2.3.5 Cognitive effects of tolterodine in clinical trials.................................................23

2.3.6 Cognitive effects of trospium in clinical trials....................................................23

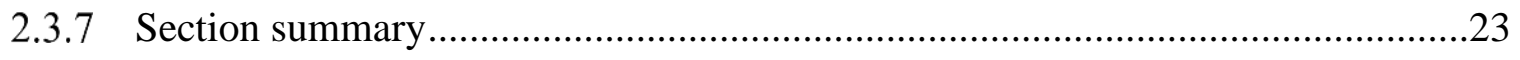

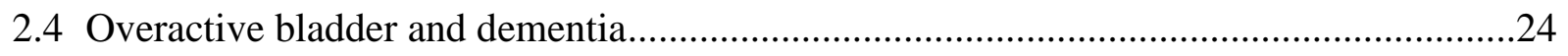

2.4.1 The association of overactive bladder and dementia ..........................................24

2.5 The association of $\mathrm{OAB}$ antimuscarinic use and incident dementia..................................25

2.5.1 Prospective studies.....................................................................................26

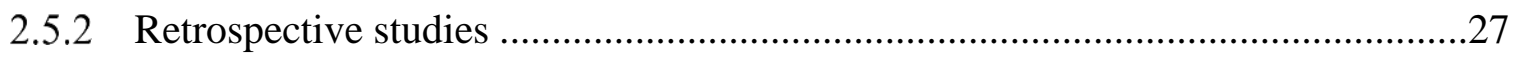

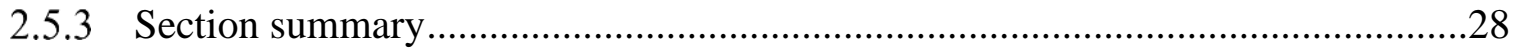

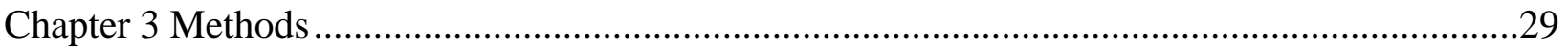

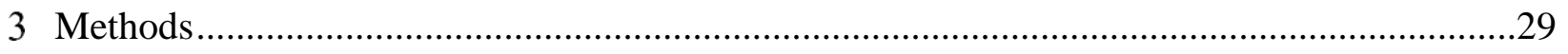

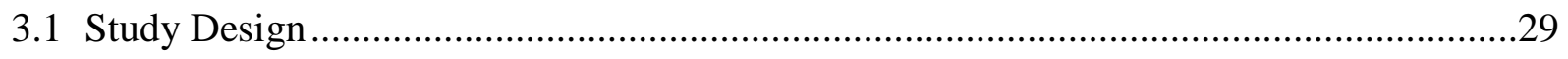

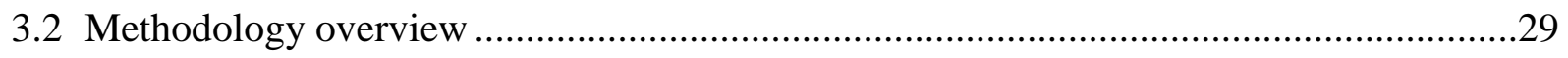

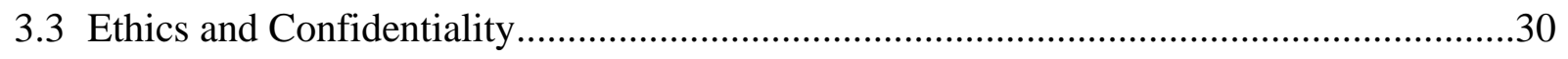

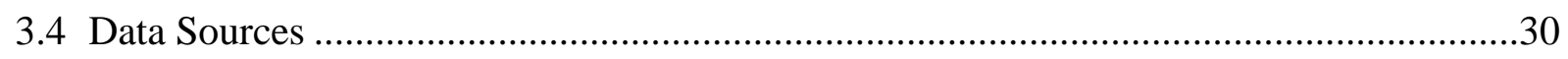

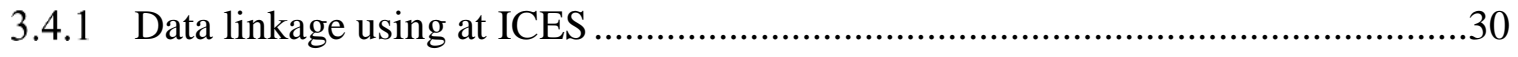

3.4.2 Registered Persons Database (RPDB) ……………...........................................31 
3.4.3 Canadian Institute for Health Information Discharge Abstract Database (CIHI-

DAD) and National Ambulatory Care Reporting System (NACRS) ...................31

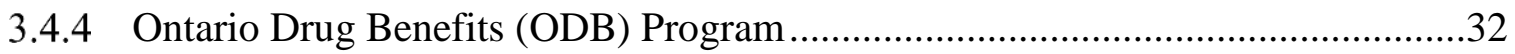

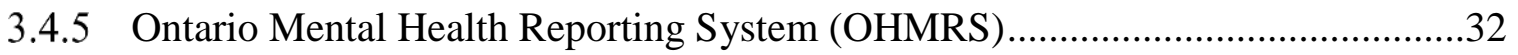

3.4.6 National Rehabilitation Reporting System (NRS) ........................................33

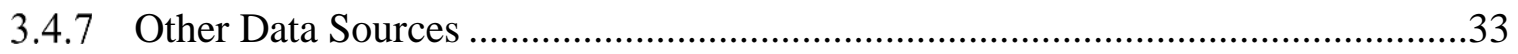

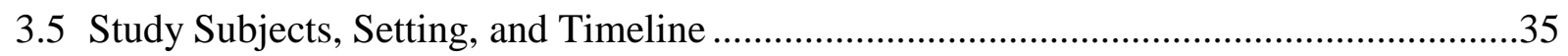

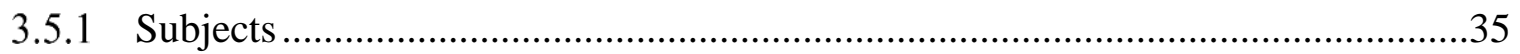

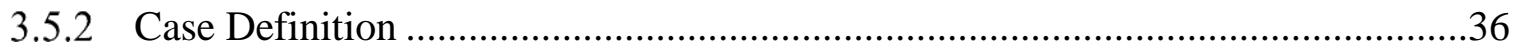

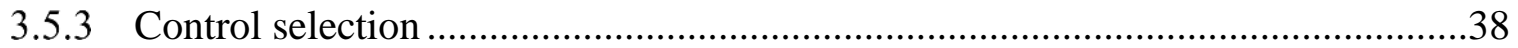

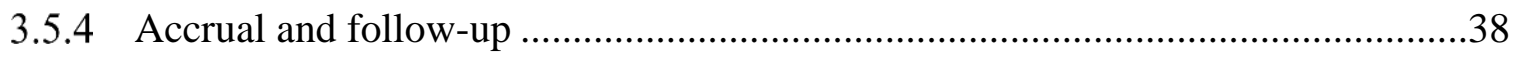

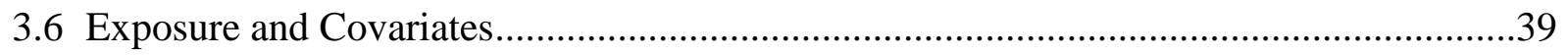

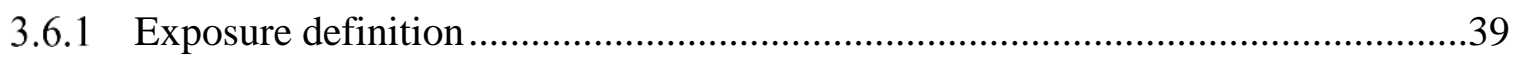

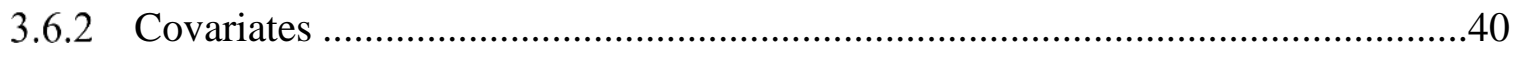

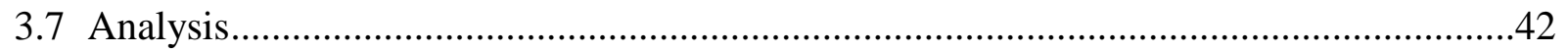

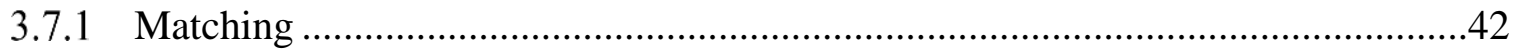

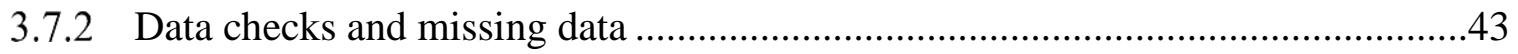

3.7.3 Baseline cohort characteristics and descriptive statistics.................................43

3.7.4 Primary analysis: The effect of antimuscarinic OAB drug exposure on

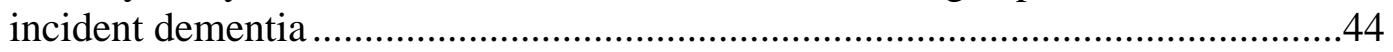

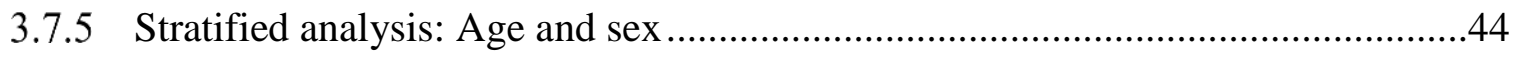

3.7.6 Sensitivity analysis: addressing protopathic bias..........................................44

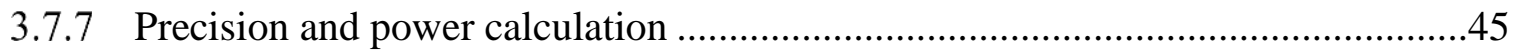

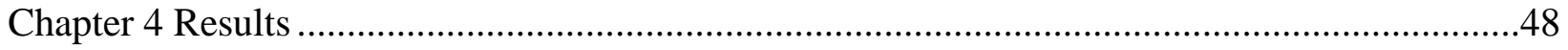

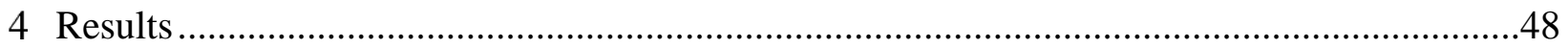

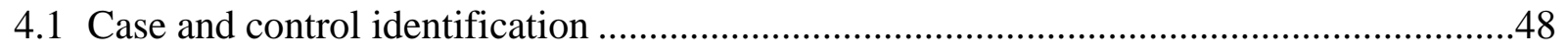

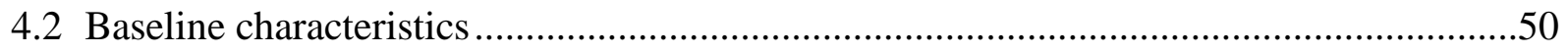


4.3 Primary analysis: Association between antimuscarinic OAB drugs and incident dementia.....

4.4 Stratified analysis: The effect of sex on the association between antimuscarinic OAB drugs and incident dementia

4.5 Stratified analysis: The effect of age on the association between antimuscarinic OAB drugs and incident dementia

4.6 Sensitivity Analysis: Addressing protopathic bias .................................................62

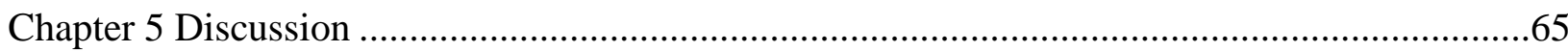

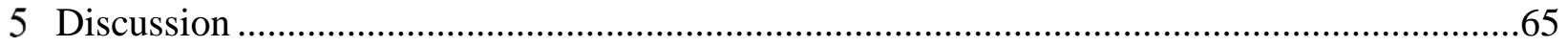

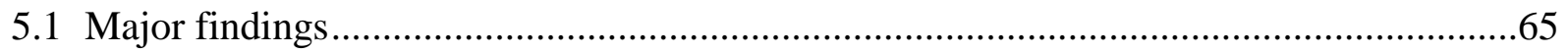

5.1.1 Observed association between antimuscarinic OAB drugs and incident

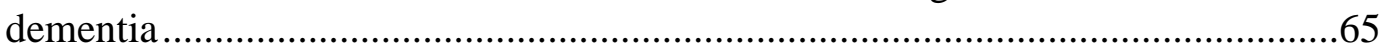

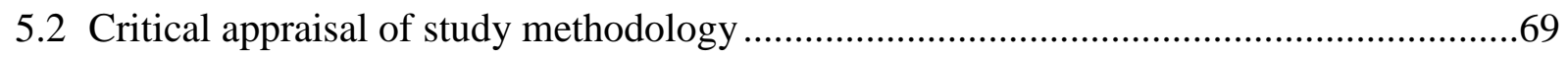

5.2.1 Study design: Case-control versus cohort study .......................................69

5.2.2 Inclusion and exclusion criteria .............................................................. 71

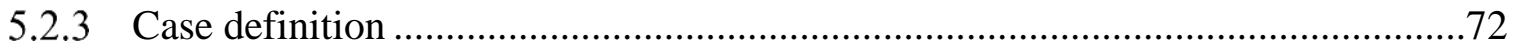

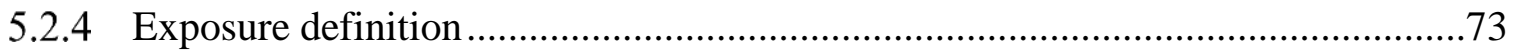

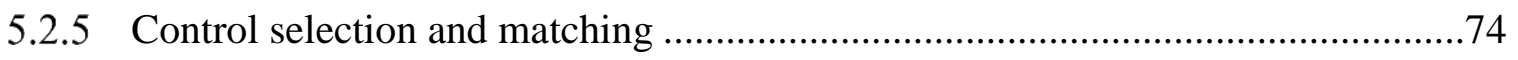

5.2.6 Analysis: Conditional logistic regression model ......................................... 77

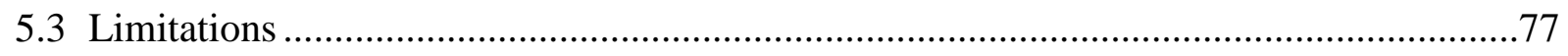

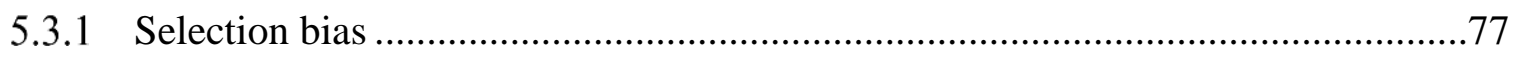

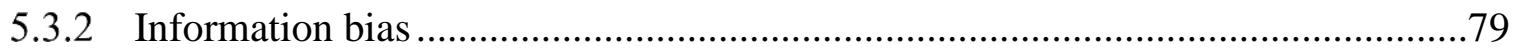

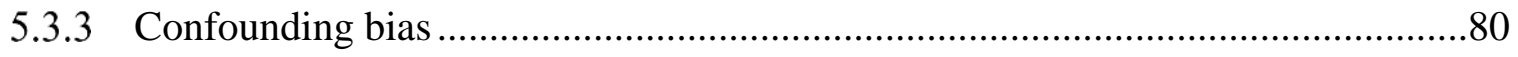

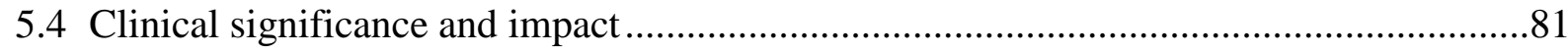

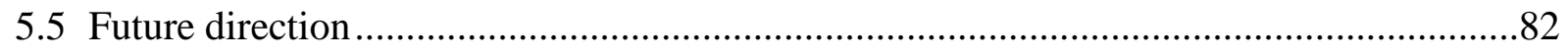

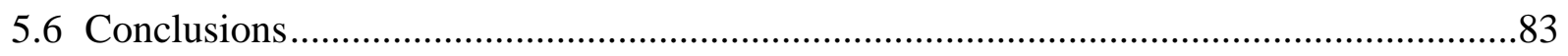

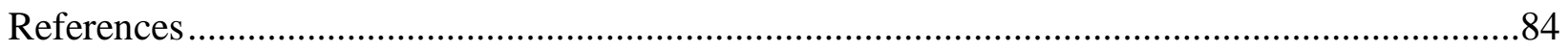

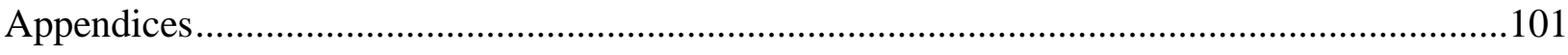




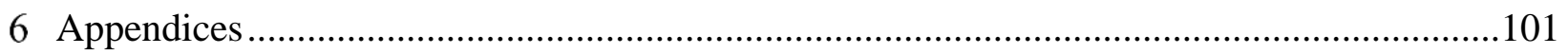

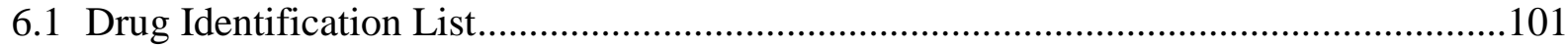

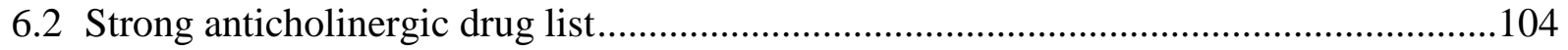

6.3 Cardiovascular, psychological, and neurological covariates and their derivation...........105

6.4 Baseline characteristics of unmatched cases and controls in sensitivity analysis ...........108

6.5 Baseline characteristics of matched cases and controls in sensitivity analysis ..............109 


\section{List of Tables}

Table 1 Summary of major OAB prevalence studies modified from Eapen and Radomski(16)...5

Table 2 Overactive bladder oral medications available through the Ontario Drug Benefits (ODB) formulary in Ontario, Canada and their selectivity for M3 muscarinic receptors adapted from Glavind and Chancellor.

Table 3 Ranking of $\mathrm{OAB}$ antimuscarinic drugs among various anticholinergic drug scales. ...... 17

Table 4 Comparison of three common criteria used for the clinical diagnosis of Alzheimer's disease

Table 5 Other administrative databases used in this study 34

Table 6 Algorithm for identifying cases with dementia or Alzheimer's modified from

Jaakimainen et al. 37

Table 7 Overactive bladder drugs available through Ontario drug benefit

Table 8 Covariates 41

Table 9 Baseline demographic characteristics before matching cases and controls

Table 10 Baseline characteristics of cases of dementia and matched controls taking OAB drugs in Ontario between 2010 and 2017.

Table 11 Unadjusted conditional logistic models evaluating the association between antimuscarinic $\mathrm{OAB}$ drug prescriptions and incident dementia. 55

Table 12 Unadjusted conditional logistic models, stratified by sex, evaluating the association between antimuscarinic $\mathrm{OAB}$ drug prescriptions and incident dementia.

Table 13 Unadjusted conditional logistic models, stratified by age, evaluating the association between antimuscarinic $\mathrm{OAB}$ drug prescriptions and incident dementia. 
Table 14 Unadjusted conditional logistic models evaluating the association between antimuscarinic $\mathrm{OAB}$ drug prescriptions and incident dementia where the $\mathrm{OAB}$ drug exposure period observed is 181 to 365 prior to dementia diagnosis. 


\section{List of Figures}

Figure 1 A model of the lower urinary tract control system, showing the voiding reflex and brainstem (green) and circuits 1, 2, and 3 (red/blue, yellow, and blue, respectively) from de Groat

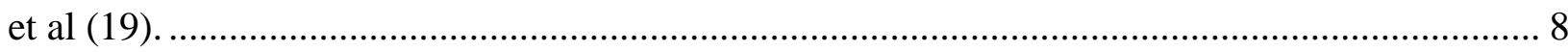

Figure 2 Neural circuits that control continence and micturition(19). a) Urine storage reflex, b)

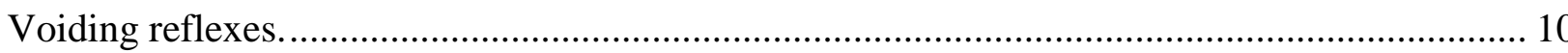

Figure 3 Hypotheses of the etiology of overactive bladder............................................. 11

Figure 4 Overactive bladder antimuscarinic drugs central nervous system relative penetration. 13

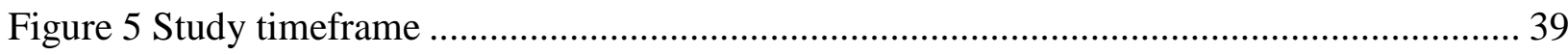

Figure 6 Estimated sample sizes across range of odds ratios and proportion of control exposure47

Figure 7 Number of cases required varying ratio of controls per case, other inputs constant...... 47

Figure 8 Study flow diagram

Figure 9 Adjusted* conditional logistic regression models evaluating the association between antimuscarinic $\mathrm{OAB}$ drug prescriptions and incident dementia. 56

Figure 10 Adjusted* conditional logistic regression model evaluating the association between antimuscarinic $\mathrm{OAB}$ drug prescription and incident dementia stratified by sex

Figure 11 Adjusted* conditional logistic regression model evaluating the association between antimuscarinic $\mathrm{OAB}$ drug prescription and incident dementia stratified by age

Figure 12 Adjusted* conditional logistic regression models of the association between antimuscarinic $\mathrm{OAB}$ drug prescriptions and incident dementia where the $\mathrm{OAB}$ drug exposure period observed is 181 to 365 prior to dementia diagnosis

Figure 13 Matching results between cases of incident dementia and controls sampled from the general population 


\section{Chapter 1 \\ Introduction and Study Objectives}

\section{Introduction and Study Objectives}

\subsection{Rationale}

Overactive bladder $(\mathrm{OAB})$ and dementia are prevalent geriatric conditions. Antimuscarinic drugs, a type of anticholinergic agent that target muscarinic receptors in the bladder, are a mainstay of management. Chronic use of anticholinergic medications results in increased Alzheimer-type pathology (beta amyloidosis and senile plaque formation) and may induce a nondegenerative form of mild cognitive impairment (MCI), which can precede dementia. In prospective and retrospective cohort studies, prolonged use of anticholinergics has been associated with cognitive impairment (CI) and incident dementia. Elderly patients using antimuscarinic drugs for $\mathrm{OAB}$ are at risk for developing $\mathrm{CI}$ as they are deficient in cholinergic neurotransmission which is necessary for several cognitive processes.

Amongst $\mathrm{OAB}$ drugs, there is significant variability in cognitive side effects, likely owing to varying degrees of muscarinic receptor selectivity and central nervous system penetration. Selective agents target M3 receptors in the bladder with greater affinity than M1 receptors in the central nervous system, which are implicated in memory and cognition. Mirabegron, a newer agent for patients with $\mathrm{OAB}$, targets $\beta-3$ adrenergic receptors and is not known to have any cognitive effects. The incidence of dementia associated with antimuscarinic OAB drugs, in the setting of selective M3 antimuscarinics, antimuscarinics that have limited CNS penetration, and beta-3 adrenergic agonist prescribing, has not been studied. This information is important as it can have significant implications for the management of OAB amongst the elderly. 


\subsection{Objectives}

\subsubsection{Primary objective}

To determine the odds of receiving an antimuscarinic OAB drug (exposure) compared to a nonantimuscarinic OAB drug (mirabegron), among older individuals who develop dementia (outcome), as compared to a matched sample of control patients without dementia.

\subsubsection{Secondary objective}

To determine the effect of sex and age on the odds of receiving an antimuscarinic OAB drug (exposure) compared to a non-antimuscarnic OAB drug (mirabegron), among older individuals who develop dementia (outcome), as compared to a matched sample of control patients without dementia.

\subsection{Study Hypothesis}

For the primary objective, we hypothesize that there will be an increased odds of receiving antimuscarinic $\mathrm{OAB}$ drugs compared to a non-antimuscarinic drug (mirabegron), among individuals who develop dementia. For the secondary objective, we hypothesize that there will not be a significant effect of sex or age on the odds of receiving an antimuscarinic OAB drug among individuals who develop dementia compared to matched controls. 


\section{Chapter 2 \\ Background}

\section{Background}

\subsection{Overactive Bladder}

\subsubsection{Definition of Overactive Bladder}

Overactive bladder $(\mathrm{OAB})$ is a syndrome defined by the International Continence Society as the presence of urinary urgency, with or without urinary incontinence (UI) usually accompanied by urinary frequency and nocturia, in the absence of any obvious pathology such as urinary tract infection (1). These symptoms may result from other pathology and it is important to rule out other causes prior to diagnosing $\mathrm{OAB}$. Patients are often diagnosed with $\mathrm{OAB}$ once they report these symptoms as being bothersome(2). Patient with neurologic disease can develop these urinary symptoms, sometimes referred to as neurogenic $\mathrm{OAB}(3)$, however, most studies of $\mathrm{OAB}$ exclude individuals with symptoms related to neurologic conditions.

\subsubsection{Epidemiology of Overactive Bladder}

$\mathrm{OAB}$ is a prevalent condition in both men and women. Bothersome $\mathrm{OAB}$ symptoms are prevalent in $23 \%$ of adults over 40 years old(4), and the prevalence increases with age, affecting up to $50 \%$ of people older than $75(5,6)$.

Two survey studies of OAB in Canada have been performed. Among these studies, the prevalence of $\mathrm{OAB}$ varies depending on the definitions used. Corcos and Schick reported the overall prevalence of OAB to be $18.1 \%$ (14.8\% in men, $21.2 \%$ in women) (7). They defined $\mathrm{OAB}$ as urgency with or without other symptoms. More recently, Herschorn et al. found the prevalence is lower at $13.9 \%$ of respondents ( $13.1 \%$ of men, $14.7 \%$ of women) in a Canadian population-based survey, owing to a stricter definition of OAB (urgency with one or more additional symptoms)(8). 
Larger survey studies have also been conducted in other populations and are summarized in Table 1. The largest of these studies, EPIC, a population-based cross-sectional survey evaluating OAB symptoms in Canada, Germany, Italy, and Sweden of adults aged $\geq 18$ years, showed an overall prevalence of lower urinary tract symptoms (LUTS) of 11.8\%(5). When they looked specifically at LUTS that define OAB, these were reported in $12.8 \%$ of women and $10.8 \%$ of men. Storage symptoms (difficulty with storing urine) were more common in women (59.2\% of symptomatic women) than in men $(51.3 \%)$. With respect to urinary incontinence, women had a much higher rate of any urinary incontinence (urge, mixed, stress, and other) than men (13.1\% vs $5.4 \%$ ). Most patients had a combination of urinary symptoms. Urgency with or without UI in the absence of frequency or nocturia was present in $21 \%$ of men and $23 \%$ of women. Approximately $50 \%$ of OAB patients had a combination of two symptoms, and approximately one-third of patients reported a combination of three OAB symptoms.

Patients with OAB experience a poor quality of life(9), with increased rates of depression(10,11) and falls(12). Moreover, it is clear that $\mathrm{OAB}$ is associated with adverse health outcomes including metabolic syndrome(13), cardiovascular disease(14), and mortality(15). 
Table 1 Summary of major OAB prevalence studies modified from Eapen and Radomski(16).

\begin{tabular}{|c|c|c|c|c|c|c|c|c|c|}
\hline Study & Setting & Participants & $\begin{array}{l}\text { Age of } \\
\text { Participants }\end{array}$ & \multicolumn{2}{|c|}{ OAB Prevalence } & \multirow[t]{2}{*}{$\begin{array}{l}\text { Nocturia* } \\
\text { prevalence }\end{array}$} & \multirow[t]{2}{*}{$\begin{array}{l}\text { Urgency } \\
\text { prevalence }\end{array}$} & \multirow[t]{2}{*}{$\begin{array}{l}\text { Frequency } \\
\text { prevalence }\end{array}$} & \multirow[t]{2}{*}{$\begin{array}{l}\text { UUI or MUI } \\
\text { prevalence }\end{array}$} \\
\hline & & & & Female & Male & & & & \\
\hline $\begin{array}{l}\text { EPIC (Irwin } \\
\text { et. al) (6) }\end{array}$ & $\begin{array}{l}\text { Canada, Germany, } \\
\text { Italy, Sweden, UK } \\
\text { Apr-Dec } 2005\end{array}$ & 19,165 & $\geq 18$ years & $12.8 \%$ & $10.8 \%$ & $\begin{array}{l}\text { M:34.5\% } \\
\text { F: } 54.5 \%\end{array}$ & $\begin{array}{l}\text { M: } 10.8 \% \\
\text { F: } 12.8 \%\end{array}$ & $\begin{array}{l}\text { M: } 6.8 \% \\
\text { F:7.4\% }\end{array}$ & $\begin{array}{l}\text { M: } 1.8 \% \\
\text { F: } 3.9 \%\end{array}$ \\
\hline $\begin{array}{l}\text { NOBLE } \\
\text { (Stewart et. al) } \\
(18) \\
\end{array}$ & $\begin{array}{l}\text { USA } \\
\text { Nov 2000-Jan } \\
2001 \\
\end{array}$ & 5,204 & $\geq 18$ years & $16.9 \%$ & $16.0 \%$ & & - & - & - \\
\hline $\begin{array}{l}\text { EpiLUTS } \\
\text { (Coyne et. al) } \\
\text { (5) } \\
\end{array}$ & $\begin{array}{l}\text { USA } \\
2005\end{array}$ & 20,000 & $\geq 40$ years & 43.1 & 27.2 & - & $\begin{array}{l}\text { M: } 15.6 \% \\
\text { F: } 10.9 \%\end{array}$ & - & $\begin{array}{l}\text { M: } 7.3 \% \\
\text { F: } 10.2 \%\end{array}$ \\
\hline $\begin{array}{l}\text { Milsom et. al } \\
\text { (19) }\end{array}$ & $\begin{array}{l}\text { France, Germany, } \\
\text { Italy, Spain, } \\
\text { Sweden, UK } \\
2002 \\
\end{array}$ & 16,776 & $\geq 40$ years & 17.4 & 15.6 & - & $1.6 \%$ & $4.9 \%$ & $1.2 \%$ \\
\hline
\end{tabular}

*Nocturia defined as $\geq 1$ episode/night

OAB - Overactive Bladder, UUI-Urgency urinary incontinence, MUI - Mixed urinary incontinence, $M$ - Male, F-Female. 


\subsubsection{Physiology of micturition and urinary storage}

To elucidate the mechanisms of $\mathrm{OAB}$ and the treatments available, it is important to first understand the structures and pathways involved in normal urine storage and voiding. These exist in three key areas: the lower urinary tract (LUT), spinal pathways that relay efferent and afferent signals between the LUT and the brain, and higher centers in the brain that act as modulators of these pathways.

The LUT consists of the bladder (and urethra) which is composed primarily of smooth muscle known as the detrusor, and an inner surface composed of urothelial cells that act as a barrier to absorption of urine. The bladder acts as a reservoir for filling at low pressure and the ability to contract and release urine completely in an antegrade fashion. This is done in co-ordination with the activity of the smooth and striated muscle of the internal and external urethral sphincters, respectively.

Signals from the brain are relayed through spinal pathways consisting of four general components(19): primary afferent neurons, spinal efferent neurons, spinal interneurons, and brain neurons that modulate spinal reflex pathways.

The main central nervous system (CNS) structures involved in normal storage and voiding are the periaqueductal gray matter (PAG) which acts as a relay center for afferent activity from the bladder and efferent signals from the higher centers of the brain; the prefrontal cortex (PFC), which directs voluntary decisions to void; and the pontine micturition center (PMC), which provides descending signals to the sacral spinal nuclei and initiates voiding. Functional magnetic resonance (fMRI) studies have identified the interplay between these areas and the current paradigm is a model of three forebrain neural circuits involved in voiding and storage(19) (see Figure 1):

1. Frontal: Consists of the PAG, thalamus, insula, lateral prefrontal cortex (IPFC), and medial prefrontal cortex (mPFC). The insula registers homeostatic visceral sensations, and in fMRI studies is seen to have increased activation with bladder filling(20). During voiding, the mPFC is activated, and during storage the IPFC is activated(21). The IPFC is also involved with cognition and memory(19). 
2. Midcingulate: Consists of the supplementary motor area (SMA) and dorsal anterior cingulate cortex (dACC). This circuit manages sensory information from the bladder such as urgency but is likely not activated in individuals with normal voiding. It appears to act as a "backup" continence mechanism(19). When there is an urge to void, the dACC is coactivated with the SMA, causing contraction of the pelvic floor and striated sphincter muscles(19).

3. Subcortical: Consists of the hippocampal and paralimbic regions. During slow filling of the bladder, unconscious monitoring of ascending bladder signals leads to activation of a subcortical network that includes the PAG and parts of hippocampal region (23). It is thought that the PAG monitors the status of the bladder via this circuit. Due to the involvement of the limbic system, it may also be involved in the emotional aspects of voiding (ie. the sense of safety)(19). 
Figure 1 A model of the lower urinary tract control system, showing the voiding reflex and brainstem (green) and circuits 1, 2, and 3 (red/blue, yellow, and blue, respectively) from de Groat et al (19).

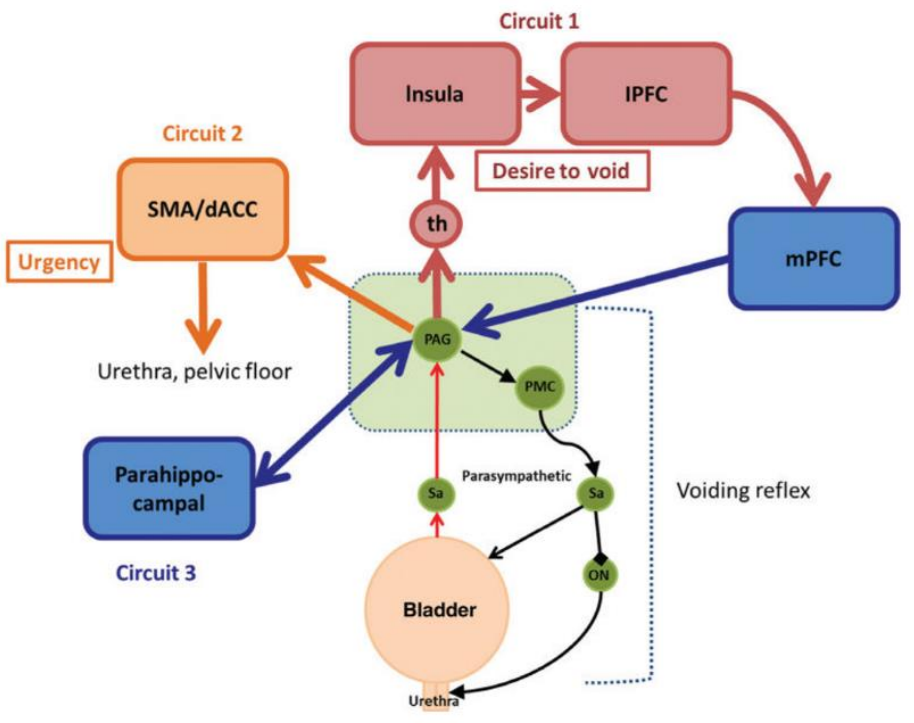

(used with permission, Wiley)

$P A G=$ periaqueductal gray $; P M C=$ pontine micturition center $;$ th $=$ thalamus $; m P F C=$ medial prefrontal cortex $;$ $I P F C=$ lateral prefrontal cortex $;$ SMA = supplementary motor area $;$ dACC $=$ dorsal anterior cingulate cortex.

During urine storage, the guarding reflex, a spinal reflex pathway, promotes continence and afferent signals from the bladder ascend to inhibit the PAG (see Figure 2). Low-level vesical A $\delta$ afferent nerves synapse with spinal tracts in the lumbosacral spinal cord and stimulate reflex efferent sympathetic and parasympathetic pathways to the bladder. Sympathetic nerves, originating in the thoracolumbar spinal cord (T10 to L2) activate post-ganglionic fibers through the hypogastric nerve, causing them to release noradrenaline at the level of $\beta 3$ adrenergic receptors on the detrusor, relaxing the smooth muscle. At the same time, sympathetic innervation targets $\alpha-1$ receptors at the internal urethral sphincter, causing it to contract and facilitating the storage of urine. Parasympathetic nerves in the sacral spinal cord (S2 to S4) are inhibited, 
preventing contraction of the detrusor muscle. Somatic alpha motor neurons, originating from the ventral horn in the sacral spinal cord segments (S2-S4) and synapsing with the pudendal nerve, release acetylcholine $(\mathrm{ACh})$ targeting nicotinic receptor on the striated muscle of the external sphincter, causing it to contract.

Once the bladder is full, stretch receptors in the bladder wall fire afferent signals via the pelvic nerve to the spinal cord. This activates the spinobulbospinal reflex pathways, passing signals through to the brain(23). The signals sent to the brain relay through the PAG before reaching the PMC, to coordinate other brain centers discussed above and activate the voiding reflex (Figure 2). Adults with normal continence are able to postpone voiding until it is appropriate(22) through higher brain centers. Once the voiding reflex is initiated, there is an increase in parasympathetic tone via postganglionic neurons in the pelvic nerve, releasing acetylcholine (ACh) at the level of the bladder. There is also inhibition of pudendal and sympathetic outflow, causing the internal and external urethral sphincter muscles to relax. In the bladder smooth muscle, M2 and M3 muscarinic receptor subtypes are expressed; however, the M3 subtype is the main receptor involved in excitatory transmission by $\mathrm{ACh}$, causing the detrusor to contract. M2 receptors suppress adrenergic inhibitory mechanisms and may contribute to dysfunctional bladder contraction(19). 
Figure 2 Neural circuits that control continence and micturition(19). a) Urine storage reflex, b) Voiding reflexes.
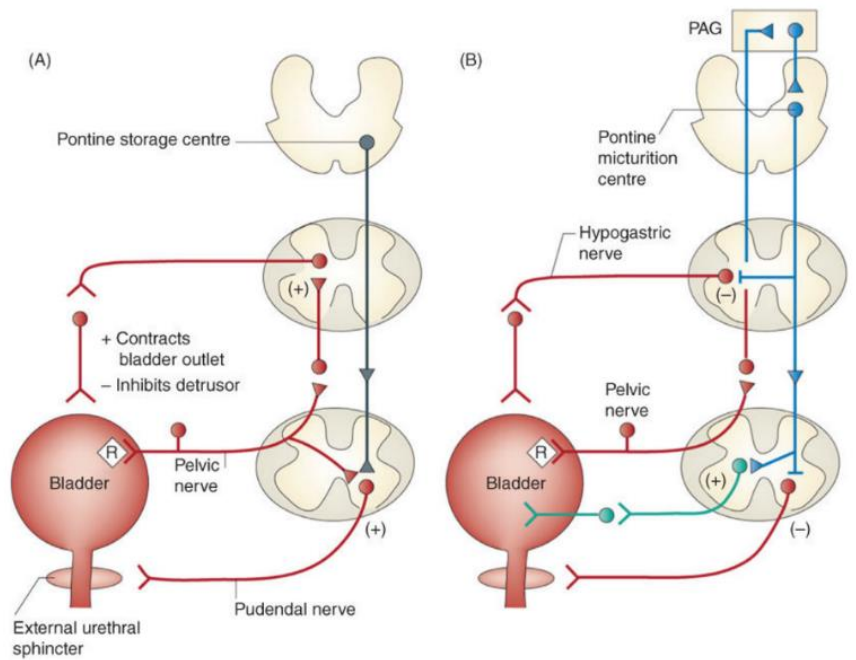

(used with permission, Wiley)

\subsubsection{Pathophysiology and mechanisms of OAB}

Current paradigms regarding the pathophysiology of urge urinary incontinence and OAB, divide its underlying causes into two categories: increased sensory (afferent) activity and abnormal management of afferent signals (Figure 3). The increased afferent activity may be the result of abnormal function of the urothelium (urothelium-based hypothesis), which reacts to mechanical and chemical stimuli through various receptors, such as unmyelinated C fibers. Another cause of increased afferent activity may be dysfunction in detrusor myocyte excitability and an exaggerated response to stimuli (myogenic hypothesis), possibly caused by increased coupling of myocytes through connexin expression, as seen by Haferkamp et al. in patients with neurogenic detrusor overactivity(24). Dysregulation of the handling of afferent signals may be due to inappropriate activation of the voiding reflex or deficits in the guarding reflex or higher central nervous system inhibition pathways (neurogenic hypotheses). The association between cognitive decline and $\mathrm{OAB}$ is discussed in section 2.4.1.

As patients age, there are changes in bladder structure and function (decreased capacity and increased involuntary contractions) and alterations in the central nervous system control of the 
bladder(25). It is likely that there is an integrative cause of $\mathrm{OAB}$, where a combination of the above mechanisms might trigger inappropriate detrusor contractions, suppress urinary control, and lead to OAB symptoms.

Figure 3 Hypotheses of the etiology of overactive bladder.

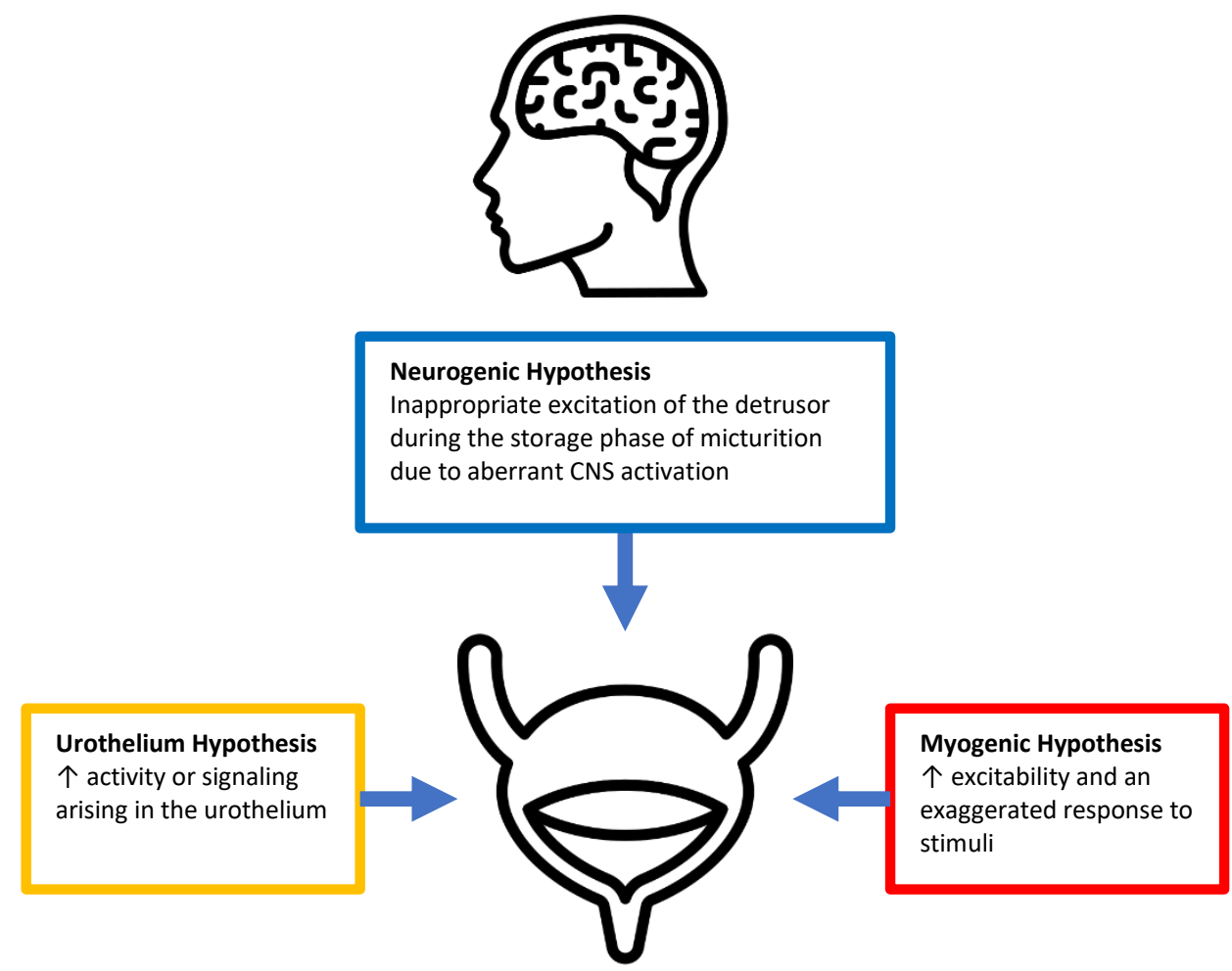

Icons used under free license, designed by Smashicons and prettyicons at flaticon.com

\subsubsection{Management of OAB}

Initial management of $\mathrm{OAB}$ includes behavioral therapies, including the use of bladder training, bladder control strategies, pelvic floor muscle training, and fluid management(26-28).

Behavioral therapies can be supplemented with pharmacotherapy(29), which constitutes secondline therapy. This includes antimuscarinic drugs, a type of anticholinergic agent that targets muscarinic receptors, and oral $\beta 3$-adrenoceptor agonists. Beyond oral pharmacotherapy, for patients who are refractory, intradetrusor onabotulinumtoxinA is used as a third-line treatment in 
patients with symptoms refractory to oral therapy or if they cannot tolerate side effects(26). This can be an effective therapy, especially for controlling urgency urinary incontinence, however it does require repeat injections every 6-12 months and it is an invasive procedure with the risk of urinary tract infections, hematuria, and lower urinary tract injury(26). Another third-line surgical option is electrical stimulation, which includes peripheral tibial nerve stimulation or implantation of a sacral neuromodulation device. These appear to be a good option for patients who are refractory to or intolerant of oral pharmacotherapy(29).

\subsubsection{Antimuscarinic therapy for OAB}

Antimuscarinic medications have been used to treat patients with OAB since the 1970s (30). These drugs act by blocking muscarinic receptors on the bladder, namely the $\mathrm{M}_{2}$ and $\mathrm{M}_{3}$ subtypes, thereby reducing uninhibited detrusor contractions. In randomized clinical trials antimuscarinics are more effective than placebo at reducing the number of incontinence episodes per day by 0.4 to 1.1 episodes, reducing urinary frequency by 0.5 to 1.3 episodes per day, and reducing urgency episodes by 0.6 to 1.5 episodes per day(31). Although the antimuscarinics drugs were statistically significantly more effective than placebo when quantifying symptoms, $45 \%$ of those taking placebo in parallel arm trials were likely to report cure or improvement in their symptoms while $60 \%$ reported cure/improvement in the medication groups (32). When comparing these drugs to each other none appears superior in terms of both efficacy and minimizing adverse effects $(33,34)$. Nonetheless, current guidelines recommend the use of any antimuscarinic or beta-3 agonist as first-line drug treatment for OAB since efficacy among the drugs is considered to be similar(26-28).

There have been observed shifts in OAB treatment patterns between drugs $(35,36)$. This is likely because newer agents have more convenient dosing regimens, therefore improving adherence(37). For example, tolterodine allowed for a single daily dose as compared to three or four daily doses of oxybutynin. As well, newer agents are perceived to have improved side-effect profiles due to their increased specificity for M3 muscarinic receptors(38) (Table 2) and limited central nervous system (CNS) penetration(39). 
Antimuscarinics are part of the larger class of anticholinergic medications, and are considered to have a high level of anticholinergic burden using various clinical scales(40). There is a trade-off of efficacy compared to adverse effects of antimuscarinic OAB drugs. In a network metaanalysis evaluating all the antimuscarinic trials, the drugs with the most positive efficacy/adverse events relationship were $40 \mathrm{mg}$ daily trospium chloride, $100 \mathrm{mg} / \mathrm{g}$ daily oxybutynin topical gel, and $4 \mathrm{mg}$ daily fesoterodine(41). Side effects of antimuscarinics include dry mouth, constipation, blurred vision, and cognitive impairment (somnolence and drowsiness)(42). Dry mouth is the most common side effect(34), and is thought to occur secondary to non-selective binding of M3 receptors in the submandibular glands (43). Since elderly patients are deficient in cholinergic neurotransmission, which is necessary for several cognitive processes(44), cognitive impairment is a worrisome possibility. This occurs secondary to M1 receptor binding in the CNS. Therefore, more contemporary $\mathrm{OAB}$ drugs have focused on targeting the urinary bladder over the salivary gland and CNS(38) and reducing blood-brain barrier penetration(45). Table 2 shows the muscarinic receptor selectivity of each available drug. Figure 4 demonstrates the relative degree of CNS penetration among the different agents. We discuss further the cognitive effects of antimuscarinic $\mathrm{OAB}$ drugs in section 2.3.

Figure 4 Overactive bladder antimuscarinic drugs central nervous system relative penetration.

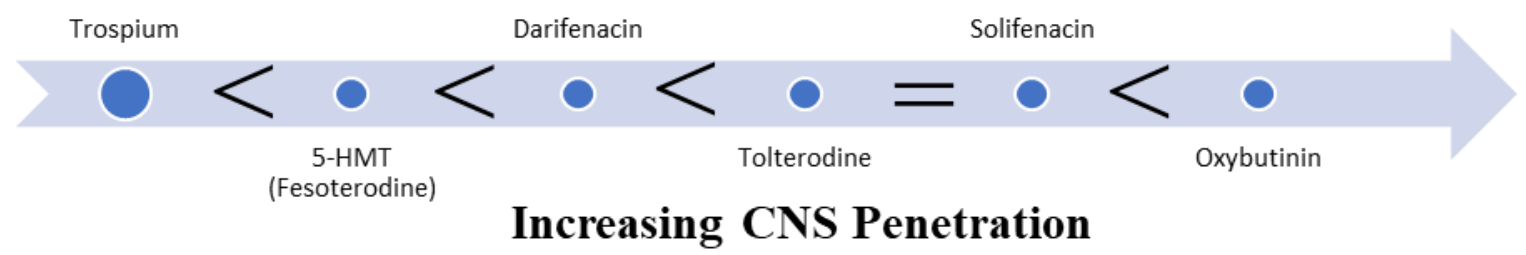

Adapted from Callegari et al. (39). 
Table 2 Overactive bladder oral medications available through the Ontario Drug Benefits (ODB) formulary in Ontario, Canada and their selectivity for M3 muscarinic receptors adapted from Glavind and Chancellor.

\begin{tabular}{|c|c|c|c|}
\hline \multirow{2}{*}{ Drug } & \multirow{2}{*}{ First date in ODB } & \multicolumn{2}{|c|}{ Receptor Selectivity } \\
\hline & & M3 vs. M1 & M3 vs. M2 \\
\hline Oxybutinin $^{1}$ & April 1990 & 1.8 & 6.2 \\
\hline Tolterodine $^{1}$ & June 1999 & 0.6 & 0.95 \\
\hline Darifenacin ${ }^{1}$ & Dec 2011 & 16 & 53 \\
\hline Solifenacin $^{1}$ & Dec 2011 & 2.2 & 15 \\
\hline Trospium $^{2}$ & Dec 2011 & 1.5 & 1.3 \\
\hline Fesoterodine $^{2}$ & April 2013 & 0.2 & 0.5 \\
\hline Mirabegron & May 2015 & - & - \\
\hline
\end{tabular}

${ }^{1}$ Ki ratios; Ki represents the inhibitory constant and is defined kinetically as the ratio of rate constants for the binding of a drug to a target receptor.

${ }^{2}$ Ki ratios determined from the antilog of pKi values

$O D B$ - Ontario drug benefits

\subsection{7 $\quad$ 33-adrenoceptor agonist therapy for OAB}

While antimuscarinic medications have been the mainstay of oral therapy for OAB, close to $30 \%$ of OAB patients are now being prescribed mirabegron $(35,36)$, currently the only approved $\beta 3$ adrenoceptor agonist for OAB. These medications are particularly appealing for the OAB patient population as they appear to have limited adverse effects relative to antimuscarinics $(46,47)$.

Mirabegron targets $\beta 3$-adrenoceptors with a higher affinity than that for $\beta 1$ - and $\beta 2$ -

adrenoceptors, thereby mediating relaxation of bladder smooth muscle during the storage phase. There is some evidence from functional assays in mouse and rat isolated tissues, that it also exerts $\alpha_{1 \mathrm{~A}}$-adrenoceptor antagonism in urethral smooth muscle, and $\alpha_{1 \mathrm{D}}$-adrenoceptor antagonism in the aorta (48). In industry-sponsored trials $(49,50)$ and in pooled analyses $(51-53)$, mirabegron results in a significantly greater reduction in UUI episodes, urgency, and frequency compared with placebo. It also provides positive changes in symptom specific bother, health related quality of life, and patients' perception of their bladder condition(54). Use of mirabegron is also associated with greater median persistence and 1-year adherence (5.6-7.4 months and 32\%-38\%, respectively) compared to antimuscarinics (median persistence < 5 months, 1-year adherence $12 \%-25 \%)(55)$. 
Since $\beta_{3}$-adrenoreceptors are expressed on cardiovascular tissue(56), there are concerns that mirabegron may have adverse cardiovascular side-effects. In phase III trials, mirabegron produces a minor increase in resting heart rate, blood pressure, and QTc interval on electrocardiograms(57). Despite this, pooled evidence from trials indicates that the cardiovascular safety of mirabegron is acceptable at therapeutic doses and similar to that of antimuscarinics(57). In the three 12-week phase 3 trials of mirabegron, the incidence of QTc prolongation was $0-0.3 \%$ and cardiac arrhythmia was $2.2-2.5 \%$ (51). In the 1-year trial of mirabegron, the incidence of QTc prolongation was $0.4 \%$ and cardiac arrythmia was 3.9\%(58). An independent population-level post-marketing study has also demonstrated that mirabegron does not increase the risk of arrhythmia or major cardiac events after 1 year of follow-up (59).

Although mirabegron appears safe (54), the rates of overall treatment emergent adverse events in phase III trials are comparable to antimuscarinics tolterodine $(51,58)$ and solifenacin(60). In phase III trials, the most common adverse events reported were nasopharyngitis, headache, and constipation(61). A recent network meta-analysis by Kelleher et al. found that the risk of constipation with mirabegron was lower compared with five antimuscarinics(47). Mirabegron was also better tolerated for dry mouth and urinary retention. There is limited data on the cognitive effects of mirabegron, although none of the phase III randomized clinical trials have identified any treatment emergent adverse cognitive effects. In phase 4 studies, mirabegron did not have any cognitive side effects at 12 weeks(62).

\subsubsection{OAB Antimuscarinics and anticholinergic burden}

The risk of cognitive effects secondary to antimuscarinic drug exposure has been investigated using both in vitro methods and evidence-based anticholinergic drug scales. Amongst all the anticholinergic drug scales, oxybutynin and tolterodine are ranked as having a strong anticholinergic burden. $\mathrm{OAB}$ antimuscarinics can represent a significant amount of the total anticholinergic burden experienced by a patient. Yoshida et al. identified in a Japanese population-based study among $58.8 \%$ of patients with overactive bladder, $\geq 80 \%$ of the total Anticholinergic Burden (ACB) score was attributable to $\mathrm{OAB}$ antimuscarinics(63). The various anticholinergic drug scales and their ranking of $\mathrm{OAB}$ antimuscarinic drugs are listed in Table 3. 
The most commonly used in vitro method for measuring anticholinergic burden, serum anticholinergic activity (SAA), is a measure of anticholinergic activity on rat brain muscarinic receptors in an individual's serum. The assay does not distinguish between anticholinergic activity due to medications, stress response, or acute illness(64), limiting its clinical utility, with no correlation seen between SAA and cerebral cholinergic activity measured by electroencephalograpy(65). Nonetheless, Mulsant et al. demonstrated an association between serum anticholinergic activity (SAA) and lower Mini Mental State Exam scores in a cohort of 201 community-dwelling individuals (66).

Anticholinergic drug scales are more commonly employed clinically to determine anticholinergic burden. There are several ordinal scales, and they rank drugs in 4 levels of anticholinergic potential, from limited or none to very strong, with low to moderate concordance amongst five of the scales(40). Among all these scales, the total anticholinergic burden on a patient is calculated by the sum of each drug's anticholinergic score, assuming the patient is receiving a typical daily dose and that the individual drugs' anticholinergic effects follow a linear additive model.

The anticholinergic burden (ACB) scale is the most widely used of the clinical scales (67). In this three-level scale, level 1 refers to potentially anticholinergic drugs which have SAA or in vitro muscarinic receptor affinity but no known clinical effects. Level 2 and 3 refer to definite clinical anticholinergic activity based on the literature or expert opinion. The use of a definite anticholinergic on the ACB scale can increase the risk of cognitive impairment by $46 \%$ over 6 years(68). 
Table 3 Ranking of OAB antimuscarinic drugs among various anticholinergic drug scales.

\begin{tabular}{|c|c|c|c|c|c|c|c|c|}
\hline \multirow{2}{*}{ Medication } & \multicolumn{7}{|c|}{ Anticholinergic Drug Scale rating } \\
\cline { 2 - 9 } & $\mathbf{A C B}(67)$ & $\mathbf{A R S}^{\mathbf{1}}(69)$ & $\mathbf{C h e w}^{\mathbf{2}}(\mathbf{7 0})$ & $\mathbf{A D S}^{\mathbf{3}}(\mathbf{7 1})$ & $\mathbf{A A S}^{\mathbf{4}}(72)$ & $\mathbf{A L S}^{\mathbf{5}}(73)$ & $\mathbf{C r A S}^{\mathbf{6}}(\mathbf{7 4})$ & $\mathbf{D u r a n}^{\mathbf{7}}(\mathbf{7 5})$ \\
\hline Darifenacin & 3 & - & - & - & - & - & - & 3 \\
\hline Trospium & - & - & - & 3 & - & - & - & - \\
\hline Fesoterodine & - & - & - & 3 & - & - & - & - \\
\hline Flavoxate & 3 & - & - & 3 & - & - & - & 3 \\
\hline Oxybutynin & 3 & 3 & ++ & 3 & 4 & 2 & - & 3 \\
\hline Solifenacin & - & - & - & 3 & - & - & - & - \\
\hline Tolterodine & 3 & 2 & +++ & 3 & - & 3 & 3 & 3 \\
\hline
\end{tabular}

Anticholinergic Cognitive Burden Scale (ACB), Anticholinergic Risk Scale (ARS), Chew's scale (Chew), Anticholinergic Activity Scale (AAS), Anticholinergic Load Scale (ALS), Clinician-Rated Anticholinergic Scale (CrAS), Duran's scale (Duran), Anticholinergic Burden Classification (ABC), Drug Burden Index (DBI)

1. ARS: Level 0 No activity, Level 1 moderate anticholinergic activity, Level 2 strong anticholinergic activity, Level 3 very strong

2. Chew: 0 absence of anticholinergic activity $(A A) ; 0 /+$ none or minimal $A A ;+A A$ equivalent to $0.5-5 \mathrm{pmol} / \mathrm{mL}$ of atropine equivalents; ++ (AA of 5-15 pmol/mL $) ;+++(A A$ of $>15 \mathrm{pmol} / \mathrm{mL})$

3. ADS: Level 0 No activity, Level 1 potentially anticholinergic based on SAA, Level 2 anticholinergic adverse effects documented at excessive doses, Level 3 markedly anticholinergic.

4. AAS: Based on Chew scale, used to evaluate the association between anticholinergic drug use and cognitive decline in Parkinson's disease

5. ALS: Based on SAA as measured in Chew scale and expert opinion. Level 0 (no effect) to Level 3 (strong effect).

6. CrAS: four-point scale (0-3) based on pre-existing published anticholinergic scales and expert opinion

7. Duran: this was a systematic review attempting to consolidate several scales. 0 (no anticholinergic) to 3 (high potency.

\subsubsection{Section summary}

Overactive bladder is prevalent, especially in elderly individuals. The pathophysiology of overactive bladder is multifactorial and one of the causes is likely neurogenic with dysfunction of cerebral and spinal circuits that control urine storage. Oral pharmacotherapy for OAB with antimuscarinics and $\beta-3$ adrenergic agonists is common. Antimuscarinics are effective at controlling symptoms, however they are associated with several adverse effects. The antimuscarinics are strong anticholinergics and have both peripheral and central effects, the most concerning of which are cognitive side effects. Mirabegron, the only $\beta-3$ adrenergic agonists currently available, appears to be more favourable for cognitive function, although it has not been compared to antimuscarinics directly. 


\subsection{Dementia and Alzheimer's disease}

\subsubsection{Definition and Epidemiology}

For the purposes of this review, we focus on Alzheimer's disease (AD) dementia, as it is the most common etiology of dementia in elderly individuals. AD accounts for approximately $60 \%$ of all diagnosed cases of dementia in the United States(76). Other types of dementia include vascular dementia, dementia with Lewy bodies, frontotemporal dementia, or combinations of these types.

The epidemiology of AD, and dementia in general, has been well studied, although should be interpreted with caution, depending on the definitions used (77). Worldwide, the prevalence of all-cause dementia is approximately 5-7\% among individuals age 60 and older(78). In Canada, based on data from the Canadian Chronic Disease Surveillance System (which excludes Saskatchewan), the age-standardized prevalence of dementia in 2015 was $6.93 \%(n=419,470)$, with 7.54\% $(\mathrm{n}=266,160)$ among women and 6.03\% $(\mathrm{n}=153,310)$ among men aged 65 and older(77). This is anticipated to increase up to 1.4 million individuals by 2031(79).

$\mathrm{AD}$ dementia is on a continuum of clinical and biological cognitive function which consists of an:

1. asymptomatic preclinical phase with biomarkers (80),

2. symptomatic predementia, otherwise known as mild cognitive impairment(81),

3. dementia phase.

The preclinical stage may begin years before a diagnosis, wherein biological processes responsible for cognitive impairment are underway, although they are not manifest with symptoms. This stage does not have established diagnostic criteria and is not intended for clinical diagnosis, but rather has been identified in the context of a research agenda to identify biomarkers to signal when these changes in the brain begin. Mild cognitive impairment represents a clinical diagnosis where cognitive changes are recognized on mental status testing, although they do not impact a person's daily activities. 
Table 4 Comparison of three common criteria used for the clinical diagnosis of Alzheimer's disease

\begin{tabular}{|c|c|c|c|}
\hline & NIA-AA(82) & DSM-V & ICD-11(83) \\
\hline Cognitive & $\begin{array}{l}\text { Cognitive or behavioral } \\
\text { (neuropsychiatric) decline } \\
\text { from previous levels of } \\
\text { functioning, involve a } \\
\text { minimum of two } \\
\text { domains: memory, } \\
\text { visuospatial abilities, } \\
\text { reasoning and complex } \\
\text { tasks, language, and } \\
\text { personality and } \\
\text { behaviour. }\end{array}$ & $\begin{array}{l}\text { Cognitive decline from a } \\
\text { previous level of } \\
\text { performance in one or } \\
\text { more of: complex } \\
\text { attention, executive } \\
\text { function, learning and } \\
\text { memory, language, } \\
\text { perceptual-motor } \\
\text { function, social cognition }\end{array}$ & $\begin{array}{l}\text { Cognitive decline from a } \\
\text { previous level of } \\
\text { functioning with } \\
\text { impairment in two or } \\
\text { more cognitive domains: } \\
\text { memory, executive } \\
\text { functions, attention, } \\
\text { language, social cognition } \\
\text { and judgment, } \\
\text { psychomotor speed, } \\
\text { visuoperceptual or } \\
\text { visuospatial abilities }\end{array}$ \\
\hline Testing & $\begin{array}{l}\text { MMSE or similar } \pm \\
\text { neuropsychological } \\
\text { testing }\end{array}$ & - & - \\
\hline Functional impairment & $\begin{array}{l}\text { Interferes with ability to } \\
\text { function at work or at } \\
\text { usual activities }\end{array}$ & $\begin{array}{l}\text { Interferes with } \\
\text { independence in } \\
\text { activities of daily living. }\end{array}$ & $\begin{array}{l}\text { Interferes with } \\
\text { independence in the } \\
\text { person's performance of } \\
\text { activities of daily living. }\end{array}$ \\
\hline Exclusions & $\begin{array}{l}\text { Age at onset }<40 \text { or }>90 \\
\text { Delirium or major } \\
\text { psychiatric disorder } \\
\text { explain symptoms }\end{array}$ & $\begin{array}{l}\text { Substance abuse or other } \\
\text { major mental disorder }\end{array}$ & $\begin{array}{l}\text { Coma (MB20.1), delirium } \\
\text { (6D70), disorders of } \\
\text { intellectual development } \\
(6 \mathrm{~A} 00), \\
\text { neurodevelopmental } \\
\text { disorders (6A00-6A0Z), } \\
\text { stupor (MB20.0), old age } \\
\text { (senility) (MG2A) }\end{array}$ \\
\hline
\end{tabular}

NIA-AA - National Institutes of Health and the Alzheimer's Association

DSM-V - Diagnostic and Statistical Manual of Mental Disorders, 5th Edition

ICD-11 - International Classification of Disease, Eleventh Revision

In 2011, the National Institute of Neurological and Communicative Disorders and Stroke and the Alzheimer's Disease and Related Disorders Association (NINCDS-ADRDA) criteria for AD diagnosis were revised by the National Institutes of Health and the Alzheimer's Association (NIA-AA)(82). These criteria are reliable for the diagnosis of probable AD, and have had a sensitivity of $81 \%$ and specificity of $70 \%$ across several clinical pathological studies(84). They specified that all-cause dementia is diagnosed when "there are cognitive or behavioral (neuropsychiatric) symptoms that: interfere with the ability to function at work or at usual activities; and represent a decline from previous levels of functioning and performing; and are 
not explained by delirium or major psychiatric disorder. The cognitive or behavioral impairment should involve a minimum of two domains: memory, visuospatial abilities, reasoning and complex tasks, language, and personality and behaviour. Other criteria for AD dementia are summarized in Table 4.

\subsubsection{Pathophysiology of Alzheimer's disease}

AD can be familial or sporadic, with sporadic being the more common form (95\%). Familial AD is caused by mutations in amyloid precursor protein (APP), presenilin-1 (PS1), or presenilin-2 (PS2) genes(85). Sporadic AD has known risk factors including older age, cerebrovascular and cardiovascular risk factors, psychological risk factors (ie. history of psychological disorder) and genetic factors, such as inheritance of apolipoprotein E (APOE) $\varepsilon 4(86)$.

The two pathological hallmarks of Alzheimer's disease in the central nervous system (CNS) are the formation of neurofibrillary tangles (NFTs) which arise from intraneuronal hyperphosphorylation of tau protein, and extracellular amyloid- $\beta$ peptide $(A \beta)$ plaques, formed through proteolytic cleavage of APP by a family of enzymes ( $\gamma$-secretases and $\beta$-secretases), which include PS1 and PS2. These two major proteins are the basis of biomarker staging in clinical models of AD (87). The most common explanatory model for the disease, the "amyloid hypothesis", postulates that increased formation of $\mathrm{A} \beta$ and decreased clearance are the primary drivers of pathogenesis and clinical symptoms including neurofibrillary tangles containing tau protein, neuronal loss, and cognitive decline(88). However, no single neuropathology is causally associated with $\mathrm{AD}$, but rather it appears that it is a result of multiple concomitant factors not completely understood(89). Other pathological processes involved in AD include cerebral amyloid angiopathy (CAA) and loss of basal forebrain cholinergic neurons and GABAergic dysfunction. CAA is a vascular pathology in which $A \beta$ aggregates form in the wall of cerebral arteries and arterioles, replacing a significant amount of contractile smooth muscle cells in the tunica media with $\mathrm{A} \beta$ deposits resulting in a loss of vascular contractility and partial occlusion in small distal arterioles by $\mathrm{A} \beta$ aggregates. Neuronal loss results in the classical cerebral atrophy of $\mathrm{AD}(90)$. 


\subsubsection{Section summary}

Dementia and Alzheimer's disease (AD) affect 5-7\% of people worldwide. AD is the most common form representing $60 \%$ of all dementia. AD consists of a preclinical and mild cognitive impairment (MCI) phase prior to $\mathrm{AD}$. The two pathological hallmarks of $\mathrm{AD}$ are the formation of neurofibrillary tangles (NFTs) which arise from intraneuronal hyperphosphorylation of tau protein, and extracellular amyloid- $\beta$ peptide $(\mathrm{A} \beta)$ plaques in the central nervous system.

\subsection{The cognitive effects of antimuscarinic overactive bladder drugs}

Oral antimuscarinic drugs are associated with burdensome treatment related adverse events. These events occur often(42) and with greater severity(41) in elderly patients compared to younger patients. Elderly patients using antimuscarinics are especially at risk for cognitive impairment (CI), due to the increased permeability of the blood-brain barrier(91), lower pglycoprotein activity, an efflux transporter for the CNS(92), slower drug metabolism and elimination(93), and decreased central cholinergic transmission which is necessary for several cognitive processes(44). Moreover, patients with pre-existing Alzheimer's dementia are more sensitive to temporary cholinergic blockade than age matched controls(94).

Despite variable measurement and reporting of cognitive outcomes in OAB antimuscarinic trials(95), there is still clinical evidence that they have a detrimental effect on cognition.

\subsubsection{Cognitive effects of oxybutynin in clinical trials}

Oxybutinin is the most widely studied of these drugs in terms of cognitive effects. In a randomized placebo-controlled trial of oxybutynin, it caused significant cognitive decrements on seven of 15 cognitive measures in as little as 90 minutes after administration (96). In another trial of healthy patients $\geq 60$ years randomized to oxybutynin extended release (ER), darifenacin, or 
placebo, there was no significant difference in recall on the Name-Face Association test at 3 weeks between darifenacin and placebo(97). However, oxybutynin ER resulted in memory impairment, with significantly lower scores than placebo and darifenacin. In women with pretreatment cognitive impairment and urge urinary incontinence, randomization to 4 weeks of treatment with oxybutynin ER $5 \mathrm{mg}$ or placebo once daily, there was no difference in mean MMSE score change and Confusion Assessment Method (CAM) scores from baseline to day 28 between groups(98).

\subsubsection{Cognitive effects of darifenacin in clinical trials}

Darifenacin, in a double-blind, 3-period crossover study of 14 days each, did not affect cognitive function at the end of treatment compared with baseline, and it was not significantly different from placebo (99). In the same trial as mentioned above by Kay et al., the effects of darifenacin (7.5 mg OD for two weeks and $15 \mathrm{mg}$ OD for one week) on recall in the Name-Face Association Test were similar to placebo at week 3 of treatment(97).

\subsubsection{Cognitive effects of fesoterodine in clinical trials}

In a small placebo- and alprazolam-controlled crossover study of fesoterodine 4 or $8 \mathrm{mg}$ for 6 days in healthy volunteers $\geq 65$, fesoterodine did not have a significant effect versus placebo on any cognitive function assessed, while alprazolam did(100). In a larger randomized trial of 794 individuals $\geq 65$, randomized to fesoterodine or placebo for 12 weeks, there was no meaningful change in mini-mental status exam (MMSE) scores by the end of the study(101). Other trials designed specifically to compare the cognitive adverse events of fesoterodine to other OAB drugs or placebo were not identified.

\subsubsection{Cognitive effects of solifenacin in clinical trials}

In a randomised, double-blind, placebo- and oxybutynin-controlled study of solifenacin $10 \mathrm{mg}$ in 12 healthy elderly volunteers, there was no significant effect of solifenacin on any cognitive 
measures (memory, attention, mood, alertness) when measured at the time of its probably maximum serum concentration compared to placebo(102). In the larger SENIOR trial, another randomised, double-blind, triple-crossover of solifenacin $10 \mathrm{mg}$, oxybutynin $5 \mathrm{mg}$ twice daily or placebo for 21 days, both drugs were not associated with significant changes in any cognitive function outcomes (attention and memory)(103).

\subsubsection{Cognitive effects of tolterodine in clinical trials}

In children 5-12 years, a small double-blinded crossover placebo controlled trial of tolterodine ER and oxybutynin ER, showed no deleterious effects on attention and memory scores over a 2 week period (104). Besides case reports (105), we could not identify other trials designed specifically to compare the cognitive adverse events of tolterodine to other OAB drugs or placebo.

\subsubsection{Cognitive effects of trospium in clinical trials}

In a phase I randomized, single-blind, parallel-group quantitative-topographical EEG (qEEG) study, patients were given trospium chloride $15 \mathrm{mg}$ tid for a single day, with minimal changes in qEEG among those who received trospium(106). In a controlled trial, 12 adults were given extended-release trospium chloride $60 \mathrm{mg}$ once daily over a 10-day period with no detectable trospium in their CSF on day 10, and no significant net drug effect on learning or recall(45).

\subsubsection{Section summary}

Although there is biological and clinical evidence to implicate antimuscarinic drugs in affecting cognition and causing long-term cognitive deterioration, there are few clinical trials designed specifically to compare cognitive adverse events among the $\mathrm{OAB}$ antimuscarinic drugs with each other and/or placebo. Moreover, given the lack of longer-term trials of $\mathrm{OAB}$ antimuscarinic medications evaluating cognition, it is unknown whether long-term use of these medications causes irreversible cognitive decline. 


\subsection{Overactive bladder and dementia}

\subsubsection{The association of overactive bladder and dementia}

There is an increased prevalence of OAB among patients with dementia(107). This association between cognitive decline and overactive bladder symptoms is likely multifactorial(107). Sakakibara identifies that there is considerable variability in the incontinence prevalence rates reported among patients diagnosed with dementia, from $11 \%$ in outpatient clinics to $90 \%$ in institutional samples, likely owing to differences in functional impairment and comorbidity among the specific populations(107).

Perhaps the best evidence for a neurogenic mechanism of overactive bladder is seen in patients with neurological disease who exhibit detrusor overactivity on urodynamics, otherwise known as neurogenic detrusor overactivity. In fact, many conditions affecting the central nervous system, including multiple sclerosis, Parkinson's disease, stroke, brain and spinal cord injury, and psychological disorders, are associated with $\mathrm{OAB}$. The biological impetus for this association is the dysregulation of cerebral circuits involved in urinary storage(19) discussed in section 2.1.3, as they share many pathways involved in cognitive function.

Another cause of $\mathrm{OAB}$ for patients with dementia is functional incontinence, which results from poor mobility and decreased motivation. An excellent review by Sakakibara et al. covers some of the possible functional mechanisms involved in OAB in patients with dementia(107). Suskind et al. demonstrated that patients with urinary urgency have slower Timed Up and Go Test times (108) which can act as a surrogate for other functional issues. Thom et al. have also found that incident UI in elderly patients is associated with impairment in activities of daily living(109), suggesting an important relationship between UI and other functional impairments.

Conditions associated with aging, that also correlate with dementia, may explain the association between LUTS and dementia. Stress urinary incontinence develops with age owing to deficits in urethral pressure(110), pelvic floor disorders(111), and increased body mass index (112). Other phenomena that may impact the prevalence of OAB with dementia include comorbidities such as diabetes mellitus(113), congestive heart failure(114), and bladder outlet obstruction. Nocturnal 
polyuria is also prevalent with age, possibly the result of other comorbidity such as congestive heart failure, but it may also be related to stroke and the regulation of arginine vasopressin (AVP) neurons in of hypothalamic region of the brain. Diabetes can cause polyuria and cause impaired detrusor contractile function, resulting in large post-void residuals that can exacerbate incontinence.

\subsection{The association of OAB antimuscarinic use and incident dementia}

Several prospective and retrospective cohort studies have explored the cognitive effects of patients who undergo antimuscarinic therapy. However, these studies have compared OAB antimuscarinic users to non-users. There is limitation with such an approach as OAB is associated with cognitive impairment and dementia, and therefore comparing these two groups introduces a selection bias. To address this, the cohort should consist only of patients with $\mathrm{OAB}$ and the groups compared can be exposed or unexposed to antimuscarinics. Another approach might be to compare exposure to $\mathrm{OAB}$ antimuscarinics to non-antimuscarinic drugs for the same indication, such as mirabegron. Another limitation of these studies is they measure a class-effect (all anti-muscarinics, or all non-selective antimuscarinics), but do not evaluate specific OAB drugs. Based on the above explanation of the variable muscarinic receptor selectivity and CNS penetration of the available $\mathrm{OAB}$ drugs, there is plausibility that their effects on cognition will vary.

In addition, these studies do not address important confounding with respect to $\mathrm{OAB}$ antimuscarinic use:

1. Patients with overactive bladder have an increased use of anticholinergic medications, besides antimuscarinics(63), increasing the probability of cognitive side effects.

2. Institutionalization and mild cognitive impairment are important risk factors for overactive bladder symptoms and the prescription of antimuscarinic drugs $(115,116)$. 
3. Older individuals are likely to have comorbidities that are associated with dementia and that cause lower urinary tract symptoms without being in the causal pathway between antimuscarinic OAB drugs and dementia.

\subsubsection{Prospective studies}

In a longitudinal French study of community dwelling individual $>60$ years, continuous use of anticholinergics for 1 year, including oxybutynin, was a strong predictor of mild cognitive impairment (MCI), although there was no apparent increase in the risk of developing dementia at follow-up after eight years (117). In the 3-city study in France $(n=6,912)$, a prospective population-based cohort study with 4 years of follow-up, there was a 1.65 (1.00-2.73) times increased odds of incident dementia and a 1.94 (1.01-3.74) times odds of incident Alzheimer's disease, as measured by DSM-IV criteria, in patients exposed to strong anticholinergics(118). The limitations of this study include a low proportion of subjects receiving OAB antimuscarinics ( $1.3 \%$ of the study sample), and the absence of evaluation of a class effect for the OAB antimuscarinics. Gray et al. also reported on a prospective population-based cohort study from Seattle, Washington of 3434 participants, 65 years or older, with no dementia at study entry(119). They found a 10-year cumulative dose-response relationship for anticholinergics and dementia (test for trend, $\mathrm{p}<.001$ ). Those in the highest anticholinergic exposure category (>1095 days or 3 years of daily use) had significantly increased risk for dementia (adjusted HR, 1.54; 95\% CI, 1.21-1.96) or Alzheimer's disease (HR, 1.63; 95\% CI, 1.24-2.14) compared with those with no use. OAB antimuscarinics represented $11 \%$ of overall anticholinergic exposure, although once again there was no evaluation of class effect.

The association between anticholinergics and incident dementia has also been examined in patients with other central nervous system disorders. Among patients with Parkinson's disease (PD), the chronic use (> 2 years) of anticholinergics results in increased Alzheimer-type pathology (beta amyloidosis and senile plaque formation) (120). This study was limited in that it only explored one OAB antimuscarinic, oxybutynin. As well, although there was evidence of increased $\beta$-amyloidosis and senile plaque formation in chronically treated PD patients, it is unclear from the study whether this correlated with clinical cognitive decline. Among patients 
with multiple sclerosis in a matched-cohort prospective study, those starting either tolterodine or oxybutynin experienced worse cognitive performance after 12 weeks compared to controls(121). Again, this study did not identify individual effects of the drugs and pooled the effects of tolterodine and oxybutynin. There were only two evaluations of cognitive function (baseline and 12-week follow-up), limiting conclusions regarding long-term effects.

\subsubsection{Retrospective studies}

In large retrospective observational studies, there is also evidence of the detrimental effects of OAB antimuscarinics. In the largest retrospective cohort study of over 40,000 patients, among patients with incident dementia, the odds of previous exposure to OAB antimuscarinic drugs was $1.23(1.18-1.28)(122)$. This association was persistent out to exposures measured 15-20 years before diagnosis. However, the only drugs examined as OAB antimuscarinics were tolterodine, oxybutynin, and solifenacin, and once again their effect was measured as a class effect. Moga et al. found that there was an increased odds of cognitive decline on the mini-mental status exam and several other cognitive measures upon initiating an OAB antimuscarinic (OR 1.4; 1.19-1.65) when compared to non-users. The odds of cognitive decline were increased further (OR 1.54; 1.26-1.89) when they restricted their analysis to new-users of non-selective antimuscarinics(123). Their study was well designed; however, it was limited in that it compared $\mathrm{OAB}$ antimuscarinic users to non-users. This may introduce a selection bias as discussed previously, whereby patients with lower urinary tract symptoms have a different dementia risk compared to patients with normal urinary function. They attempt to account for this using propensity score matching, however, besides urinary incontinence, urinary function remains unmeasured in their sample. As well, they attempt to classify the OAB antimuscarinics into 'selective' and 'non-selective' antimuscarinics, but this does not address the individual effects of the drugs with their unique pharmacologic properties. 


\subsubsection{Section summary}

With only limited prospective and retrospective observational data suggesting a class-effect among some of these drugs there is a need to identify the differential effects of the individual antimuscarinic drugs on the development of cognitive impairment and dementia. As well, it is important to address some of the confounding in this association that has been overlooked in previous observational studies that is specific to older patients with lower urinary tract symptoms. 


\section{Chapter 3 Methods}

\section{Methods}

\subsection{Study Design}

We conducted a population-based case-control study of patients in Ontario, Canada using linked administrative health datasets. These datasets were linked using unique encoded identifiers and analyzed at ICES (http://www.ices.on.ca) using standardized disease classification, procedural terms, and abstraction formats.

This study uses a nested case-control (NCC) design, whereby we include all cases, but only a random sample of controls, from a well-defined cohort. In this study the cohort was all individuals eligible to receive government funded health insurance in Ontario during the study accrual period. In NCC studies, the quality of the match procedure and the use of an appropriate analysis that accounts for the matched design are crucial to maximizing statistical efficiency and minimizing bias (124). As compared to a cohort study, the NCC design may introduce bias and result in less precise estimates, especially when considering time-varying exposures and competing risks(125). However, there are important benefits to the NCC design such as an increased relative computational efficiency compared to the cohort design with time-dependent exposures(126), although with modern computing power, the absolute differences in computing time are small(125). Another benefit of NCC study design, when considering operationalization of time-varying exposures and the recentness of exposure, is the ease of operationalizing exposure, analyzing the data, and interpreting the findings.

\subsection{Methodology overview}

We accrued individuals who were diagnosed with dementia (cases) from the population of individuals $\geq 66$ years old who were prescribed a single $\mathrm{OAB}$ drug in the 180 days prior to diagnosis, from April 1, 2010 to March 31, 2017. Cases were identified using physician billing records, hospital admission diagnoses, and pharmacy dispensing records and hard-matched to controls identified from the Ontario Registered Persons Database (RPDB) who had not 
developed dementia by their index date. We then evaluated the association between receiving a prescription of an antimuscarinic OAB drug, compared to mirabegron as the referent exposure, and a diagnosis of dementia using conditional logistic regression.

\subsection{Ethics and Confidentiality}

This study used information from administrative databases that was fully de-identified. Individual subjects were identified using an anonymous unique identifier called the ICES Key Number (IKN). Individual patient informed consent is not required for the use of encoded administrative health data in Ontario. Research ethics approval was obtained through the Sunnybrook Research Ethics Board (Protocol 355-2017), and from the University of Toronto (Protocol 36771).

\subsection{Data Sources}

\subsubsection{Data linkage using at ICES}

In Ontario, greater than $95 \%$ of residents receive all necessary healthcare services, physician services and prescription medication through the Ontario Health Insurance Plan (OHIP). Only $1 \%$ of OHIP claims originate from outside of Ontario. During those interactions, information is recorded by the Ministry of Health and Long-term care and held at ICES (http://www.ices.on.ca) under a data sharing agreement that governs the privacy and security of the data. ICES is a prescribed entity for the purposes of section 45 of Ontario's Personal Health Information Privacy Act, meaning it can collect this data via health information custodians, such as physicians and hospitals, and use it for statistical analysis to monitor the healthcare system.

Data that is collected by ICES includes personal identifiers such as health card number, name, date of birth, and postal code. This allows the assignment of a unique, confidential ICES identification number (IKN), which then allows deterministic linkage across health services databases within their inventory. 


\subsubsection{Registered Persons Database (RPDB)}

The RPDB contains information on all persons who have ever been registered under OHIP. In this study the RPDB was used to identify all eligible controls $\geq 66$ years old during the accrual period. Data included from the RPDB includes age at index date, gender, local health integration network (LHIN), urban vs. rural status (derived through postal code of residence), income quintile (derived through neighbourhood), and date of death.

\subsubsection{Canadian Institute for Health Information Discharge Abstract Database (CIHI-DAD) and National Ambulatory Care Reporting System (NACRS)}

The CIHI-DAD collects clinical, demographic, and administrative data on all hospital discharges across Canada, except Quebec. Since 2002, the DAD collects up to 25 diagnoses, with a single "most responsible" diagnosis, which accounts for the greatest portion of the length of stay and/or greatest use of resources. Diagnoses are coded according to the $10^{\text {th }}$ revision of the International Classification of Diseases (ICD-10). The CIHI-DAD also contains information on procedures, coded using the Canadian Classification of Health Interventions (CCI) procedure codes from 2002 onwards. The CIHI-DAD has been validated using re-abstraction, and re-abstracters agreed $85 \%$ of the time(127).

In this study the CIHI-DAD data was used to identify cases based on diagnostic codes, as well as identifying several covariates (see section 3.6.2). A full list of codes used is shown in Table 8.

The NACRS contains demographic, administrative and clinical data for all hospital-based and community-based ambulatory care including day surgery and emergency department visits collected at the time of servicing patients. The main clinical elements in NACRS are the presenting complaint and emergency department discharge diagnosis. The discharge diagnosis includes more than 800 diagnoses in common terms that are mapped to ICD-10 codes. In this study, NACRS discharge diagnosis was used to capture outpatient diagnoses to identify cases and important covariates (see section 3.6.2). 


\subsubsection{Ontario Drug Benefits (ODB) Program}

The ODB provides coverage for over 4,400 drug products for Ontario residents 65 years or older and those on social assistance. The ODB database consists of claims submitted by pharmacists for prescribed drugs at the time of medication dispensing. The database is reliable, with an error rate of $0.7 \%$ when validated with 5000 randomly sampled prescriptions at 50 pharmacies across southern Ontario(128). Data available includes the dispensing date, pill quantity dispensed, although not necessarily dose, and cost. Non-prescription medications, such as daily aspirin prophylaxis, are not consistently captured.

In this study, the ODB database was used to ascertain cases and controls based on receipt of an $\mathrm{OAB}$ drug during the observation window, and cases were ascertained based on receipt of a cholinesterase inhibitor. As well it was used to measure covariates including total drugs dispensed in the previous year, dispensing of statins, strong anticholinergic drugs and benign prostate hyperplasia related drugs (see section 3.6.2).

\subsubsection{Ontario Mental Health Reporting System (OHMRS)}

The OHMRS database consists of administrative, socio-demographic, and clinical data on admission for patients in adult-designated inpatient mental health beds from 68 participating general, provincial psychiatric, and specialty psychiatric facilities. There is data available from October 2005, onwards. OHMRS data is collected using the Resident Assessment Instrument Mental Health (RAI-MH@) version 2.0, which gathers information on admission diagnosis, discharge diagnosis, and information at other points in time during a hospital stay.

In this study, the OHMRS database was used to identify patients who had a psychiatric hospital admission as part of the exclusion criteria, and to identify psychiatric diagnoses to measure covariates related to mental health diagnoses. 


\subsubsection{National Rehabilitation Reporting System (NRS)}

The NRS data base collects data from participating adult inpatient rehabilitation facilities and programs across Canada. Data is available from 2002, onwards. The data is collected at admission and discharge, including socio-demographic information, administrative data, and health characteristics. Health data includes the most responsible health condition and comorbid health conditions, coded using ICD-10.

In terms of relevant health data used in this study, we used this database to identify patients with a history of spinal cord injury.

\subsubsection{Other Data Sources}

We used several ICES derived datasets to identify various covariates for the individuals in this study. Where possible, we used datasets or algorithms that were validated using another source (see Table 5), including the algorithm to identify dementia diagnoses (see Table 6). For some variables, such as stroke, we used algorithms that have previously been employed in other studies, however they have not been validated via another source or database. These datasets and their derivation algorithms are outlined in Appendix 6.3. 
Table 5 Other administrative databases used in this study

\begin{tabular}{|c|c|c|c|c|}
\hline Database & Availability & Data sources & Description & Validation \\
\hline $\begin{array}{l}\text { Ontario Diabetes } \\
\text { Database (ODD) }\end{array}$ & $\begin{array}{l}\text { April 1991-March } \\
2017\end{array}$ & $\begin{array}{l}\text { CIHI-DAD, } \\
\text { OHIP }\end{array}$ & $\begin{array}{l}\text { Cumulative database containing data on all diabetic } \\
\text { patients in Ontario. }\end{array}$ & $\begin{array}{l}\text { Primary chart review } \\
\text { Sensitivity } 86 \% \\
\text { Specificity } 97 \%(129)\end{array}$ \\
\hline $\begin{array}{l}\text { Ontario } \\
\text { Myocardial } \\
\text { Infarction Dataset } \\
\text { (OMID) }\end{array}$ & $\begin{array}{l}\text { April 1992-March } \\
2017\end{array}$ & CIHI & $\begin{array}{l}\text { Captures index hospitalizations for acute myocardial } \\
\text { infarctions. Does not capture outpatient or recurrent } \\
\text { events related to myocardial infarction within a year } \\
\text { of the index event, or events that occur as a } \\
\text { complication during hospital admissions in a } \\
\text { noncardiac surgical ward. }\end{array}$ & $\begin{array}{l}\text { Chart review in } 196 \text { acute care } \\
\text { hospitals in Ontario } \\
\text { True diagnosis was AMI in } \\
94 \% \text { or more of patients }(130)\end{array}$ \\
\hline $\begin{array}{l}\text { Congestive Heart } \\
\text { Failure }(\mathrm{CHF})\end{array}$ & $\begin{array}{l}\text { OHIP: April } 1991 \text { - } \\
\text { March } 2017 \\
\text { DAD/SDS: April } \\
\text { 1988 - March } 2017 \\
\text { NACRS: April } 2002 \\
\text { - March } 2017 \\
\text { OMHRS: All years }\end{array}$ & $\begin{array}{l}\text { OHIP/NACRS, CIHI- } \\
\text { DAD/OMHRS, RPDB }\end{array}$ & $\begin{array}{l}\text { All Ontario individuals with a hospital admission, or } \\
\text { outpatient visit for CHF identified since } 1991 \text {. }\end{array}$ & $\begin{array}{l}\text { Random sample from } \\
\text { electronic medical record } \\
\text { database of primary care } \\
\text { physicians in Ontario, Canada } \\
\text { (EMRALD) } \\
\text { Sensitivity: } 84.8(77.7,92.0) \\
\text { Specificity: } 97.0(96.3,97.9) \\
\text { PPV: } 55.6(47.6,63.6)(131)\end{array}$ \\
\hline $\begin{array}{l}\text { Ontario } \\
\text { hypertension } \\
\text { dataset (HYPER) }\end{array}$ & 1991 & $\begin{array}{l}\text { OHIP, CIHI-DAD/SDS } \\
\text { (SDS records from } \\
\text { NACRS since April } \\
\text { 2003), } \\
\text { RPDB }\end{array}$ & $\begin{array}{l}\text { All Ontario patients with hypertension identified } \\
\text { since } 1991 .\end{array}$ & $\begin{array}{l}\text { Random sample of abstracted } \\
\text { primary care paper medical } \\
\text { records and self-reported } \\
\text { survey data from a national } \\
\text { census } \\
\text { Sensitivity } 72 \% \\
\text { Specificity } 95 \% \\
\text { PPV } 87 \%(132)\end{array}$ \\
\hline
\end{tabular}




\subsection{Study Subjects, Setting, and Timeline}

\subsubsection{Subjects}

Study subjects were selected from the general population, including all men and women $\geq 66$ years old. Cases were identified using a modified validated algorithm for dementia and Alzheimer's disease(133). We excluded individuals:

1. admitted to a long-term care facility or psychiatric hospital one year prior to their index date to ensure we were evaluating community dwelling individuals;

2. with prevalent dementia (diagnosed $\geq$ age 66), based on the dementia diagnosis algorithm in section 3.5.2, looking back up to 5 years from their index date;

3. without an $\mathrm{OAB}$ drug prescription in the 180 days prior to index date;

4. with more than a single $\mathrm{OAB}$ drug prescribed during the 180 days prior to the index date;

5. with less than 60 days and 2 prescriptions of an OAB drug dispensed during the 180 days prior to index date (this is further explained in section 3.6.1);

6. older than 105 years old at diagnosis (to avoid misclassification of non-pathologic cognitive ageing as a dementia diagnosis(134));

7. who died before dementia diagnosis date, as recorded in the RPDB.

Exclusion criteria 3 and 4 were used since our objective was to evaluate the differential risk of dementia based on a single $\mathrm{OAB}$ drug exposure and to ensure that patients who were switching drugs during this period due to prodromal symptoms of dementia were not included.

A study flow chart of these exclusions can be seen in Figure 8. 


\subsubsection{Case Definition}

Cases were defined based on a validated algorithm for identifying dementia and Alzheimer's disease(133) using databases at ICES (Table 6) combining hospital admission diagnosis from CIHI-DAD, prescription data from ODB, and physician services data from OHIP.

Cases were individuals who met ANY of the three criteria:

1. Dementia or Alzheimer's Diagnosis during hospitalization;

2. Prescription claim for Cholinesterase inhibitor;

3. Two physician services claims for "senile dementia, presenile dementia" or "other cerebral degenerations" at least 30-days apart within a 1-year period.

The index date assigned to the case was the date when the first eligible criteria was met and for condition 3 , on the date of the first of two physician services claims.

The diagnostic codes we used to identify dementia were not limited to Alzheimer's disease and senile dementia but captured a larger range of etiologies, as these are the codes employed in the validated criteria from Jaakkimainen et al (133). We employed a somewhat modified case definition from that identified as the "optimal" criteria by Jaakkimainen et al.(133), where the third criteria required three claims over a two year period. This was done due to the time constraints of our accrual period. The optimal algorithm had a sensitivity of 79.3\% (72.9-85.8), specificity of $99.1 \%$ (98.8-99.4), a positive predictive value of $80.4 \%$ (74.0-86.8), and negative predictive value of $99.0 \%$ (98.7-99.4). Based on the inferential statistics of various physician claim algorithms reported in their study, it is difficult to estimate the changes we might expect. Having fewer physician claims (two vs. three claims) increases the sensitivity while reducing specificity. A shorter observation period (one year vs. two years), has the opposite effect. Either way, due to the similarity of our algorithm, we do not expect a significant difference in the validity of our algorithm compared to that reported in their study. 
Table 6 Algorithm for identifying cases with dementia or Alzheimer's modified from Jaakimainen et al.

\begin{tabular}{|c|c|c|c|}
\hline Criteria & Setting & Database & Codes \\
\hline Dementia or Alzheimer's disease diagnosis & Hospital admission & CIHI-DAD & $\begin{array}{l}\text { ICD-9 } \\
\text { 46.1x: Creutzfeldt-Jakob disease } \\
\text { 290.0x: Senile dementia, uncomplicated } \\
\text { 290.1x: Presenile dementia } \\
\text { 290.2x: Senile dementia with delusional or } \\
\text { depressive features } \\
\text { 290.3x: Senile dementia with delirium } \\
\text { 290.4x: Vascular dementia } \\
\text { 294.x: Persistent mental disorders due to } \\
\text { conditions classified elsewhere } \\
\text { 331.0x: Alzheimer's disease } \\
\text { 331.1x: Frontotemporal dementia } \\
\text { 331.5x: Idiopathic normal pressure hydrocephalus } \\
\text { ICD-10 } \\
\text { F00.x: Dementia in Alzheimer's disease } \\
\text { F01.x: Vascular dementia } \\
\text { F02.x: Dementia in other diseases classified } \\
\text { elsewhere } \\
\text { F03.x: Unspecified dementia } \\
\text { G30.x: Alzheimer's disease }\end{array}$ \\
\hline Cholinesterase Inhibitor prescription & Outpatient pharmacy & ODB & $\begin{array}{l}\text { DCLAS= 'CHOLINESTERASE INHIBITOR' } \\
\text { See Appendix } 6.1 \text { for drug identification numbers }\end{array}$ \\
\hline Dementia or Alzheimer's physician services claim & Outpatient visit with physician & OHIP & $\begin{array}{l}\text { 290: Senile dementia, presenile dementia } \\
\text { 331: Other cerebral degenerations }\end{array}$ \\
\hline
\end{tabular}




\subsubsection{Control selection}

Controls were derived from the RPDB which consists of all individuals alive and eligible for

OHIP during the accrual period. We limited the individuals to those $\geq 66$ years old and applied exclusion criteria 3 and 4 from section 3.5.1. Index dates were then randomly assigned to controls based on the distribution of diagnosis dates of the cases. Controls were then excluded by applying the same remaining criteria as with cases, with the addition of excluding controls who became a case prior to their assigned index date. We used risk set sampling without replacement, meaning the entire sample of individuals from RPDB were eligible to be controls only once, including those who later became cases (ie. they receive a dementia diagnosis).

\subsubsection{Accrual and follow-up}

The project time frame is illustrated in Figure 5. Cases and controls were accrued from individuals in Ontario who were OHIP eligible from April 1, 2010 to March 31, 2017. The index date for cases was the date of dementia diagnosis as per the algorithm in section 3.5.2. The index date for controls was randomly assigned as described in section 3.5.3. To meet the third criterion for the case definition, up to a 1-year observation period is required from the date of the first OHIP physician claim for dementia to confirm a second physician claim. Therefore, the last possible diagnosis date for OHIP claims of dementia is Mar 31, 2017, and we continued to observe patients 1 year beyond this (Mar 31, 2018) for the second claim. 


\section{Figure 5 Study timeframe}

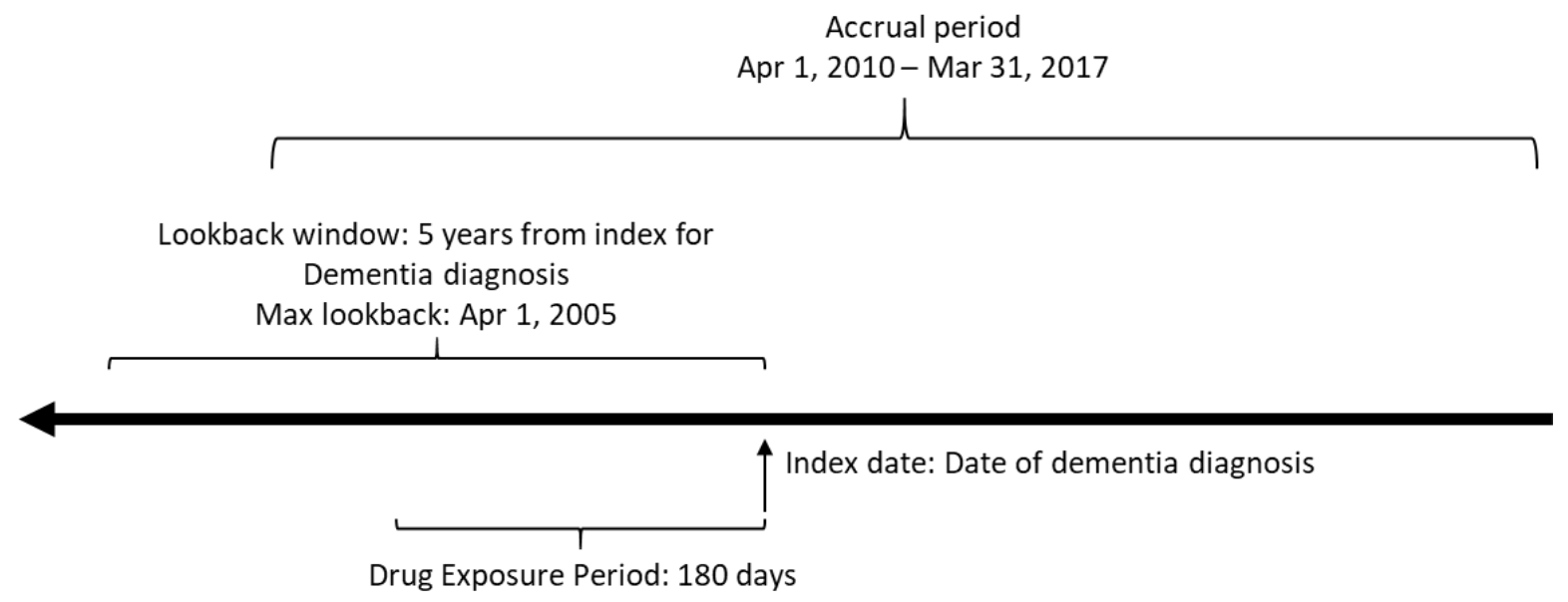

\subsection{Exposure and Covariates}

\subsubsection{Exposure definition}

Exposure was measured by identifying a single OAB drug dispensed twice within the 180-day drug exposure period prior to index date, with a cumulative supply of $\geq 60$ days. OAB drugs, exclusively indicated for $\mathrm{OAB}$, were identified using their drug identification numbers (DIN) as listed in appendix 6.1, and they were available in ODB on the dates listed in Table 7.

Table 7 Overactive bladder drugs available through Ontario drug benefit

\begin{tabular}{|l|l|}
\hline Drug & First date in ODB \\
\hline Oxybutinin & April 1990 \\
\hline Tolterodine & June 1999 \\
\hline Darifenacin & Dec 2011 \\
\hline Solifenacin & Dec 2011 \\
\hline Trospium & Dec 2011 \\
\hline Fesoterodine & April 2013 \\
\hline Mirabegron & May 2015 \\
\hline
\end{tabular}




\subsubsection{Covariates}

We considered variables that were associated with the exposure to $\mathrm{OAB}$ drugs and incident dementia (See Table 8). Sociodemographic factors were captured as they are known to influence dementia. We captured the number of strong anticholinergic drugs, measured using the Anticholinergic Drug Scale(71), that were dispensed in the year prior to index date, as their use is associated with incident dementia(119) (Appendix 6.1 for drug identification numbers). Dispensing of urinary medications used for benign prostatic hyperplasia was captured, as the receipt of these drugs is a surrogate of lower urinary tract symptoms which may also be associated with the use of OAB drugs and incident dementia(135). Surrogate measures of patient comorbidity and healthcare utilization were captured as seen in Table 8 . We also identified important prevalent cardiovascular, psychiatric, and neurologic comorbidity, as these are known risk factors of incident dementia $(136,137)$ and are also associated with lower urinary tract symptoms $(10,11,14,138)$. These were identified using various ICES derived cohorts or nonvalidated algorithm as seen in appendix 6.3. 


\section{Table 8 Covariates}

\begin{tabular}{|l|l|}
\hline Category & Variable \\
\hline Sociodemographic and geographic & Age, Sex, Geographic Location (LHIN and rural status), Income Quintile \\
\hline Comorbidity & Charlson Index (based on previous 5 years of hospitalization data \\
& Number of physician visits in the past 1 year \\
& Number of drugs used in past 365 days \\
& Strong Anticholinergic Drugs used in past 365 day \\
\hline Cardiovascular risk factors & Diabetes Mellitus \\
& Dyslipidemia \\
& Hypertension \\
& Stroke/TIA \\
& Congestive heart disease, heart failure \\
& Peripheral arterial disease \\
& Atrial fibrillation \\
& Acute myocardial infarction \\
& Other coronary heart disease \\
& Pulmonary Embolism or Deep Vein Thrombosis \\
\hline Psychological risk factors & Mood disorder \\
& Anxiety or sleep disorder \\
& Psychosis, agitation and related disorders \\
& All other mental disorder \\
& Alcohol abuse \\
\hline Neurological risk factors & Parkinson's disease \\
& Epilepsy \\
& Spinal cord injury \\
\hline
\end{tabular}

LHIN - Local Health Integration Network, TIA - transient ischemic attack 


\subsection{Analysis}

All statistical analyses were performed using Enterprise Guide 6.1 (SAS Institute Inc., Cary, NC, USA). Statistical hypothesis tests were two sided, and significant p-values were set at $<0.05$.

\subsubsection{Matching}

Cases were matched to controls in up to a maximum of 1:4 on index year, age \pm 2 years, sex. We used a "greedy" matching algorithm without replacement, as described by Rosenbaum (139) and it was executed with a SAS macro(140). Briefly this macro randomly sorts the $\mathrm{N}$ cases and M controls and matches the first case in the list to the closest control, i.e. the one with the smallest distance measure (Dij). The distance measure is the weighted sum of the absolute differences in the matching variables between case (i) and potential control pairs (j) (Equation 1).

\section{Equation 1 "Distance" between the ith case and the jth potential control employed in greedy matching algorithm. $w_{k}$ is a non-negative weight associated with matching variable} (k).

$$
D_{i j}=\sum_{k=1}^{p}\left|x_{i k}^{1}-x_{j k}^{0}\right| \times w_{k}
$$

It then moves on to the second case and matches it to the closest control among those remaining and repeats the process until all $\mathrm{N}$ cases have been matched. With multiple controls per case, once all cases are matched to one control, it then makes another pass through the list to match the second control for each case, up to three controls per case.

The purpose of matching in a case-control study is to improve efficiency by balancing the number of cases and controls in the confounder strata(124). We limited our matching variables to strong confounders of the association between $\mathrm{OAB}$ drug exposure and dementia, while still being able to obtain at least 1:4 matching in most cases. Typically, a higher ratio of controls to 
cases increases the precision of estimates during statistical testing, and there is marginal improvement beyond a 1:4 ratio, except when the effect of exposure is large (124). In our sample size estimation, we found that the number of cases required to reject the null hypothesis did not vary significantly beyond 1:4 matching (see Figure 7). With respect to age matching, we used an age tolerance, where a case of age $=\mathrm{x}$ was randomly matched to a healthy person with an age within the $[\mathrm{x}-\delta, \mathrm{x}+\delta]$ range using a $(0,1)$-uniform distribution. This matching approach is widely employed in case-control studies $(141,142)$ to increase the number of matches. It was important to match on index year to achieve time comparability between cases and controls for drug exposures, as the availability of drugs and other unmeasured confounders can vary over time.

\subsubsection{Data checks and missing data}

The linked dataset we obtained after inclusions and exclusions were applied, was analysed using descriptive statistics to ensure plausibility. We also evaluated all the available variables for everyone to identify any missing data, which was expected to be missing at random. We intended to use listwise deletion to address individuals missing data however, we found that those variables with missing data were not significantly different between cases and controls and were not required for model adjustment. Therefore, we did not remove any individuals from the study for missing data.

\subsubsection{Baseline cohort characteristics and descriptive statistics}

To evaluate the efficacy of the matching in creating balance between cases and controls, descriptive statistics and weighted standardized differences were calculated to compare the distribution of baseline characteristics. A weighted standardized difference of greater than 0.1 was considered as a meaningful difference. 


\subsubsection{Primary analysis: The effect of antimuscarinic OAB drug exposure on incident dementia}

Conditional logistic regression was used to estimate the association between receiving prescriptions of all antimuscarinics, as a class, compared to receiving mirabegron, and a diagnosis of dementia. We also repeated the above analysis with receipt of each individual antimuscarinic $\mathrm{OAB}$ drug as a categorical variable in the model. The model was adjusted for all unbalanced covariates after matching. Since we used loose-matching (based on demographics, where matching between cases and controls was not unique) and we wished to evaluate whether the sparse data problem applied to our dataset(143,144), we also evaluated the association between receiving prescriptions of each individual antimuscarinic $\mathrm{OAB}$ drug and incident dementia using unconditional logistic regression and compared the results to the conditional model. We reported adjusted odds ratios with $95 \%$ confidence intervals, with a level of significance at $\mathrm{p}<0.05$.

\subsubsection{Stratified analysis: Age and sex}

We stratified the analysis on sex. Sex was a hard-matched variable (see section 3.7.1) as it is a strong predictor of both incident dementia and lower urinary tract symptoms (hence, OAB drug exposure), and therefore stratified analysis was performed to determine if there was a difference in the effect of $\mathrm{OAB}$ drug exposure on incident dementia between men and women. For the same reason age $>80$ years was also selected as a stratification variable, although this age was selected post-hoc, following the evaluation of the age distribution in our sample. These stratified analyses were exploratory in nature and therefore we did not include them in sample size calculations.

\subsubsection{Sensitivity analysis: addressing protopathic bias}

To address protopathic bias, where patients may start, switch or stop OAB treatment in the six months prior to diagnosis due to prodromal symptoms of dementia, we adjusted the drug exposure period to within the 181-365 days prior to index date. In doing so we applied a 6-month lag-time, where we did not consider the $\mathrm{OAB}$ drug exposure history in the 6-month period prior 
to the index date (145). This required re-applying exclusion criteria to cases and controls as described in section 3.5.1. Previous studies evaluating the effect of anticholinergic exposure on incident dementia have employed a 0(118,146), 6 month(119), or 4-year lag period(122). Therefore, a 6-month period was reasonable within the study timeline limitations of accrual and case identification.

\subsubsection{Precision and power calculation}

Prior to conducting this study, we planned to have matched pairs of cases and controls with up to 4 matched control (s) per case. In a recent study of patients developing incident dementia following anticholinergic drug use, approximately $8 \%$ of cases and $6 \%$ of controls had been exposed to $\mathrm{OAB}$ drugs with an adjusted odds ratio of dementia of 1.17 and the correlation coefficient for exposure between matched cases and controls was zero (122). If the true odds ratio for disease in exposed subjects relative to unexposed subjects is 1.2 , we determined that we needed to study 6,398 case patients with 25,592 matched controls to be able to reject the null hypothesis with a power of $90 \%$, assuming that the type I error probability is 5\% (147).

While all patients in the study are exposed to an $\mathrm{OAB}$ drug, we expected that the proportion of controls exposed to an antimuscarinic $\mathrm{OAB}$ drug would be higher than 5\% for at least three of the antimuscarinic drugs, based on a recent study of $\mathrm{OAB}$ drug utilization in Ontario (35). This reduced the sample size required, as determined when we increased the proportion of controls exposed, keeping the other inputs constant (Figure 6). Since we anticipated difficulty with finding suitable matches, we also varied the number of matched controls per case and found that the number of controls required did not decrease significantly past 4 controls, with a marginal decrease between 4 and 5 controls per case (Figure 7).

It is important to note that our sample size calculations assumed a binary exposure variable and stratum homogeneity in terms of exposure prevalence, although our exposure is polychotomous with seven categories ( $7 \mathrm{OAB}$ drugs) and our strata are likely heterogenous in terms of exposure proportion. This would increase the required sample size estimated $(148,149)$. With respect to dementia, between 2010 and 2013, there was an annual average of 44,150 incident cases of 
dementia in individuals > 65 years old in Ontario (150). This amounts to approximately 300,000 potential cases of dementia over the accrual period from 2010 to 2017. If we assume a conservative estimate of 5\% exposure prevalence among these cases, then there should be approximately 15,000 cases who have been exposed to OAB drugs.

In post-hoc analysis, our study included 11,427 cases and up to 4 controls per case (with $32 \%$ $(n=3,635)$ matched to 4 controls and $17 \%(n=1,937)$ matched to 3 controls). Our study was found to have $90 \%$ power to detect an odds ratio of 1.12 , with an alpha of 0.05 , and a control exposure prevalence of $10 \%$. With higher control exposure prevalence, the power increases, and therefore our study was well powered to evaluate our question.

Sample size calculations were conducted using the "sample size for matched case control studies" in the R package, epiR (151). 
Figure 6 Estimated sample sizes across range of odds ratios and proportion of control exposure

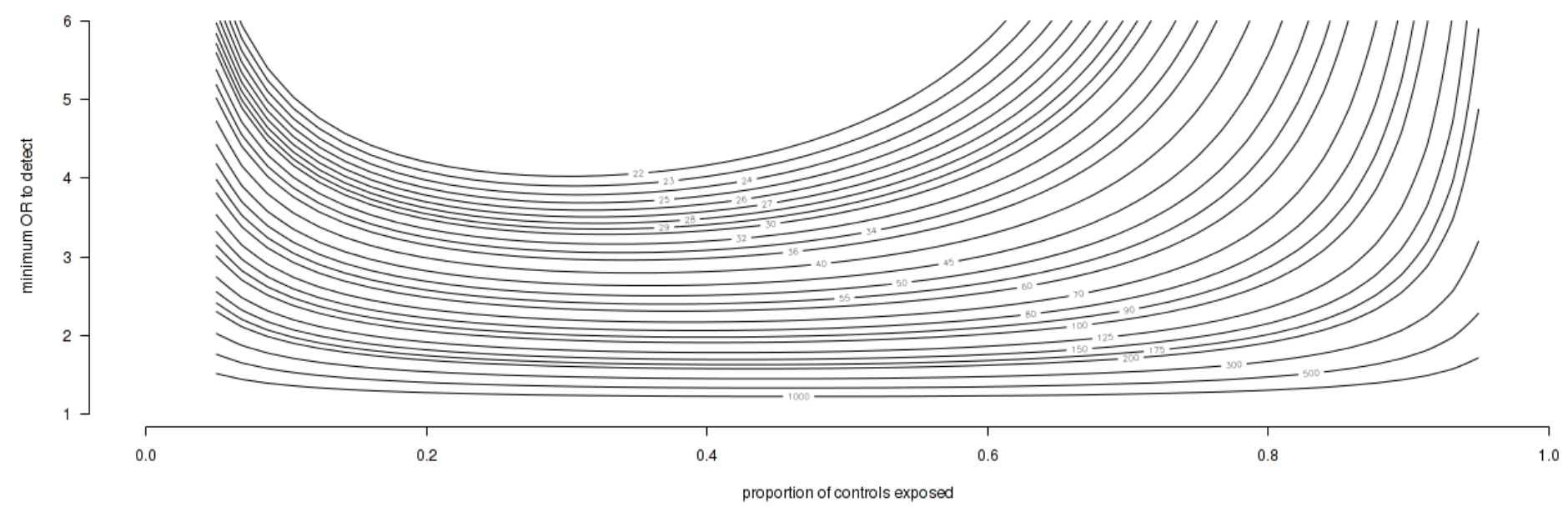

Figure 7 Number of cases required varying ratio of controls per case, other inputs constant

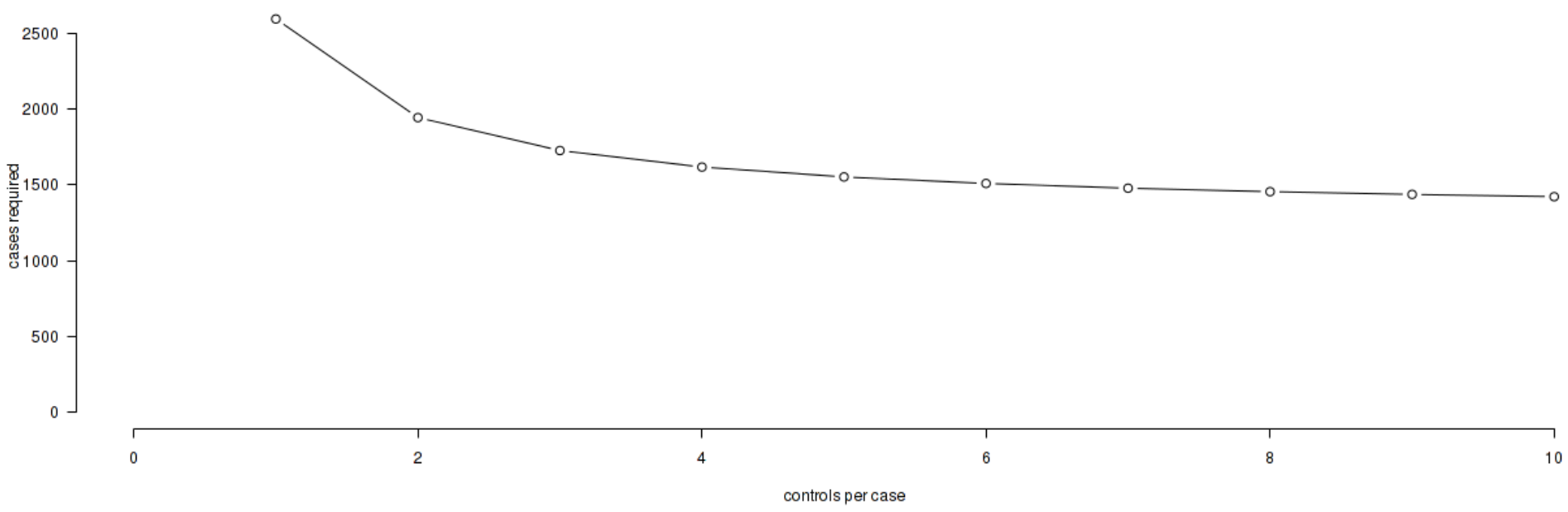




\section{Chapter 4 Results}

\section{Results}

\subsection{Case and control identification}

We identified 6,931,580 people in the registered persons database (RPDB) with birth dates ranging from January 1, 1900 to December 31, 1960 (ages 50 to 117 during the accrual period). We then identified 351,978 cases in this group with a diagnosis of dementia between April 1, 2010 and March 31, 2017 and age 66 years or older at the time of diagnosis (since patients are eligible for ODB beginning at age 65 years). During the drug exposure period (180 days prior to index), prior to applying all exclusion criteria, 14,341 (4.1\%) individuals diagnosed with dementia were dispensed at least one OAB drug. To identify controls, we assigned index dates probabilistically to the RPDB cohort and then excluded those who died prior to index date $(\mathrm{n}=1,787,134)$, and with the same exclusion criteria as the cases. Since we allowed cases to act as controls prior to their diagnosis date (index date), we excluded those controls who were diagnosed with dementia prior to their randomly assigned index date $(n=336)$. After applying exclusion criteria, we were left with 11,427 cases and 38,657 controls in the dataset. Figure 8 summarizes the inclusion and exclusion criteria for cases and controls. Cases were then matched with up to 4 controls, with 3,635 (32\%) cases having four controls and $35(0.3 \%)$ unmatched cases. 


\section{Figure 8 Study flow diagram}

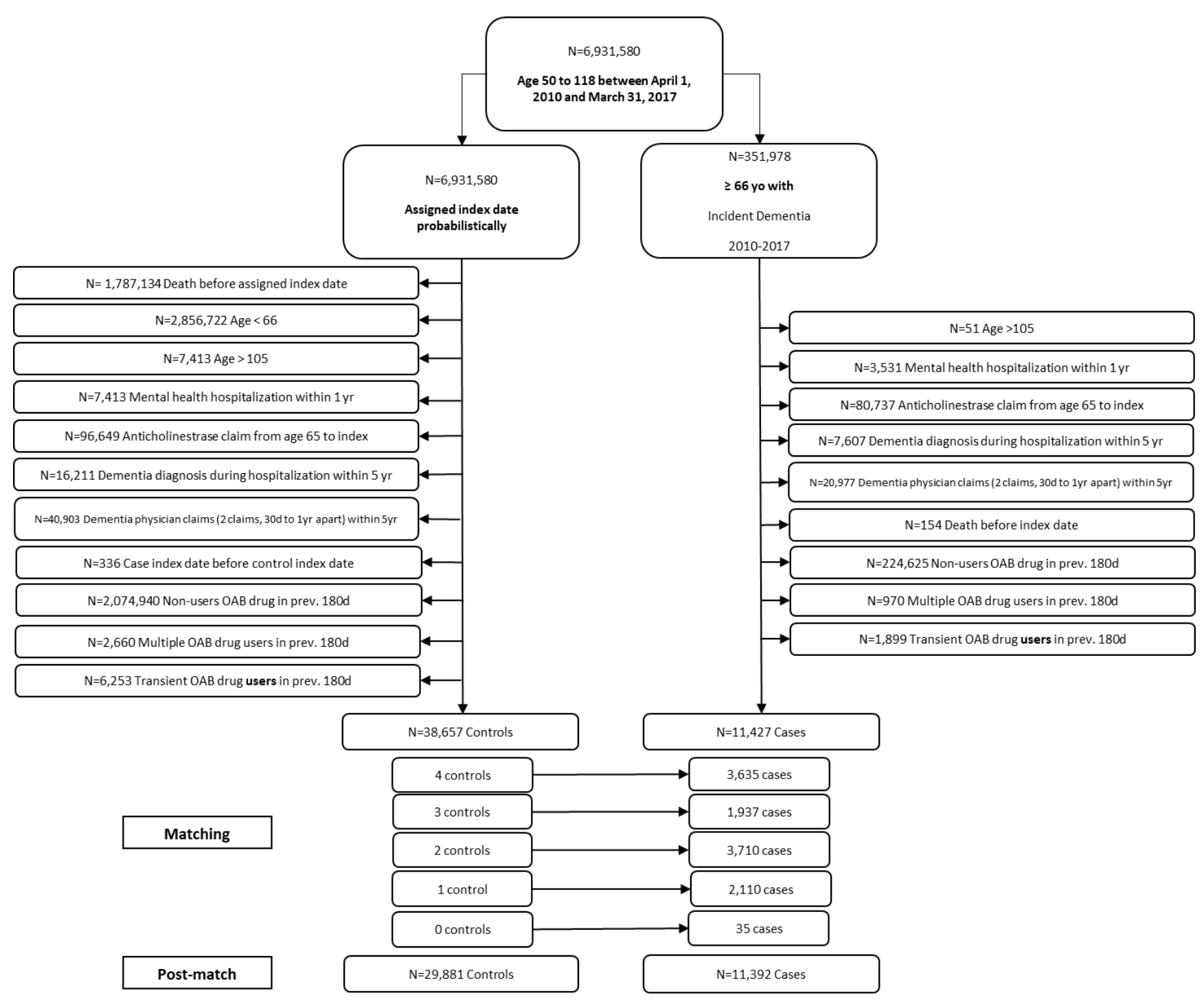




\subsection{Baseline characteristics}

We evaluated a selection of baseline demographic characteristics of cases and controls prematching (Table 9) and all the baseline characteristics post-matching (Table 10). Prior to matching, there were some significant differences between the cases and controls. Cases had a significantly higher median age (83 years; Interquartile range [IQR] 77-87) compared to controls (76 years; IQR 71-83; (standardized difference [StDiff] 0.69). There was also an increased prevalence of stroke in the previous three years among cases $(n=2,261 ; 20 \%)$ compared to controls $(n=3,619 ; 9 \%)$. The percentage of females was similar among cases and controls $(n=7,722 ; 68 \%$ vs. $n=27,039 ; 70 \%)$.

After matching (Table 10), the cases and controls were alike in terms of demographic characteristics, however imbalances persisted when considering baseline levels of comorbidity (cardiovascular, neurological, and psychiatric) and healthcare utilization. The median age of individuals included in the study was 80 years (IQR 75-85). Most individuals were female $(\mathrm{n}=27,739 ; 67 \%)$ and non-rural $(\mathrm{n}=35,587 ; 86 \%)$. There was an even distribution of individuals across index years and income quintiles. Most individuals had a Charlson comorbidity index of 0, although there was imbalance between cases and controls (Table 10). Similarly, most individuals had not been admitted to a hospital in the previous year $(n=31,051 ; 75 \%)$, with a higher percentage of cases admitted compared to controls. Cases also had a significantly higher median number of primary care visits and the median number of unique drugs dispensed in the previous year. There were a similar proportion of cases and controls who received a strong anticholinergic drug (measured using the Anticholinergic Drug Scale(71)) besides an OAB drug in the past year. A higher percentage of cases had cardiovascular comorbidities including stroke, atrial fibrillation, and congestive heart failure. Likewise, cases had a higher prevalence of all psychological risk factors measured compared to controls. There was also a significant difference among the proportion of cases versus controls with Parkinson's disease (808; 7\%) vs. 658; 2\%; StDiff 0.20). 
Table 9 Baseline demographic characteristics before matching cases and controls

\begin{tabular}{|l|r|r|r|r|r|}
\hline Variable & & \multicolumn{1}{c|}{$\begin{array}{c}\text { Control } \\
(\mathbf{n = 3 8 , 6 5 7})\end{array}$} & \multicolumn{1}{c|}{$\begin{array}{c}\text { Cases } \\
(\mathbf{n = 1 1 , 4 2 7})\end{array}$} & \multicolumn{1}{|c|}{$\begin{array}{c}\text { Total } \\
(\mathbf{n = 5 0 , 0 8 4})\end{array}$} & \multicolumn{1}{|c|}{ StDiff } \\
\hline Age (years) & $\begin{array}{r}\text { Median } \\
(\mathrm{IQR})\end{array}$ & $76(71-83)$ & $83(77-87)$ & $78(72-84)$ & 0.69 \\
\hline Age Group (years), n (\%) & $65-70$ & $8,777(22.7 \%)$ & $902(7.9 \%)$ & $9,679(19.3 \%)$ & 0.42 \\
\hline & $71-75$ & $8,854(22.9 \%)$ & $1,371(12.0 \%)$ & $10,225(20.4 \%)$ & 0.29 \\
\hline & $76-80$ & $8,463(21.9 \%)$ & $2,175(19.0 \%)$ & $10,638(21.2 \%)$ & 0.07 \\
\hline & $81-85$ & $6,755(17.5 \%)$ & $2,938(25.7 \%)$ & $9,693(19.4 \%)$ & 0.2 \\
\hline & $86-90$ & $4,067(10.5 \%)$ & $2,583(22.6 \%)$ & $6,650(13.3 \%)$ & 0.33 \\
\hline & $\geq 91$ & $1,741(4.5 \%)$ & $1,458(12.8 \%)$ & $3,199(6.4 \%)$ & 0.3 \\
\hline Sex (female), n (\%) & & $27,039(69.9 \%)$ & $7,722(67.6 \%)$ & $34,761(69.4 \%)$ & 0.05 \\
\hline Stroke/TIA in previous 3 years, n (\%) & & $3,619(9.4 \%)$ & $2,261(19.8 \%)$ & $5,880(11.7 \%)$ & 0.3 \\
\hline
\end{tabular}


Table 10 Baseline characteristics of cases of dementia and matched controls taking OAB drugs in Ontario between 2010 and 2017.

\begin{tabular}{|c|c|c|c|c|c|}
\hline Variable & & $\begin{array}{r}\text { Control } \\
(\mathrm{n}=\mathbf{2 9 , 8 8 1 )}\end{array}$ & $\begin{array}{r}\text { Cases } \\
(n=11,392)\end{array}$ & $\begin{array}{r}\text { Total } \\
(n=41,273)\end{array}$ & StDiff* \\
\hline \multicolumn{6}{|l|}{ Demographics } \\
\hline Age & Median (IQR) & $79(74-84)$ & $83(77-87)$ & $80(75-85)$ & 0.07 \\
\hline Sex (female), n, (\%) & & $20,040(67.1 \%)$ & $7,699(67.6 \%)$ & $27,739(67.2 \%)$ & 0 \\
\hline \multirow[t]{8}{*}{$\begin{array}{r}\text { Year of diagnosis, } \mathrm{n}, \\
(\%)\end{array}$} & 2010 & $3,193(10.7 \%)$ & $1,324(11.6 \%)$ & $4,517(10.9 \%)$ & 0.06 \\
\hline & 2011 & $3,705(12.4 \%)$ & $1,526(13.4 \%)$ & $5,231(12.7 \%)$ & 0.05 \\
\hline & 2012 & $3,990(13.4 \%)$ & $1,585(13.9 \%)$ & $5,575(13.5 \%)$ & 0.03 \\
\hline & 2013 & $4,209(14.1 \%)$ & $1,657(14.5 \%)$ & $5,866(14.2 \%)$ & 0.02 \\
\hline & 2014 & $4,513(15.1 \%)$ & $1,696(14.9 \%)$ & $6,209(15.0 \%)$ & 0.02 \\
\hline & 2015 & $4,696(15.7 \%)$ & $1,699(14.9 \%)$ & $6,395(15.5 \%)$ & 0.05 \\
\hline & 2016 & $4,880(16.3 \%)$ & $1,681(14.8 \%)$ & $6,561(15.9 \%)$ & 0.07 \\
\hline & 2017 & $695(2.3 \%)$ & $224(2.0 \%)$ & $919(2.2 \%)$ & 0.03 \\
\hline \multirow[t]{15}{*}{ LHIN, n, (\%) } & Toronto Central & $2,272(7.6 \%)$ & $785(6.9 \%)$ & $3,057(7.4 \%)$ & 0.02 \\
\hline & Erie St. Clair & $2,942(9.8 \%)$ & $999(8.8 \%)$ & $3,941(9.5 \%)$ & 0.03 \\
\hline & South West & $1,669(5.6 \%)$ & $651(5.7 \%)$ & $2,320(5.6 \%)$ & 0.01 \\
\hline & $\begin{array}{r}\text { Waterloo } \\
\text { Wellington } \\
\end{array}$ & $3,964(13.3 \%)$ & $1,495(13.1 \%)$ & $5,459(13.2 \%)$ & 0.02 \\
\hline & Hamilton Niagara & $1,237(4.1 \%)$ & $411(3.6 \%)$ & $1,648(4.0 \%)$ & 0.01 \\
\hline & Central West & $1,579(5.3 \%)$ & $678(6.0 \%)$ & $2,257(5.5 \%)$ & 0.03 \\
\hline & $\begin{array}{r}\text { Mississauga } \\
\text { Halton } \\
\end{array}$ & $2,024(6.8 \%)$ & $895(7.9 \%)$ & $2,919(7.1 \%)$ & 0.03 \\
\hline & Central & $3,181(10.6 \%)$ & $1,233(10.8 \%)$ & $4,414(10.7 \%)$ & 0.01 \\
\hline & Central East & $3,438(11.5 \%)$ & $1,301(11.4 \%)$ & $4,739(11.5 \%)$ & 0.01 \\
\hline & South East & $1,615(5.4 \%)$ & $586(5.1 \%)$ & $2,201(5.3 \%)$ & 0.01 \\
\hline & Champlain & $2,253(7.5 \%)$ & $1,112(9.8 \%)$ & $3,365(8.2 \%)$ & 0.07 \\
\hline & $\begin{array}{r}\text { North Simcoe } \\
\text { Muskoka }\end{array}$ & $1,578(5.3 \%)$ & $555(4.9 \%)$ & $2,133(5.2 \%)$ & 0.01 \\
\hline & North East & $1,538(5.1 \%)$ & $504(4.4 \%)$ & $2,042(4.9 \%)$ & 0.02 \\
\hline & North West & $581(1.9 \%)$ & $185(1.6 \%)$ & $766(1.9 \%)$ & 0.02 \\
\hline & Missing & $10(0.0 \%)$ & $<=5(0.0 \%)$ & $12(0.0 \%)$ & 0.01 \\
\hline Rural, n, (\%) & & $4,211(14.1 \%)$ & $1,449(12.7 \%)$ & $5,660(13.7 \%)$ & 0.03 \\
\hline \multirow[t]{6}{*}{$\begin{array}{r}\text { Income quintile, } \\
\mathrm{n},(\%)\end{array}$} & 1 & $6,540(21.9 \%)$ & $2,648(23.2 \%)$ & $9,188(22.3 \%)$ & 0.03 \\
\hline & 2 & $6,323(21.2 \%)$ & $2,497(21.9 \%)$ & $8,820(21.4 \%)$ & 0.02 \\
\hline & 3 & $5,988(20.0 \%)$ & $2,153(18.9 \%)$ & $8,141(19.7 \%)$ & 0.03 \\
\hline & 4 & $5,555(18.6 \%)$ & $2,106(18.5 \%)$ & $7,661(18.6 \%)$ & 0 \\
\hline & 5 & $5,395(18.1 \%)$ & $1,946(17.1 \%)$ & $7,341(17.8 \%)$ & 0.02 \\
\hline & Missing & $80(0.3 \%)$ & $42(0.4 \%)$ & $122(0.3 \%)$ & 0.01 \\
\hline \multicolumn{6}{|c|}{ Health status and utilization } \\
\hline \multirow[t]{4}{*}{$\begin{array}{r}\text { Charlson index, } \mathrm{n}, \\
(\%)\end{array}$} & 0 & $19,093(63.9 \%)$ & $6,263(55.0 \%)$ & $25,356(61.4 \%)$ & 0.17 \\
\hline & 1 to 2 & $7,539(25.2 \%)$ & $3,290(28.9 \%)$ & $10,829(26.2 \%)$ & 0.08 \\
\hline & 3 to 4 & $2,301(7.7 \%)$ & $1,305(11.5 \%)$ & $3,606(8.7 \%)$ & 0.12 \\
\hline & $>4$ & $948(3.2 \%)$ & $534(4.7 \%)$ & $1,482(3.6 \%)$ & 0.07 \\
\hline Primary care visits & Median (IQR) & $6(3-10)$ & $8(4-13)$ & $6(4-11)$ & 0.23 \\
\hline Hospital admission & $\mathrm{n},(\%)$ & $5,172(17.3 \%)$ & $5,050(44.3 \%)$ & $10,222(24.8 \%)$ & 0.59 \\
\hline $\begin{array}{r}\text { Unique drugs } \\
\text { dispensed }\end{array}$ & Median (IQR) & $11(8-16)$ & $13(9-18)$ & $12(8-16)$ & 0.26 \\
\hline
\end{tabular}




\begin{tabular}{|c|c|c|c|c|c|}
\hline $\begin{array}{r}\text { Strong } \\
\text { anticholinergics }\end{array}$ & $\mathrm{n},(\%)$ & $2,929(9.8 \%)$ & $1,430(12.6 \%)$ & $4,359(10.6 \%)$ & 0.09 \\
\hline \multicolumn{6}{|c|}{ Cardiovascular risk factors, $n,(\%)$} \\
\hline Hypertension & & $25,065(83.9 \%)$ & $9,832(86.3 \%)$ & $34,897(84.6 \%)$ & 0.02 \\
\hline Diabetes & & $11,095(37.1 \%)$ & $4,536(39.8 \%)$ & $15,631(37.9 \%)$ & 0.07 \\
\hline Dyslipidemia & & $18,729(62.7 \%)$ & $6,892(60.5 \%)$ & $25,621(62.1 \%)$ & 0.02 \\
\hline Atrial fibrillation & & $5,646(18.9 \%)$ & $2,854(25.1 \%)$ & $8,500(20.6 \%)$ & 0.10 \\
\hline $\begin{array}{r}\text { Myocardial } \\
\text { infarction }\end{array}$ & & $407(1.4 \%)$ & $224(2.0 \%)$ & $631(1.5 \%)$ & 0.03 \\
\hline Stroke/TIA & & $3,068(10.3 \%)$ & $2,255(19.8 \%)$ & $5,323(12.9 \%)$ & 0.21 \\
\hline $\begin{array}{r}\text { Congestive heart } \\
\text { disease }\end{array}$ & & $4,310(14.4 \%)$ & $2,499(21.9 \%)$ & $6,809(16.5 \%)$ & 0.13 \\
\hline $\begin{array}{r}\text { Other coronary } \\
\text { disease }\end{array}$ & & $6,758(22.6 \%)$ & $3,045(26.7 \%)$ & $9,803(23.8 \%)$ & 0.06 \\
\hline $\begin{array}{r}\text { Peripheral arterial } \\
\text { disease }\end{array}$ & & $2,546(8.5 \%)$ & $1,259(11.1 \%)$ & $3,805(9.2 \%)$ & 0.07 \\
\hline Venous thrombosis & & $1,702(5.7 \%)$ & $829(7.3 \%)$ & $2,531(6.1 \%)$ & 0.05 \\
\hline \multicolumn{6}{|c|}{ Psychological Risk Factors, $n,(\%)$} \\
\hline Anxiety & & $8,309(27.8 \%)$ & $4,560(40.0 \%)$ & $12,869(31.2 \%)$ & 0.24 \\
\hline Mood Disorder & & $813(2.7 \%)$ & $743(6.5 \%)$ & $1,556(3.8 \%)$ & 0.16 \\
\hline Schizophrenia & & $863(2.9 \%)$ & $1,355(11.9 \%)$ & $2,218(5.4 \%)$ & 0.32 \\
\hline Alcohol Abuse & & $384(1.3 \%)$ & $489(4.3 \%)$ & $873(2.1 \%)$ & 0.17 \\
\hline \multicolumn{6}{|c|}{ Neurological Risk Factors, $n,(\%)$} \\
\hline Parkinson's disease & & $658(2.2 \%)$ & $808(7.1 \%)$ & $1,466(3.6 \%)$ & 0.20 \\
\hline Epilepsy & & $220(0.7 \%)$ & $180(1.6 \%)$ & $400(1.0 \%)$ & 0.07 \\
\hline Spinal Cord Injury & & $72(0.2 \%)$ & $30(0.3 \%)$ & $102(0.2 \%)$ & 0.01 \\
\hline
\end{tabular}

*StdDiff is weighted based on matched number of controls per case. 


\subsection{Primary analysis: Association between antimuscarinic $O A B$ drugs and incident dementia}

The most commonly prescribed drug among cases and controls was tolterodine $(\mathrm{n}=20,588 ; 50 \%)$ followed by oxybutynin $(n=8,484 ; 21 \%)$ and solifenacin $(n=6,783 ; 16 \%)$. To evaluate the odds of incident dementia among people receiving an antimuscarinic compared to mirabegron, we used conditional logistic regression models. In unadjusted analysis, receipt of any antimuscarinic, compared to mirabegron, was not associated with incident dementia (OR 1.01; 95\% confidence interval [CI] 0.90-1.13). When we evaluated the estimates associated with the individual antimuscarinic drugs in a separate conditional logistic regression model, there was an increased odds of incident dementia associated with receipt of darifenacin (Odds Ratio [OR] $1.21 ; 95 \%$ CI 1.03-1.43). Receipt of the other antimuscarinic drugs was not significantly associated with incident dementia (Table 11).

Adjustment was performed for all variables that had a StDiff $>0.10$ after matching. In adjusted analysis (Figure 9), receipt of any antimuscarinic drugs was not associated an increased odds of incident dementia, compared to mirabegron (OR 1.12; 95\% CI 0.98-1.27). However, among individual antimuscarinics, there was a significantly increased odds of incident dementia associated with receiving darifenacin (OR 1.30; 95\% CI 1.08-1.56) and solifenacin (OR 1.24; 95\% CI 1.08-1.43). We did not observe a significant association between incident dementia and the receipt of fesoterodine, oxybutynin, tolterodine, and trospium (Figure 9). 
Table 11 Unadjusted conditional logistic models evaluating the association between antimuscarinic OAB drug prescriptions and incident dementia.

\begin{tabular}{|c|c|c|c|c|c|c|c|c|}
\hline \multirow{3}{*}{$\begin{array}{l}\text { Drug } \\
\text { Mirabegron } \\
\text { Antimuscarinics } \\
\end{array}$} & \multicolumn{2}{|c|}{ Exposed cases } & \multicolumn{2}{|c|}{ Exposed Controls } & OR & \multicolumn{2}{|c|}{$95 \% \mathrm{CI}$} & \multirow[t]{2}{*}{$\mathbf{p}$} \\
\hline & 493 & $(4.3 \%)$ & 1489 & $(5.0 \%)$ & \multicolumn{3}{|c|}{ - Reference - } & \\
\hline & 10899 & $(95.7 \%)$ & 28392 & $(95.0 \%)$ & 1.01 & 0.90 & 1.13 & 0.88 \\
\hline Darifenacin & 395 & $(3.5 \%)$ & 881 & $(2.9 \%)$ & 1.21 & 1.03 & 1.43 & 0.024 \\
\hline Solifenacin & 1946 & $(17.1 \%)$ & 4837 & $(16.2 \%)$ & 1.12 & 0.99 & 1.27 & 0.072 \\
\hline Trospium & 52 & $(0.5 \%)$ & 130 & $(0.4 \%)$ & 1.09 & 0.77 & 1.54 & 0.634 \\
\hline Fesoterodine & 535 & $(4.7 \%)$ & 1443 & $(4.8 \%)$ & 1.06 & 0.91 & 1.22 & 0.482 \\
\hline Oxybutynin & 2359 & $(20.7 \%)$ & 6125 & $(20.5 \%)$ & 0.92 & 0.81 & 1.05 & 0.200 \\
\hline Tolterodine & 5612 & $(49.3 \%)$ & 14976 & $(50.1 \%)$ & 0.91 & 0.81 & 1.03 & 0.139 \\
\hline
\end{tabular}


Figure 9 Adjusted* conditional logistic regression models evaluating the association between antimuscarinic OAB drug prescriptions and incident dementia.

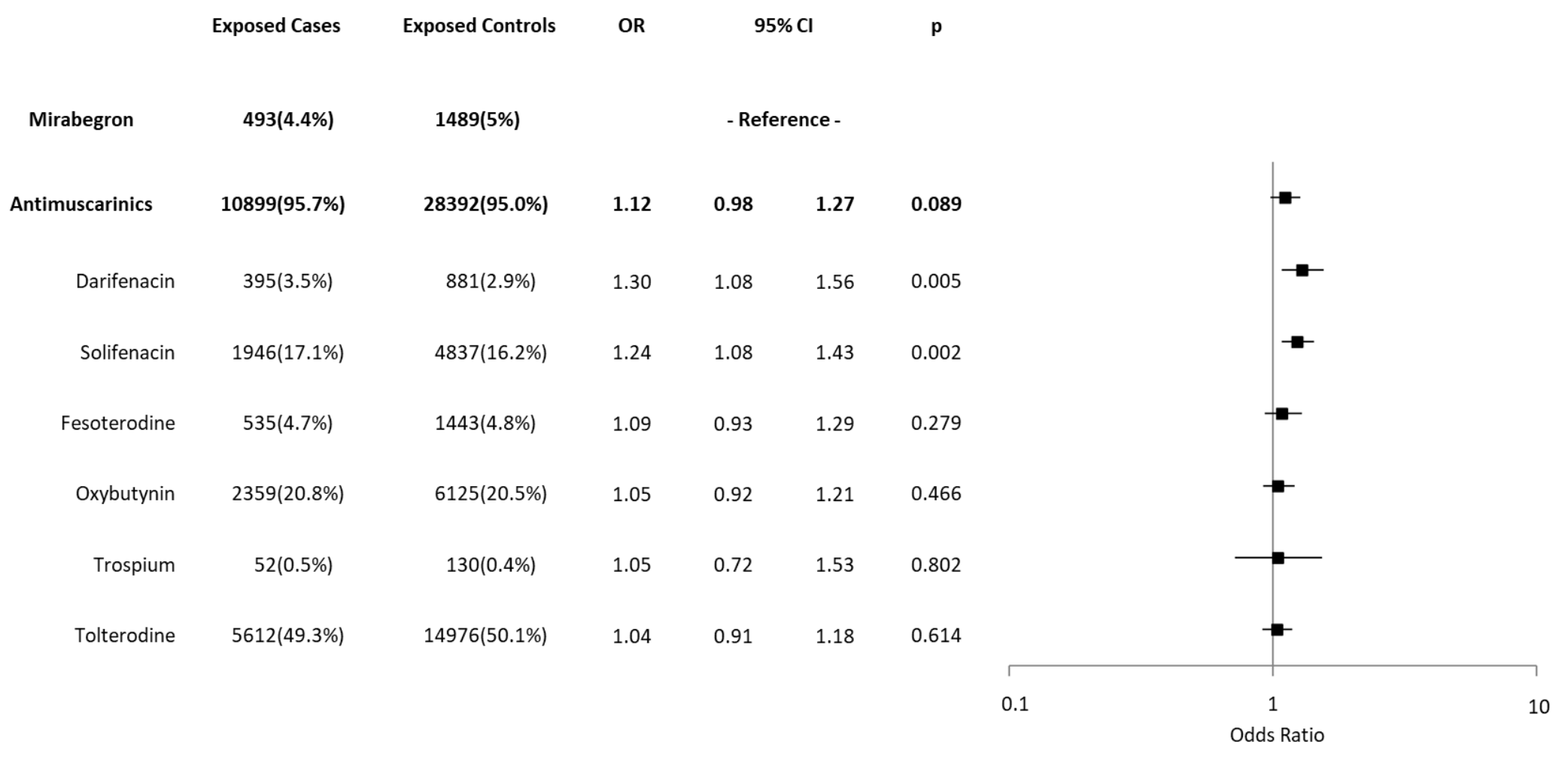

*Models were adjusted for Charlson comorbidity index category, a history of stroke, congestive heart failure, anxiety, mood disorder, schizophrenia, alcohol abuse, and Parkinson's disease and the number of unique drugs, number of primary visits, and having any hospital admission in the previous year.

**Receipt of antimuscarinics was evaluated as a composite variable in a separate conditional logistic model from the individual antimuscarinic drugs 


\subsection{Stratified analysis: The effect of sex on the association between antimuscarinic $O A B$ drugs and incident dementia}

We stratified the analysis by sex to examine its effect on the association between receipt of individual antimuscarinic $\mathrm{OAB}$ drugs and incident dementia. We did not observe notable differences in the estimates of association among females compared to the complete sample. In unadjusted conditional logistic regression models (Table 12) we found that among females, receipt of darifenacin, compared to mirabegron, was associated with significantly increased odds of incident dementia (OR 1.33; 95\% CI 1.07-1.66). In adjusted models (Figure 10), receipt of darifenacin (OR 1.44; 95\% CI 1.13-1.83) and solifenacin (OR 1.22; 95\% CI 1.01-1.47) were associated with an increased odds of incident dementia. Receipt of other antimuscarinics was not significantly associated with incident dementia (Figure 10).

Unlike the analysis of the complete sample, this stratified analysis demonstrates that men experienced increased odds of incident dementia only with solifenacin and not darifenacin. In unadjusted models, there were no significant associations between incident dementia and receipt of any of the individual antimuscarinics (Table 12). Receipt of tolterodine was significantly negatively associated with incident dementia (OR 0.82; 95\% CI 0.68-0.99) although this effect was non-significant in adjusted models (Figure 10). In adjusted models, receipt of solifenacin, compared to mirabegron, was associated with a significantly increased odds of incident (OR 1.31; 95\% CI 1.07-1.61). Receipt of the other antimuscarinics was not significantly associated with incident dementia (Figure 10).

\subsection{Stratified analysis: The effect of age on the association between antimuscarinic $O A B$ drugs and incident dementia}

In a post-hoc stratified analysis examining the effect of age on the association between the receipt of individual antimuscarinic $\mathrm{OAB}$ drugs and incident dementia, we selected age 80 as the cutoff, as this was the median age of the overall sample, and therefore we could expect approximately equal-sized strata. Since the age criteria for matching was within a range of \pm 2 years, 396 controls ( $2.5 \%$ of controls) did not have a matching case in their strata (all were $<80$ 
years) and these controls were excluded during analysis (cases remained as they had other matches).

We did not observe notable differences in the estimates of association among individuals $\geq 80$ compared to the complete sample. In the unadjusted model, receipt of solifenacin, compared to mirabegron, was associated with an increased odds of incident dementia (OR 1.23; 95\% CI 1.041.45). We did not observe a significant association between receipt of the other antimuscarinics and incident dementia (Table 13). When we adjusted for unbalanced covariates, the associations observed for receipt of solifenacin was associated with a stronger odds incident dementia (Figure 11), compared to the unadjusted model.

Unlike the effects observed during analysis of the complete sample, among individuals $<80$ years, there is no association between receipt of antimuscarinics and incident dementia. In unadjusted and adjusted analysis, we did not observe any positive associations between receipt of individual antimuscarinics and incident dementia. In unadjusted analyses, receipt of tolterodine was associated with decreased odds of incident dementia (OR 081; 95\% CI 0.67-0.98), although this estimate became non-significant when adjusting for unbalanced covariates (Figure 11). 
Table 12 Unadjusted conditional logistic models, stratified by sex, evaluating the association between antimuscarinic $\mathrm{OAB}$ drug prescriptions and incident dementia.

\begin{tabular}{|c|c|c|c|c|c|c|c|c|}
\hline Drug & \multicolumn{2}{|c|}{ Exposed cases } & \multicolumn{2}{|c|}{ Exposed Controls } & OR & \multicolumn{2}{|c|}{$95 \% \mathrm{CI}$} & $\mathbf{p}$ \\
\hline \multicolumn{9}{|l|}{ Female } \\
\hline Mirabegron & 246 & $(3.2 \%)$ & 777 & $(3.9 \%)$ & \multicolumn{4}{|c|}{ - Reference - } \\
\hline Darifenacin & 311 & $(4.0 \%)$ & 792 & $(4.0 \%)$ & 1.33 & 1.07 & 1.66 & 0.010 \\
\hline Fesoterodine & 1195 & $(15.5 \%)$ & 3062 & $(15.3 \%)$ & 1.15 & 0.94 & 1.40 & 0.189 \\
\hline Solifenacin & 29 & $(0.4 \%)$ & 72 & $(0.4 \%)$ & 1.13 & 0.95 & 1.34 & 0.168 \\
\hline Trospium & 3873 & $(50.3 \%)$ & 10073 & $(50.3 \%)$ & 1.07 & 0.67 & 1.71 & 0.769 \\
\hline Tolterodine & 1799 & $(23.4 \%)$ & 4740 & $(23.7 \%)$ & 0.98 & 0.83 & 1.15 & 0.767 \\
\hline Oxybutynin & 246 & $(3.2 \%)$ & 524 & $(2.6 \%)$ & 0.95 & 0.80 & 1.12 & 0.519 \\
\hline \multicolumn{9}{|l|}{ Male } \\
\hline Mirabegron & 247 & $(6.7 \%)$ & 712 & $(7.2 \%)$ & \multicolumn{4}{|c|}{ - Reference - } \\
\hline Solifenacin & 751 & $(20.3 \%)$ & 1775 & $(18.0 \%)$ & 1.14 & 0.95 & 1.38 & 0.167 \\
\hline Trospium & 23 & $(0.6 \%)$ & 58 & $(0.6 \%)$ & 1.12 & 0.67 & 1.88 & 0.658 \\
\hline Darifenacin & 149 & $(4.0 \%)$ & 357 & $(3.6 \%)$ & 1.06 & 0.82 & 1.37 & 0.639 \\
\hline Fesoterodine & 224 & $(6.1 \%)$ & 651 & $(6.6 \%)$ & 0.96 & 0.77 & 1.19 & 0.700 \\
\hline Oxybutynin & 560 & $(15.2 \%)$ & 1385 & $(14.1 \%)$ & 0.93 & 0.76 & 1.13 & 0.456 \\
\hline Tolterodine & 1739 & $(47.1 \%)$ & 4903 & $(49.8 \%)$ & 0.82 & 0.68 & 0.99 & 0.038 \\
\hline
\end{tabular}

Table 13 Unadjusted conditional logistic models, stratified by age, evaluating the association between antimuscarinic $\mathrm{OAB}$ drug prescriptions and incident dementia.

\begin{tabular}{|c|c|c|c|c|c|c|c|c|}
\hline Drug & Expos & d cases & Exposed & Controls & OR & \multicolumn{2}{|c|}{$95 \% \mathrm{CI}$} & $\mathbf{p}$ \\
\hline \multicolumn{9}{|l|}{$<80$ years old } \\
\hline Mirabegron & 205 & $(5.2 \%)$ & 790 & $(5.0 \%)$ & \multicolumn{4}{|c|}{ - Reference - } \\
\hline Trospium & 23 & $(0.6 \%)$ & 63 & $(0.4 \%)$ & 1.35 & 0.81 & 2.24 & 0.249 \\
\hline Darifenacin & 155 & $(3.9 \%)$ & 454 & $(2.9 \%)$ & 1.24 & 0.96 & 1.59 & 0.099 \\
\hline Solifenacin & 752 & $(19.0 \%)$ & 2745 & $(17.5 \%)$ & 1.00 & 0.83 & 1.21 & 0.992 \\
\hline Fesoterodine & 209 & $(5.3 \%)$ & 791 & $(5.0 \%)$ & 0.98 & 0.79 & 1.23 & 0.866 \\
\hline Oxbutynin & 762 & $(19.3 \%)$ & 3054 & $(19.4 \%)$ & 0.87 & 0.71 & 1.05 & 0.148 \\
\hline Tolterodine & 1842 & $(46.7 \%)$ & 7816 & $(49.7 \%)$ & 0.81 & 0.67 & 0.98 & 0.026 \\
\hline \multicolumn{9}{|l|}{$\geq 80$ years old } \\
\hline Mirabegron & 288 & $(3.9 \%)$ & 699 & $(4.9 \%)$ & \multicolumn{4}{|c|}{ - Reference - } \\
\hline Solifenacin & 1194 & $(16.0 \%)$ & 2092 & $(14.8 \%)$ & 1.23 & 1.04 & 1.45 & 0.017 \\
\hline Darifenacin & 240 & $(3.2 \%)$ & 427 & $(3.0 \%)$ & 1.20 & 0.96 & 1.49 & 0.112 \\
\hline Fesoterodine & 326 & $(4.4 \%)$ & 652 & $(4.6 \%)$ & 1.11 & 0.91 & 1.36 & 0.290 \\
\hline Tolterodine & 3770 & $(50.6 \%)$ & 7160 & $(50.5 \%)$ & 0.99 & 0.84 & 1.17 & 0.934 \\
\hline Oxbutynin & 1597 & $(21.5 \%)$ & 3071 & $(21.7 \%)$ & 0.97 & 0.82 & 1.15 & 0.697 \\
\hline Trospium & 29 & $(0.4 \%)$ & 67 & $(0.5 \%)$ & 0.94 & 0.59 & 1.50 & 0.797 \\
\hline
\end{tabular}


Figure 10 Adjusted* conditional logistic regression model evaluating the association between antimuscarinic OAB drug prescription and incident dementia stratified by sex

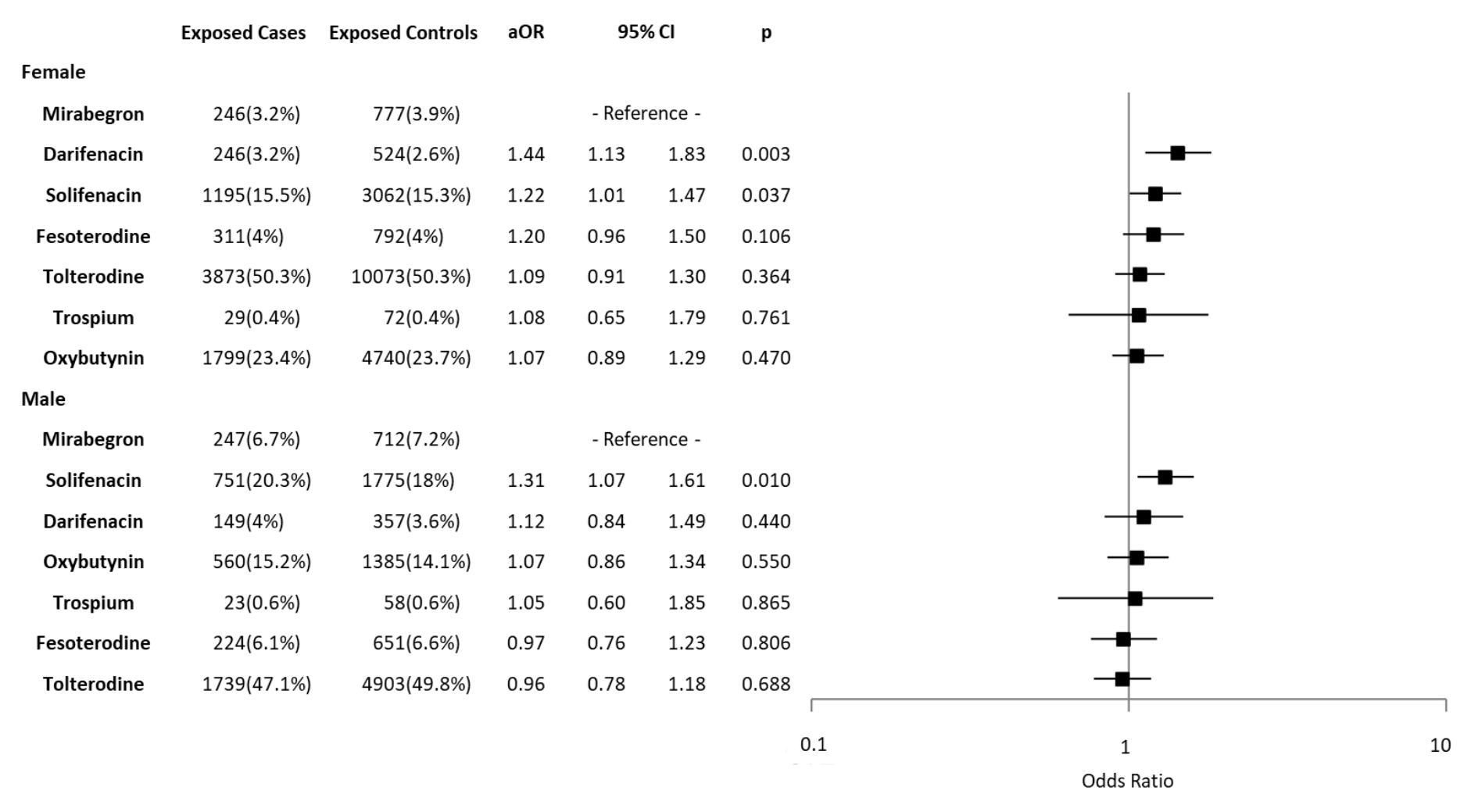

*Models were adjusted for Charlson comorbidity index category, a history of stroke, congestive heart failure, anxiety, mood disorder, schizophrenia, alcohol abuse, and Parkinson's disease and the number of unique drugs, number of primary visits, and having any hospital admission in the previous year. 
Figure 11 Adjusted* conditional logistic regression model evaluating the association between antimuscarinic OAB drug prescription and incident dementia stratified by age

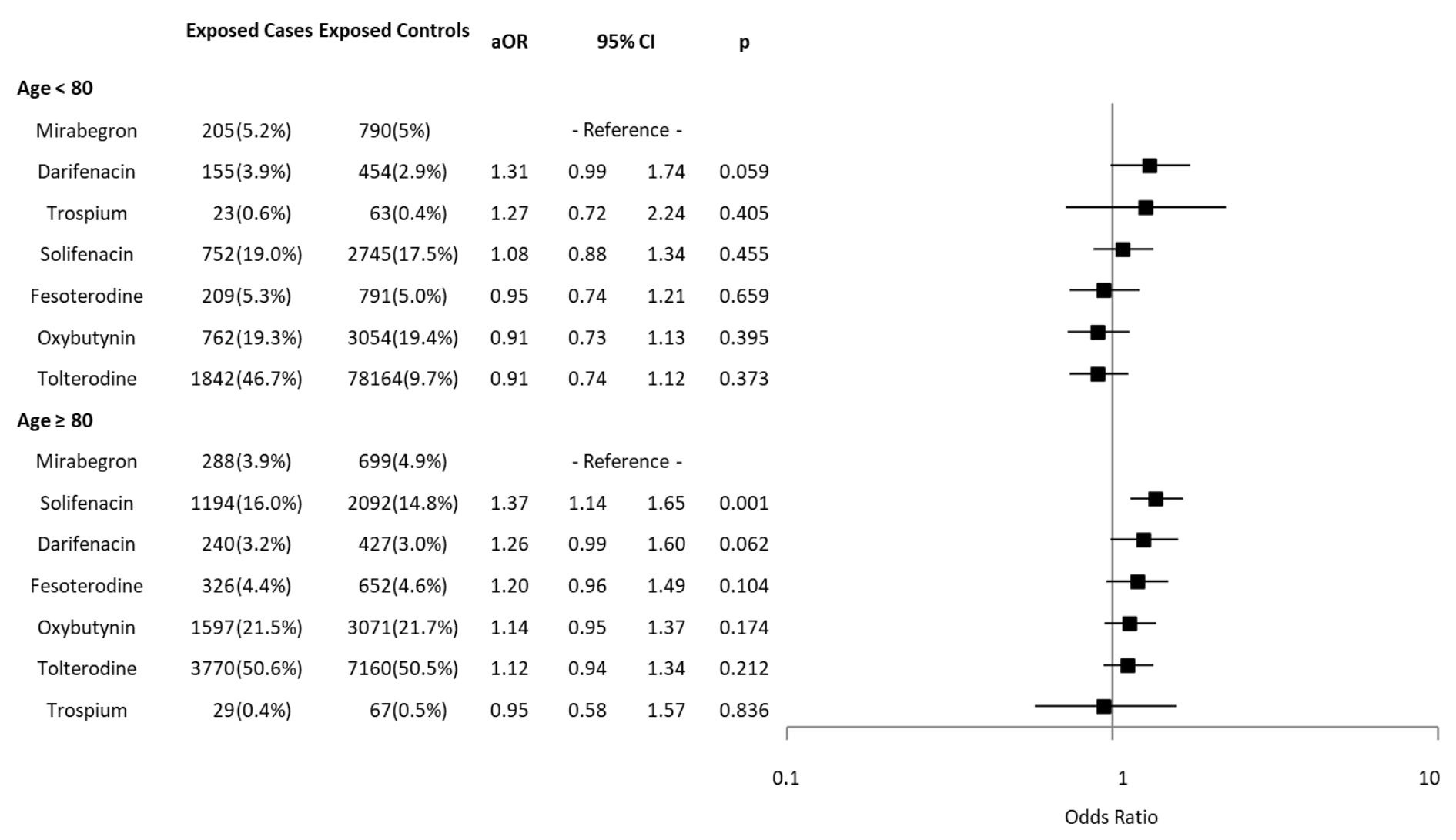

*Models were adjusted for Charlson comorbidity index category, a history of stroke, congestive heart failure, anxiety, mood disorder, schizophrenia, alcohol abuse, and Parkinson's disease and the number of unique drugs, number of primary visits, and having any hospital admission in the previous year. 


\subsection{Sensitivity Analysis: Addressing protopathic bias}

To address protopathic bias, namely the possibility that patients may start, switch or stop OAB treatment in the six months prior to diagnosis due to prodromal symptoms of dementia, we conducted sensitivity analysis by measuring OAB drug exposure in the 181-365 day period prior to the dementia diagnosis date. In order to perform the sensitivity analysis, we identified 11,258 cases and 37,119 controls using the same inclusion and exclusion criteria used for the primary analysis, except for the drug exposure period being 181-365 days prior to index date. Prior to the matching (see appendix 6.4 for the baseline characteristics of the unmatched cases and controls), the cases differed significantly from controls with respect to demographic characteristics and stroke prevalence. Cases had a higher median age (83 years; IQR 77-88 vs. 77 years; IQR 71$83)$, a lower proportion of females (69\% vs. $71 \%)$, and a higher proportion of individuals with a history of stroke/TIA in the previous three years (20\% vs. $10 \%)$. Cases were matched with up to 4 controls, excluding 39 unmatched cases. After matching, the cases and controls were balanced on all baseline demographic characteristics, although the same comorbidity and healthcare utilization characteristics that were unbalanced in the primary analysis were unbalanced in the sensitivity analysis (see appendix 6.5 for the baseline characteristics of the matched cases and controls).

In unadjusted conditional logistic regression (Table 14), receipt of any antimuscarinic drug, compared to mirabegron, was not associated with incident dementia (OR 1.12; 95\% CI 0.961.32). Extending the findings of the primary analysis, in adjusted analysis, the association between receipt of any antimuscarinic drug and incident dementia became statistically significant (OR 1.29; 95\% CI 1.09-1.54). Unlike the primary analysis, we found that compared to mirabegron, receipt of darifenacin, fesoterodine, solifenacin, and tolterodine was significantly associated with incident dementia. For oxybutynin there was a positive association approaching significance (OR 1.2; 95\%CI 1.00-1.44; p=0.052) (Figure 12). 
Table 14 Unadjusted conditional logistic models evaluating the association between antimuscarinic OAB drug prescriptions and incident dementia where the OAB drug exposure period observed is 181 to 365 prior to dementia diagnosis.

\begin{tabular}{|c|c|c|c|c|c|c|c|c|}
\hline \multirow{3}{*}{$\begin{array}{c}\text { Drug } \\
\text { Mirabegron } \\
\text { Antimuscarinics }\end{array}$} & \multicolumn{2}{|c|}{ Exposed cases } & \multicolumn{2}{|c|}{ Exposed Controls } & OR & \multicolumn{2}{|c|}{$95 \%$ CI } & \multirow[t]{2}{*}{$\mathbf{p}$} \\
\hline & 247 & $(2.2 \%)$ & 798 & $(2.8 \%)$ & & $-\operatorname{Re}$ & ce - & \\
\hline & 10972 & $(97.8 \%)$ & 28099 & $(97.2 \%)$ & 1.12 & 0.96 & 1.32 & 0.150 \\
\hline Darifenacin & 350 & $(3.1 \%)$ & 762 & $(2.6 \%)$ & 1.35 & 1.10 & 1.65 & 0.004 \\
\hline Solifenacin & 49 & $(0.4 \%)$ & 112 & $(0.4 \%)$ & 1.24 & 0.86 & 1.81 & 0.253 \\
\hline Trospium & 450 & $(4.0 \%)$ & 1117 & $(3.9 \%)$ & 1.24 & 1.03 & 1.49 & 0.027 \\
\hline Fesoterodine & 1654 & $(14.7 \%)$ & 4317 & $(14.9 \%)$ & 1.17 & 0.99 & 1.38 & 0.068 \\
\hline Oxybutynin & 2488 & $(22.2 \%)$ & 6319 & $(21.9 \%)$ & 1.04 & 0.88 & 1.23 & 0.633 \\
\hline Tolterodine & 5981 & $(53.3 \%)$ & 15472 & $(53.5 \%)$ & 1.04 & 0.88 & 1.22 & 0.651 \\
\hline
\end{tabular}


Figure 12 Adjusted* conditional logistic regression models of the association between antimuscarinic OAB drug prescriptions and incident dementia where the $\mathrm{OAB}$ drug exposure period observed is 181 to 365 prior to dementia diagnosis

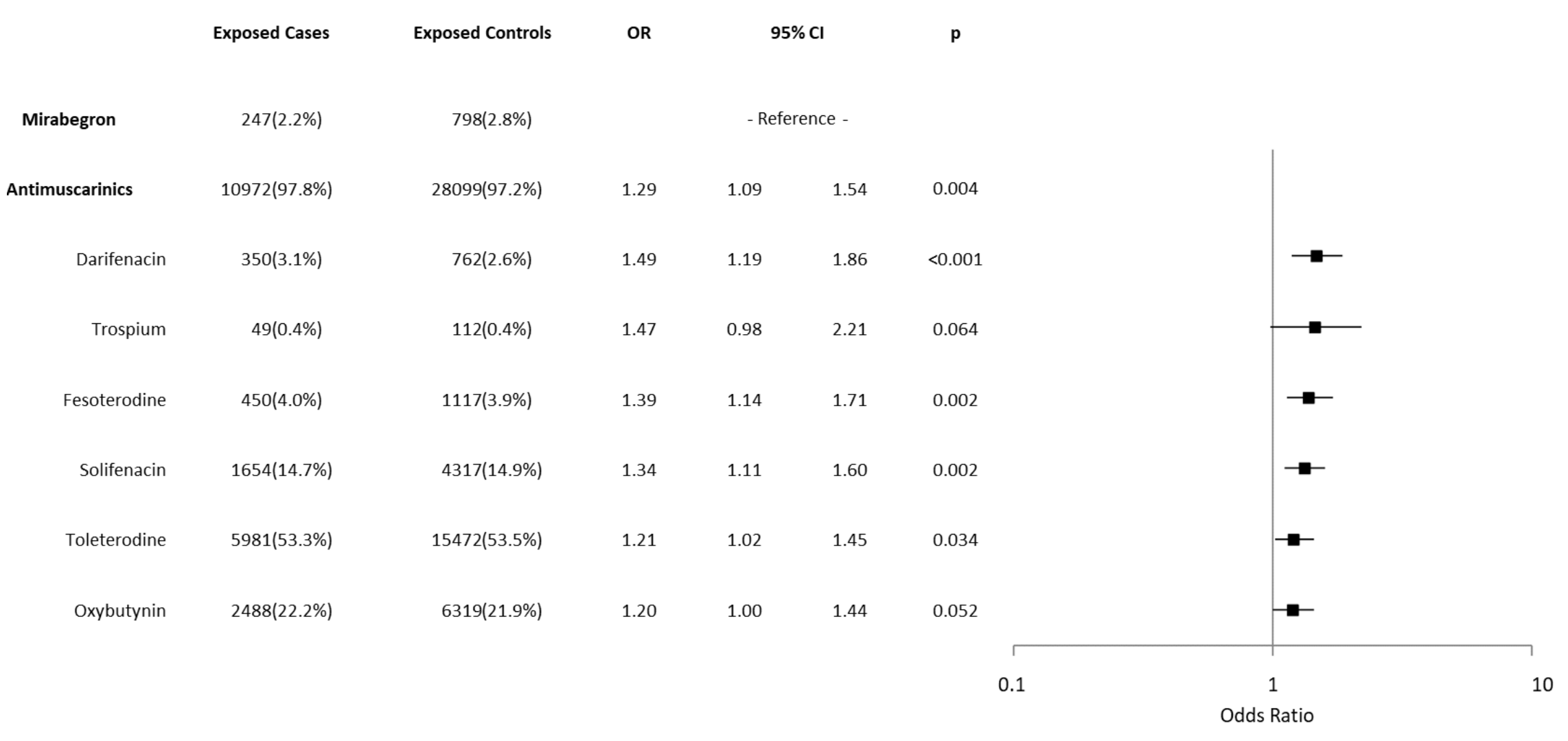

*Models were adjusted for Charlson comorbidity index category, a history of stroke, congestive heart failure, anxiety, mood disorder, schizophrenia, alcohol abuse, and Parkinson's disease and the number of unique drugs, number of primary visits, and having any hospital admission in the previous year.

**Receipt of antimuscarinics was evaluated as a composite variable in a separate conditional logistic model from the individual antimuscarinic drugs 


\section{Chapter 5 Discussion}

\section{Discussion}

\subsection{Major findings}

\subsubsection{Observed association between antimuscarinic OAB drugs and incident dementia}

In this population-based case control study of elderly individuals in Ontario, Canada, we evaluated the association between receipt of antimuscarinic OAB drugs and incident dementia. In the primary analysis, we found that individuals with incident dementia were more likely to have received darifenacin and solifenacin compared to mirabegron in the 180 days before diagnosis. With a lagged exposure period, 181-365 days before diagnosis, individuals with incident dementia were $29 \%$ more likely to have received any OAB antimuscarinic, compared to mirabegron. Patients were also more likely to have received most of the individual antimuscarinics, except for trospium and oxybutynin.

To our knowledge this is the first report to examine the association of exposure to antimuscarinic versus non-antimuscarinic $\mathrm{OAB}$ drugs and incident dementia. Richardson et al. identified a class effect for $\mathrm{OAB}$ antimuscarinics, as patients with incident dementia were 1.29 times (1.11-1.50) more likely to be exposed to $\mathrm{OAB}$ antimuscarinics versus no exposure. This is in agreement with our findings, although the reference group in this study is patients receiving mirabegron. They also found that there was a dose response with transient use (>0-13 defined daily doses [DDD]) having an odds ratio (OR) of $1.02(0.9-1.15)$ up to $\geq 1460$ DDDs having an OR of 1.24 (1.071.44). They only considered tolterodine ( $7 \%$ of 1.7 million prescriptions examined in study), oxybutynin (7\%), and solifenancin (1\%) and they only reported a class effect for these drugs (urinary anticholinergics). Moreover, their models compared exposure to non-exposure of these drugs, which may introduce confounding-by-indication bias. Patients receiving OAB antimuscarinics presumably have lower urinary tract symptoms (LUTS), which are associated with an increased risk of dementia(107). Previously, other drugs used to treat patients with LUTs that act via entirely different mechanisms were found to also be associated with dementia, supporting this notion of confounding-by-indication. Duan et al. recently demonstrated that men 
taking tamsulosin have a higher risk of developing dementia when compared to men taking other $\alpha$-adrenergic antagonists or no $\alpha$-adrenergic antagonists at all (Hazard Ratio [HR] 1.17; 1.141.21)(152). While there may be some biological plausibility for such an association $(153,154)$, there is also convincing evidence to the contrary. Tae et al., in a Korean population-based cohort, used propensity score matching to adjust for confounding-by-indication, and did not find an association between $\alpha$-adrenergic antagonists and incident dementia, versus other $\alpha$-adrenergic antagonists and no drug (155). Therefore, it was necessary to have compared OAB antimuscarinic users to patients with the same baseline risk of LUTS taking mirabegron.

In comparing receipt of the antimuscarinics to mirabegron, we expected to observe a significant association in the primary analysis between receipt of any antimuscarinics and incident dementia. Moreover, when evaluating the effects of the individual drugs, the receipt of M3 selective solifenacin and darifenacin was associated with an increased odds of incident dementia, while the receipt of non-selective oxybutynin, tolterodine, and fesoterodine had non-significant effects. This runs counter to the hypothesis that more selective drugs or drugs that are limited in central nervous system penetration, are less likely to have cognitive effects. While there are few head-to-head antimuscarinic trials evaluating cognitive effects, the available data is mixed on this point. Over a 12-week period, patients receiving oxybutynin extended release (ER) had memory impairment with lower scores on testing, compared to those taking darifenacin (M3 selective) and placebo (97). In contrast, the SENIOR trial of antimuscarinics in the elderly, comparing solifenacin, oxybutynin or placebo for 21 days, found that both drugs were not associated with significant changes in any cognitive function outcomes (attention and memory) (103). Moga et al. indirectly compare selective and non-selective antimuscarinics in a retrospective cohort study(123). They reported that there was a larger effect estimate for minimental status decline among non-selective antimuscarinic users (OR 1.54; 95\% CI 1.26-1.89) compared to users of any antimuscarinics (OR 1.40; 95\% CI 1.26-1.89). However, one could not directly compare the effect estimates reported, and the duration of exposure was not measured.

The findings of our primary analysis differ from the expected effect of antimuscarinics versus mirabegron, likely due to protopathic bias. In our study, cases had increased healthcare contact compared to controls in the year prior to dementia diagnosis. If prodromal symptoms, or mild cognitive impairment preceding their index date, were the drivers of increased healthcare 
utilization, this contact could have resulted in the stopping or switching of non-selective antimuscarinics to selective drugs, such as mirabegron. This would likely bias our results towards the null as we measured exposure in the 180 days prior to index date.

To address the possibility of protopathic bias, we introduced a lagged drug exposure period of 180 days prior to diagnosis (index date) and measured exposure during the 181 to 365 -day period. In this analysis, the association was stronger than the primary analysis, with a significantly increased odds of incident dementia among those exposed to most of the antimuscarinic drugs, compared to mirabegron. The approach of using a lag-period is commonly used to address protopathic bias. In trying to identify an appropriate lag-period, it is important to consider both the biological mechanism of the process being modeled and its temporality. In choosing our lag-time for exposure, we referred to previous studies evaluating the effect of anticholinergic exposure on incident dementia. These studies have employed a zero $(118,146)$, six month(119), or four-year lag period(122), with the same positive association regardless of lag time. When the timing of the lag-period is unclear based on literature review, a statistical approach may be appropriate, although we did not use one in this study. Tamim et al. evaluated 31 different lag-times in the association between the use of proton pump inhibitors and gastric cancer(145). They used compartmental and segmented regression models to identify a change point at which estimated regression coefficients tend to stabilize over time, indicating a suitable lag-time. In comparing the results of the primary analysis and sensitivity analysis, it appears that the drug exposure period affects the model estimates. We see that the proportion of patients receiving mirabegron increased during the 180-day period preceding diagnosis (5.0\%), compared to the 181-365-day period (2.7\%). As stated above, prescribers may recognize prodromal symptoms of dementia in the 180 days preceding the index date and stop or switch offending medications to mirabegron, which does not have known cognitive adverse effects(62). Vouri et al. found that patients with cognitive impairment and dementia were more likely to be prescribed a selective antimuscarinic compared to oxybutynin (116). However, they identified that between 2008 and 2011, patients with cognitive impairment were progressively more likely to initiate oral oxybutynin compared with other antimuscarinics, and they suggested this was driven by the lower cost of oxybutynin and formulary restrictions in their study setting (United States Medicare). In Ontario during our study period, for patients $\geq 65$ years, there were no differential copayments among the $\mathrm{OAB}$ antimuscarinic drugs and the only formulary restriction was the 
lack of Oxybutynin ER. Therefore, the differential prescribing of OAB antimuscarinics observed may be attributed to prescribers' knowledge of the risk profile of these medications with similar therapeutic benefits but varying degrees of risk for drug-associated cognitive impairment.

In stratified analysis, we found that for females receiving solifenacin and darifenacin compared to mirabegron, there was an increased odds of incident dementia. Among males, only receipt of solifenacin was associated with an increased odds of incident dementia. We chose to stratify by sex since it is a risk factor both for $\mathrm{OAB}$ and dementia, with women having a higher risk of both. Coyne et al. in a population-based survey sample found the prevalence of OAB symptoms was $27.2 \%$ in men and $43.1 \%$ in women (4). In Ontario, the age-standardized incidence rate of dementia was consistently higher for women (5.12 per 1000 population in 2013) than for men (5.08 per 1000 population in 2013) between 2008 and 2013, although women experienced a significant decrease in dementia incidence over the same time period $(6.7 \%$; 95\%CI 5.49-5.12, $\mathrm{p}=0.039)$ but men did not $(3.6 \% ; 95 \%$ CI 5.27-5.08; $\mathrm{p}=0.41)(150)$. Among men, the absence of an association between receipt of darifenacin and incident dementia may be the result of a type I error, based on the width of the confidence interval and a smaller sample of men versus women in our study. While we observed some differences between sexes, previous studies have not observed an interaction effect of sex. Gray et al. evaluated the association of cumulative exposure to anticholinergic medications and the risk of all-cause incident dementia (119). They did not identify a significant interaction with sex and the exposure measure (total standardized daily dose of anticholinergic drug).

When we stratified the analysis by age, we found that among individuals $<80$-years, there was no significant association between receipt of any of the $\mathrm{OAB}$ antimuscarinics and incident dementia. Conversely, among individuals $\geq 80$-years, receipt of solifenacin was significantly associated with incident dementia. This suggests that there is differential prescribing of antimuscarinics in elderly patients compared to younger patients. Older patients are thought to be more sensitive to the cognitive effects of antimuscarinics due to increased permeability of the blood-brain barrier(91), lower p-glycoprotein activity, an efflux transporter for the CNS(92), slower drug metabolism and elimination(93), and decreased central cholinergic transmission which is necessary for several cognitive processes(44). The outcomes observed however, may be 
the product of competing effects, with the cognitive effects of less selective antimuscarinics (oxybutynin) versus the prescribers' preference for more selective agents in cognitively susceptible and questionable individuals. Vouri et al., in their study of differential prescribing of antimuscarinics, observed that patients between 75-84 had a 2\% increased risk of receiving other antimuscarinics compared to oxybutynin, and those $\geq 85$ years had a $4 \%$ increased risk (116).

\subsection{Critical appraisal of study methodology}

\subsubsection{Study design: Case-control versus cohort study}

This study employed an incidence case-control design, as described by Pearce (156), where cases and controls were sampled from the population of individuals eligible to receive government funded health insurance in Ontario during the study accrual period. Although not technically a nested case-control (NCC) study, where a well-defined cohort is initially identified, Rothman et al. suggest that one should consider all case-control studies as being "nested" within a cohort; in this scenario that nest is the source population(157). Since the cases are a representative sample of all cases from a defined population, and the controls are sampled directly from this population, the study is also said to be a "population-based case control study"(158). Vandebroucke et al. suggest that a case-control study is more often conducted on a dynamic population rather than a cohort - the population from which cases and controls are sampled is constantly depleted and replenished over the accrual period, most likely remaining in a "steadystate" (159). This concept fits more with our study design, as we are sampling cases and controls from a dynamic population where each day during the accrual period new individuals turn 65 and others die.

In the population-based case-control design, cases are the same cases that would be considered in a cohort study, and controls are a sample that provide an estimate of the exposure and covariate prevalence in the source population(158). In our study, since controls are sampled from the population who are non-cases at the time of diagnosis (end of the follow-up period), then the odds ratio estimates the incidence odds ratio that would be obtained in a cohort study $(156,159)$. One important assumption in using this design and the control selection strategy we have used ('risk-set' or 'density' sampling), is that sampling of controls is independent, in that their risk of 
failure (becoming a case) is not different from similar individuals who have not been selected as controls at the same time.

There are important benefits to the population-based case-control design in this study context. A population-based case control study is a more computationally efficient version of its cohort study equivalent (125). Essebag et al. compared estimates from an NCC design to Cox regression on a complete cohort of 42,880 subjects(126). This was performed for a mix of time-dependent and independent covariates. They found that estimates were similar between the two designs, however, the Cox regression analysis took nearly 125 times as long as the NCC when considering 4 controls per case (1696 cases). Austin et al. argue that with modern computing power, the absolute differences in computing time are small(125), although this may not apply with large population-based cohorts and many time dependent covariates, as one might expect for this study.

Another benefit of NCC study design, is the ease of operationalization of time-varying exposures and the drug latency period. In the case of this study, we can operationalize the antimuscarinic drug exposure history (within 1 year, minimum 60 days cumulative supply, minimum two prescriptions, and a latency period of 6 months) into a meaningful measure that captures the aspects that are relevant to dementia risk. This can be difficult to implement in a longitudinal cohort study analysed using survival analysis, where one must account for time intervals in which the subject is either exposed or unexposed or one must censor when a competing event occurs - for example if a patient switches or discontinues a medication, or they die. In addition to this if the proportional hazards assumption is not met, then there is need for time dependent coefficients as well. Again, this can become computationally intensive depending on the variation of the exposure over time.

There are also notable shortcomings of the case-control design. Case-control data only allows the estimation of the odds ratio since once cannot easily determine the incidence of disease in the underlying cohort. While one cannot directly estimate absolute risk in the same way you would in a cohort study, since the odds ratio is an estimate of the risk ratio then one can calculate the attributable proportion (160). By virtue of this the population attributable fraction can be estimated using the odds ratio in a case control study. Another shortcoming of the case-control 
design is the loss of estimate precision. Austin simulated NCC and cohort study designs and found that the case-control design produces less precise estimates with higher mean standard error than a cohort study when exposure is applied at the time of cohort entry, similar to this study (125). When events or outcomes were rare and treatment or exposure occurred infrequently $(\sim 10 \%)$, then the magnitude of the relative bias was marginally greater for the cohort design than for the NCC. However, in the presence of time-varying exposures or competing risks, there was an increased percentage of bias in the NCC. Case-control studies may also suffer from reduced relative efficiency depending on the number of covariates (157); relative efficiency is the ratio of the variance of the parameter estimate from the full cohort to the variance estimated from the case-control study.

\subsubsection{Inclusion and exclusion criteria}

Since our interest was understanding the association between receipt of $O A B$ antimuscarinics and incident dementia in elderly patients, typically identified as older than 65 years, we included all patients $\geq 66$ years or older. Drug coverage by the Ontario Drug Benefits program begins at age 65 , and this would allow us to identify new users of cholinesterase inhibitors (hence incident dementia). The inclusion of all eligible patients in Ontario meeting this age criteria ensures our results are generalizable to both community dwelling individuals and those admitted to long term care facilities. This also accrues cases and controls from the same source population, limiting the selection bias inherent when cases and controls are drawn from different source populations.

To avoid misclassification of cases, we excluded patients over the age 105, since at that age the predominant pathology is likely aging-associated cognitive decline (non-pathologic) as described by Deary et al.(161), rather than Alzheimer's disease or other forms of dementia. Although dementia diagnostic criteria limit the age of diagnosis to 90 years of age (82), we extended the

criteria in our exclusions to age 105 to allow for delayed diagnoses captured using administrative data dementia algorithm (133).

Subjects were excluded if they had a mental health hospitalization record one year prior to their index/diagnosis date. In our study $1.0 \%(n=3,531)$ of the patients initially identified to have 
incident or prevalent dementia had a mental health hospitalization in the previous year before index date. These patients were excluded to limit confounding bias, while we adjusted for all unbalanced psychological covariates, as there are several reports of a strong association between dementia and mental health disorders, including depression(162) and schizophrenia(163).

Cherbuin et al. identified almost a two-fold increased risk of dementia in people with depression in late-life(136). Most relevant for this exclusion criteria, affective disorders diagnosed around the time of dementia diagnosis may be a prodromal feature of dementia rather than a risk factor. Berger et al. identified that depressive symptoms in patients are elevated for the first time in close proximity to the onset of dementia symptoms ( $<3$ years) (164). Lending further credence to this idea, in a recent cross sectional analysis examining the influence of depressive symptoms on cognitive function, there was an interactive effect of late stage mild cognitive impairment on the relationship between the presence of depressive symptoms and both episodic memory (0.96; 95\% CI, 0.31-1.62) and global cognitive function (0.46; 95\% CI, 0.028-0.89) (165).

\subsubsection{Case definition}

We identified dementia diagnosis using Ontario health administrative data of hospital admission diagnoses, outpatient physician billing diagnoses, or dispensing records for cholinesterase inhibitors. This approach has been validated using abstracted data from family practice-based electronic medical records (EMR) (133). The use of community-based patient records as a reference standard eliminates referral bias for patients seen in specialist clinics.

We modified the optimal algorithm (selected based on having a high PPV and a high sensitivity(133)), by adjusting the number of physician services claims for dementia and the time period in which they should be claimed from three physician claims in two years to two physician claims in one year. This was done to push forward the latest possible diagnosis date to March 31, 2017, since a 1-year window of observation from the first physician claim was necessary to establish a diagnosis (with an observation window out to March 31, 2018 which was the most recent data available at the time this study was executed). In modifying the algorithm, we retained several important features. We maintained the requirement for either a hospital claims, physician record, or dispensing record in the algorithm, rather than an algorithm based on 
hospital claims alone. A previous Canadian study validated hospital diagnoses coded in ICD-9 and ICD-10 alone compared to the hospital chart and found that they have high specificity (97.7$99.8 \%$ ) but low sensitivity (32.3-66.9\%) for identifying dementia(166), suggesting there is under coding during a hospital admission(166). Although we reduced the number of physician claims required, we maintained a minimum 30-day time restriction between physician visit codes to reduce the misclassification of a delirium episode. We also maintained the criteria to identify people with dementia based on receipt of a cholinesterase inhibitors. This is a specific criterion as these drugs are only indicated for dementia(168), and are not recommended for MCI treatment(169).

There are limitations with using this algorithm. Our case definition captures Alzheimer's disease and related dementia diagnoses. The definition does not include MCI which limits the possibility of evaluating or excluding earlier phases of dementia. Williamson et al. have developed an algorithm using solely primary care EMRs to identify patients with dementia including mild cognitive impairment(170), however this would not be feasible on a population level in Ontario due to inconsistent use of EMRs. This algorithm may underrepresent the number of patients with dementia, as physicians may not bill, code, or prescribe medications since they either missed the diagnosis or there was a hesitancy in labeling the patient as having dementia. In the validation study of the algorithm, there were 31 false negatives among 3,404 patients evaluated (individuals not identified as having dementia with administrative data but identified in the EMR) (133). Thirteen patients had significant evidence of dementia in the EMR, and the remainder had evidence of mild cognitive impairment, having been prescribed a medication for memory problems, or having a low mini-mental status exam score (10/30).

\subsubsection{Exposure definition}

We defined patients' exposure as receiving a single type of OAB medication in the 180 days prior to diagnosis, $\geq 60$ days cumulative supply, and $\geq 2$ prescriptions dispensed. We limited the exposure to patients taking a single drug during the drug exposure period since drug switching is common and we wished to evaluate differential effects of individual antimuscarinic drugs. In a systematic review of real world $\mathrm{OAB}$ drugs use, treatment switching (discontinuing one drug and 
starting another) occurred in $\leq 17 \%$ of patients among 7 studies (55). We required a cumulative supply of 60 days to ensure patients initiating a drug had enough exposure to experience clinical efficacy(171) and adverse effects. This duration has previously been identified as the minimum required to see an effect on cognition(172).

Along with the condition of two prescriptions, this 60-day minimum dispensing limits increases the likelihood that that patients were chronic users, especially those who are dispensed weekly supplies. Several studies evaluating adherence and persistence of OAB antimuscarinics have reported that drug switching or discontinuation occurs within a mean of 2 months of initiating an index drug, although in Ontario the median time to discontinuation ranges from 110 days for oxybutynin to 240 days for solifenacin (173-175). Since we are not measuring continuous exposure during this period, but rather cumulative, a minimum 60-days' supply also allows for liberal intermittent use, which is thought to be prevalent in OAB. Chancellor et al. found that $35 \%$ of patients initiating an $\mathrm{OAB}$ antimuscarinic stopped and reinitiated treatment sometime after 45 days(176). This is also an attempt to limit protopathic bias by excluding patients who were switching drugs during this period due to prodromal symptoms of dementia.

We required that a minimum of two prescriptions be dispensed within the drug exposure period, since a single dispensing could represent a trial of the drug, and the patient does not remain adherent to the drug. There is a high likelihood of drug discontinuation in the first few weeks after initiating and $\mathrm{OAB}$ antimuscarinic drug. In a systematic review of antimuscarinic treatment in patients with $\mathrm{OAB}$, rates of drug discontinuation at 12 weeks were high, ranging from $43 \%-$ $83 \%$ in medical claims databases(177). Repeat dispensing increases the likelihood that the patient persisted with therapy and suggests that the first dispensing was used by the patient.

\subsubsection{Control selection and matching}

In this study we selected controls from the general population of all OHIP eligible individuals during the accrual period and matched them to cases on age, sex and index date. This constituted the risk-set, which includes the case who fails at time, $t$, and all the non-case members of the cohort that are at risk at $t$. At each failure time for a control, a defined number of controls is 
randomly sampled. This is incidence density sampling or risk-set sampling(178). We did not use sampling with replacement, where individuals can participate in several sampled risk sets (ie. they can be sampled in several risk sets), since this is used if the intent is to represent person time and individuals are selected longitudinally $(159,178)$. The selection of sampled controls in a casecontrol study can be an important source of bias. We allowed controls included in a sampled risk set to later become cases during their follow-up to limit control selection bias. The use of the risk set is intuitive since we define the risk set based on temporality (time of diagnosis or index date and age), and therefore we are comparing exposure to drugs that were available during the observation period, and exposures that are experienced up to the age of diagnosis.

Figure 13 Matching results between cases of incident dementia and controls sampled from the general population
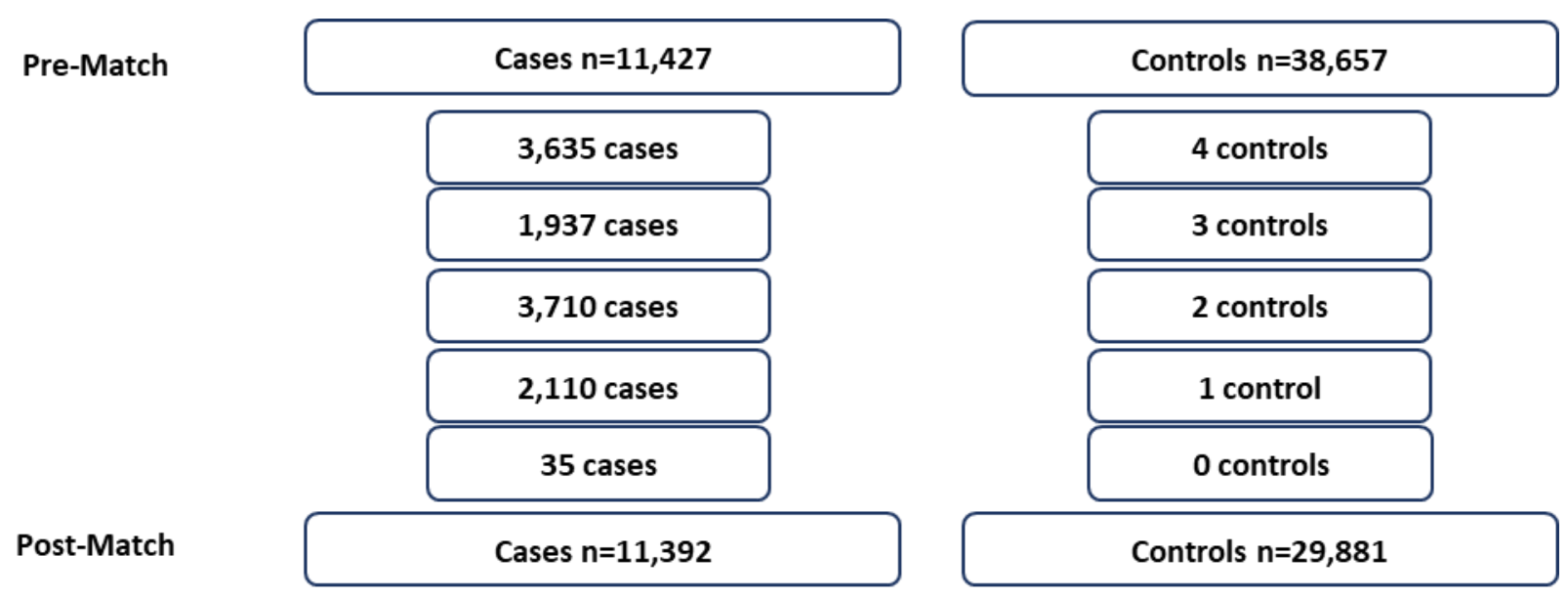

In order to maximize the statistical efficiency of a case-control study while limiting the bias, the quality of the match procedure and the use of an appropriate analysis that accounts for the matched design are important (124). To evaluate the quality of the match procedure in this study, we wish to determine if 1) the matching procedure balanced the measured covariates, 2) the performance of the greedy matching algorithm is comparable to other algorithms, and if 3) there is overmatching.

Two factors were judged to be potentially confounding the association between $\mathrm{OAB}$ antimuscarinic exposure and dementia. These factors were selected based on prior literature and the clinical experience of the investigators. The two factors were sex and age at diagnosis of 
dementia. There was an additional matching factor, the index date (diagnosis date for cases, randomly assigned date for controls), which is discussed further below. We decided to match on a difference of no more than 2 years for age. This match was successful, as we were able to pair up to 4 controls to 1 case, with only 35 unmatched cases (see Figure 13 for details). Table 9 and Table 10 show the distribution of the baseline characteristics before and after the match. We can see that the matched cases and controls have identical prevalence on the categorical match variables (sex) and a similar median age. As well, other measured characteristics of cases and controls that were not matched on appear to be similar. We used the standardized difference $<0.1$ as a balance diagnostic to compare the distribution of baseline characteristics between cases and control, as it is commonly employed and easily understood(179).

We employed a greedy matching algorithm as described by Rosenbaum (139). Another algorithm described by Rosenbaum, optimal matching, sets up the matching problem as a network flow problem to find the optimal set of matches, i.e., that with the smallest possible total distance (139). Ngo et al. compared the greedy to optimal matching algorithms using six matching factors with exact matching on 4 categorical factors and a 5-unit difference for two continuous variables in a 1:2 case:control match(180). They found that with optimal matching, more total cases were matched, and more cases were matched to two controls. If they forced the same number of pairs in each algorithm, the optimal algorithm yielded higher quality pairs (with smaller mean distance). There is however the trade-off of increased computational demands with optimal matching (139), hence the reason we opted for a greedy match algorithm.

Overmatching is a risk in case-control studies, which counteracts the efficiency of the design and can introduce bias. Pearce argues that when there is no association between the match factor and the exposure or outcome, matching on this factor becomes unnecessary and it is enough to use a random sample of controls(143). Conversely, when there is an association between the match factor and the exposure and the outcome, then matching would select controls with exposure values like that of the cases, causing a bias towards the null. In this scenario, it is necessary to control for the matching factor in the analysis(143) to evaluate whether this control will affect the main exposure effect estimate. Ngo et al. describe another approach to evaluate whether overmatching has occurred using a general linear model where the dependent variable is the exposure, and the independent variables the matching factors. We evaluated the effect of 
adjusting for age in our models (not shown) and observed minor changes in the main exposure estimates. Therefore, we concluded that age matching within a 2-year range was not overmatching.

\subsubsection{Analysis: Conditional logistic regression model}

This study was a matched case-control study, which was analysed using a conditional logistic regression model. To understand the reasoning for using a conditional logistic regression it is helpful to first examine the approach taken in an unmatched case-control study. In such a study, unconditional logistic regression is typically used for analysis, which employs maximum likelihood methods, and allows for the adjustment of multiple confounders. Another option for analysing an unmatched dataset is to use the Mantel-Haenszel method, which involves generating $2 \times 2$ tables for each level (stratum) of a confounder, and then producing an average effect across strata. This approach is difficult to compute with many confounders.

A conditional logistic regression will estimate regression coefficients based on the partial likelihood method(143) (like a Cox-proportional hazards model), or using similar methods to the Mantel-Haenszel method. One can conceive of a matched case control study as an example of extreme stratification, where there will be as many strata as there are case-control pairs(181). If unconditional methods are used in this scenario this results in exaggerated estimates of the odds ratio $(143,181)$. Thus, a conditional logistic regression is used when the strata (matched pairs) are small leading to sparse data.

\subsection{Limitations}

\subsubsection{Selection bias}

Since we do not employ a new-user design in this study, we may introduce prevalent user bias(182). Prevalent users are those who have not experienced the adverse event in question during the early period of pharmacotherapy. This form of bias can be both a selection bias and a confounding bias in cohort studies. Confounding bias due to prevalent users is limited in a case 
control study, since confounding variables are measured at the time of the index date and these characteristics could be affected by the drug regardless of when it was initiated. Selection bias occurs if the risk of the outcome varies with exposure time, as this can introduce a substantial bias for "survivors". This effect is mitigated with the case-control study design, although may still be present in a nested case-control, depending on the inclusion criteria for the nest cohort. In this study, the hypothesis was that antimuscarinic exposure would be associated with an increased odds of incident dementia. If this is true, then by including prevalent users in the study, cases would be enriched with patients who have been receiving the drugs for longer (more resilient patients), while controls would be more likely to be newer users. However, since we do not distinguish the duration of receipt amongst the cases and controls, we would likely bias our results towards the null.

Based on our study design, we are selecting for patients surviving at least 180 days after their initial anticholinergic exposure. By excluding cases unexposed to OAB medications we may be selecting for patients at an increased risk of incident dementia, as their urinary symptoms are likely more clinically significant warranting treatment. However, since all patients in the study receive $\mathrm{OAB}$ drugs along with the reference group (mirabegron), there is likely limited selection bias in this regard. In doing so, our results estimate a differential odds of incident dementia amongst users of antimuscarinic $\mathrm{OAB}$ drugs relative to mirabegron, rather than compared to the general population. As well, by using exposure criteria that select for adherent patients, we may be enriching the case and control groups, non-differentially, with patients who are more at risk for dementia. In a systematic review of real-world persistence and adherence, older patients and those with cognitive impairment were more likely to remain adherent to OAB drugs (55).

The study population was limited to individuals aged $\geq 66$ years at diagnosis due to the eligibility for medical coverage in Ontario at age 65. Therefore, these results may not be applicable to younger patients exposed to $\mathrm{OAB}$ drugs and later dementia. 


\subsubsection{Information bias}

The principle source of information bias in our study is surveillance bias as a result of the differential healthcare utilization for cases with incident dementia versus controls. As described by Haut et al., surveillance bias is a non-random type of information bias, where patients in one exposure group have a higher probability of having the study outcome detected(183). This would manifest in a case-control study where cases have a different probability of antimuscarinic drug exposure compared to controls based due to increased surveillance. In this study, baseline characteristics for matched cases and controls indicated that cases had a higher number of primary care visits, hospital admissions and unique drugs dispensed in the year prior to diagnosis. This may be the result of increased comorbidity associated with cognitive impairment and the ensuing contact with the health system. With increased healthcare contact and scrutiny of medication lists, prescribers may stop or switch non-selective antimuscarinics to selective drugs, such as mirabegron. This would likely bias our results towards the null. If cognitive symptoms or prodromal symptoms were the driver of increased healthcare utilization in the year prior to index date, this may explain why the lagged drug exposure window demonstrated a stronger association between incident dementia and receipt of all the antimuscarinics compared to the primary analysis.

As with any study using health administrative data, there is likely some misclassification in measuring exposures, outcomes, and covariates. The outcome measure of incident dementia uses a validated algorithm as discussed previously; however, it may underestimate incident dementia. Dementia is difficult to diagnose, and the algorithm was validated with a non-gold standard reference for dementia (EMR data). It is unclear which direction this might bias our results since we are underestimating dementia diagnoses in the entire sample. We suspect this would cause non-differential misclassification as the algorithm has positive predictive and negative predictive values that are similar and greater than $80 \%$. It is reassuring that prevalence estimates of dementia using this algorithm agree with epidemiological studies of dementia from other jurisdictions. Furthermore, the algorithm we use does not capture patients with mild cognitive impairment, which may represent a much larger proportion of the sample than those with dementia. 
The exposure measurement of $\mathrm{OAB}$ drug receipt, rather than consumption, means we do not know whether patients were adherent for the total supply they received. Moreover, drugs obtained without a prescription are not recorded in our data, hence we will have likely underestimated the use of certain strong anticholinergics such as older antihistamines (dimenhydrinate, diphenhydramine), although we do not necessarily expect a bias in either direction with this misclassification. We also did not consider the daily doses of $\mathrm{OAB}$ antimuscarinics or other antimuscarinics prescribed. Additionally, some patients may have been excluded as non-users in a scenario where they stopped treatment prior to the drug exposure period (180 days before index date). These instances of exposure misclassification would likely cause an underestimate of true association between antimuscarinic exposure and incident dementia. Patients may be excluded as non-users because they did not tolerate the drug or experienced an adverse effect of antimuscarinic use and therefore stopped the drug; if we assume that those participants are more likely to experience cognitive adverse effects (i.e., decline) and they were excluded from the study, we would bias our results toward the null. Similarly, our inability to identify those using immediate-release formulations prevents us from stratifying or controlling on this exposure, biasing towards the null as these formulations are known to cause more adverse effects.

Covariate misclassification is a possibility; like our case definition, we use validated algorithms for some of the covariate definitions. Some of our covariates use non-validated algorithms and we cannot determine the diagnostic characteristics of these codes. It is difficult to ascertain if this is differential between cases and controls. Cases diagnosed with dementia may have increased healthcare contact and this may result in a different ascertainment of confounding covariates. We found a higher percentage of cases, compared to controls, with neurological and psychiatric comorbidities. Whether this is a result of health care contact volumes or vice versa is difficult to determine.

\subsubsection{Confounding bias}

We considered several potential confounders in the relationship between receipt of $\mathrm{OAB}$ antimuscarinic drugs and incident dementia. Like any observational study, there is unmeasured 
or residual confounding as many risk factors for dementia are unmeasured. Health administrative databases do not contain lifestyle and socioeconomic information such as education status, which may underlie the associations observed in this study. Other confounding variables not captured through our data sources which may confound the relationship between receipt of OAB drugs and incident dementia include demographic variables (race), body mass index (BMI), and cognitive function (as determined by neurocognitive testing).

There is a possibility of residual confounding in our study given the inability to determine whether antimuscarinic prescribing was due to treatment of lower urinary tract symptoms as a prodrome of dementia. We addressed this issue by maintaining that all cases and controls had to have exposure to an $\mathrm{OAB}$ agent during the drug exposure period. Still, patients with prodromal cognitive symptoms or mild cognitive impairment, which was unmeasured in this study, may be more likely to be prescribed non-selective or selective antimuscarinics (116), depending on the motivating factors for prescribing in our jurisdiction. This would likely bias our results towards the null.

We also could not ascertain the diagnosis of OAB for patients accrued in this study and therefore receipt of $\mathrm{OAB}$ drug prescriptions acts as a surrogate measure. In a previous study of population treatment patterns of OAB in Ontario, $66.9 \%$ of users $(\mathrm{N}=76,196)$ had an OAB diagnosis within a 5-year lookback form 2013 (175). This differed based on the drug prescribed. Over $80 \%$ of users receiving darifenacin, trospium, and dual therapy had an OAB diagnosis compared to 55\% of oxybutynin users. This could represent unmeasured confounding in the association between $\mathrm{OAB}$ drug receipt and dementia in the context of differential prescribing of the drugs, as there is an association between $\mathrm{OAB}$ and dementia. Although, since the diagnosis codes for OAB are not validated, this may simply misrepresent differential misclassification in terms of coding practices.

\subsection{Clinical significance and impact}

We found that there was an association between recent receipt of some OAB antimuscarinic drugs, specifically solifenacin and darifenacin, and incident dementia, and that the strength of 
this association varies among the different $\mathrm{OAB}$ antimuscarinics compared to mirabegron. Receipt of some of the OAB drugs that one might expect to have a strong association with incident dementia (ie. oxybutynin), demonstrated a null association. It is difficult to draw definitive conclusions about the etiology of the association observed in this study with possible protopathic bias. However, these findings can still inform clinical education and decision making for providers who manage OAB.

The finding of a positive association between receipt of darifenacin and solifenacin and incident dementia can inform the decision to start or continue these antimuscarinic drugs, as compared to a non-antimuscarinic (mirabegron) in managing urinary symptoms, with the risks of possible future cognitive impairment as a result of drug selection. If we consider the findings of the sensitivity analysis, clinicians may wish to avoid antimuscarinics altogether when managing overactive bladder in elderly patients, with a suitable alternative option such as mirabegron. This coupled with other studies demonstrating the efficacy, and cardiovascular safety of mirabegron, support its use over antimuscarinics.

Even if the findings of this study only represent prescribers' proclivity to prescribing antimuscarinics, compared to mirabegron, for managing patients with early cognitive impairment, then this has important implications for prescribers. With several recent studies demonstrating that the use of strong anticholinergics is associated with incident dementia, the findings here raise questions regarding the appropriateness increased prescribing of $\mathrm{OAB}$ antimuscarinics among elderly cognitively impaired patients.

\subsection{Future direction}

To explore the cumulative effects of $\mathrm{OAB}$ antimuscarinic drugs as compared to mirabegron, we can pursue a cohort design. If we operationalize the drug receipts as time varying covariates, we could also include patients who take more than a single OAB drug over the exposure period, enhancing the generalizability of our study findings. This would also enable us to determine the incidence of dementia among patients recieving $\mathrm{OAB}$ antimuscarinics. 
To address the possibility of protopathic bias observed in our primary analysis and establish the appropriate time window in which to measure drug exposure, we can repeat our analysis with varying lag times using a statistical approach like that employed by Tamim et al. (145) to determine a suitable lag-time. As well, varying the time window in which to measure drug exposure would be appropriate in future studies, as the choice of exposure window may influence risk comparisons due to misclassification. With a chronic outcome such as dementia, where one would assume the drug exposure risk-window is likely long (ie. chronic exposure), there is the possibility of attenuation of incidence rates due to misclassifying the exposure. Therefore, it would be important to validate risk windows or perform sensitivity analyses.

With a validated algorithm for determining overactive bladder and patients with storage lower urinary tract symptoms, we could reliably explore the underlying association between overactive bladder and incident dementia among a cohort of patients unexposed to antimuscarinics. This would also allow us to explore if $\mathrm{OAB}$ antimuscarinic exposure is an effect modifier in this association.

\subsection{Conclusions}

Older patients who receive solifenacin and darifenacin, compared to mirabegron, in the 6 months prior to diagnosis have increased odds of incident dementia. Those patients who receive any of the other $\mathrm{OAB}$ antimuscarinics during this period, compared to mirabegron, do not have increased odds of incident dementia. These associations are most pronounced in patients $\geq 80$

years old at the time of dementia diagnosis, and in females. In the six months to one year prior to diagnosis, receipt of any OAB antimuscarinic is associated with increased odds of incident dementia, compared to receipt of mirabegron. 


\section{References}

1. Haylen BT, de Ridder D, Freeman RM, Swift SE, Berghmans B, Lee J, et al. An International Urogynecological Association (IUGA)/International Continence Society (ICS) joint report on the terminology for female pelvic floor dysfunction. Int Urogynecology J. 2010 Jan;21(1):5-26.

2. Abrams P, Cardozo L, Fall M, Griffiths D, Rosier P, Ulmsten U, et al. The standardisation of terminology in lower urinary tract function: report from the standardisation sub-committee of the International Continence Society. Urology. 2003 Jan;61(1):37-49.

3. Ruffion A, Castro-Diaz D, Patel H, Khalaf K, Onyenwenyi A, Globe D, et al. Systematic Review of the Epidemiology of Urinary Incontinence and Detrusor Overactivity among Patients with Neurogenic Overactive Bladder.

Neuroepidemiology. 2013;41(3-4):146-55.

4. Coyne KS, Sexton CC, Vats V, Thompson C, Kopp ZS, Milsom I. National Community Prevalence of Overactive Bladder in the United States Stratified by Sex and Age. Urology. 2011 May 1;77(5):1081-7.

5. Irwin DE, Milsom I, Hunskaar S, Reilly K, Kopp Z, Herschorn S, et al. Population-based survey of urinary incontinence, overactive bladder, and other lower urinary tract symptoms in five countries: results of the EPIC study. Eur Urol. 2006 Dec;50(6):1306-14; discussion 1314-1315.

6. Malmsten UGH, Molander U, Peeker R, Irwin DE, Milsom I. Urinary incontinence, overactive bladder, and other lower urinary tract symptoms: a longitudinal population-based survey in men aged 45-103 years. Eur Urol. 2010 Jul;58(1):149-56.

7. Corcos J, Schick E. Prevalence of overactive bladder and incontinence in Canada. Can J Urol. 2004 Jun;11(3):2278-84.

8. Herschorn S, Gajewski J, Schulz J, Corcos J. A population-based study of urinary symptoms and incontinence: the Canadian Urinary Bladder Survey. BJU Int. 2008 Jan;101(1):52-8.

9. Gibson W, Wagg A. Incontinence in the elderly, "normal" ageing, or unaddressed pathology? Nat Rev Urol. 2017;14(7):440-8.

10. Vrijens D, Drossaerts J, van Koeveringe G, Van Kerrebroeck P, van Os J, Leue C. Affective symptoms and the overactive bladder - a systematic review. J Psychosom Res. 2015 Feb;78(2):95-108. 
11. Lai HH, Shen B, Rawal A, Vetter J. The relationship between depression and overactive bladder/urinary incontinence symptoms in the clinical OAB population. BMC Urol [Internet]. 2016 Oct 6;16. Available from: http://www.ncbi.nlm.nih.gov/pmc/articles/PMC5053341/

12. Kurita N, Yamazaki S, Fukumori N, Otoshi K, Otani K, Sekiguchi M, et al. Overactive bladder symptom severity is associated with falls in communitydwelling adults: LOHAS study. BMJ Open. 2013 May 3;3(5).

13. Bunn F, Kirby M, Pinkney E, Cardozo L, Chapple C, Chester K, et al. Is there a link between overactive bladder and the metabolic syndrome in women? A systematic review of observational studies. Int J Clin Pract. 2015 Feb;69(2):199217.

14. Gacci M, Corona G, Sebastianelli A, Serni S, De Nunzio C, Maggi M, et al. Male Lower Urinary Tract Symptoms and Cardiovascular Events: A Systematic Review and Meta-analysis. Eur Urol. 2016 Nov;70(5):788-96.

15. Liu H-Y, Chung M-S, Wang H-J, Liu R-T, Chuang Y-C. Nocturia indicates a poor health status and increases mortality in male patients with type 2 diabetes mellitus. Int Urol Nephrol. 2016 Aug;48(8):1209-14.

16. Eapen RS, Radomski SB. Review of the epidemiology of overactive bladder. Res Rep Urol. 2016 Jun 6;8:71-6.

17. Stewart WF, Van Rooyen JB, Cundiff GW, Abrams P, Herzog AR, Corey R, et al. Prevalence and burden of overactive bladder in the United States. World J Urol. 2003 May;20(6):327-36.

18. Milsom I, Abrams P, Cardozo L, Roberts RG, Thüroff J, Wein AJ. How widespread are the symptoms of an overactive bladder and how are they managed? A population-based prevalence study. BJU Int. 2001 Jun;87(9):760-6.

19. de Groat WC, Griffiths D, Yoshimura N. Neural Control of the Lower Urinary Tract. Compr Physiol. 2015 Jan;5(1):327-96.

20. Kuhtz-Buschbeck JP, van der Horst C, Pott C, Wolff S, Nabavi A, Jansen O, et al. Cortical representation of the urge to void: a functional magnetic resonance imaging study. J Urol. 2005 Oct;174(4 Pt 1):1477-81.

21. Tadic SD, Griffiths D, Schaefer W, Murrin A, Clarkson B, Resnick NM. Brain activity underlying impaired continence control in older women with overactive bladder. Neurourol Urodyn. 2012;31(5):652-8.

22. Tadic SD, Tannenbaum C, Resnick NM, Griffiths D. Brain responses to bladder filling in older women without urgency incontinence. Neurourol Urodyn. 2013 Jun;32(5):435-40. 
23. Fowler CJ, Griffiths D, de Groat WC. The neural control of micturition. Nat Rev Neurosci. 2008 Jun;9(6):453-66.

24. Haferkamp A, Mundhenk J, Bastian PJ, Reitz A, Dörsam J, Pannek J, et al. Increased Expression of Connexin 43 in the Overactive Neurogenic Detrusor. Eur Urol. 2004 Dec 1;46(6):799-805.

25. Suskind AM. The Aging Overactive Bladder: A Review of Aging-Related Changes from the Brain to the Bladder. Curr Bladder Dysfunct Rep. 2017 Mar;12(1):42-7.

26. Corcos J, Przydacz M, Campeau L, Witten J, Hickling D, Honeine C, et al. CUA guideline on adult overactive bladder. Can Urol Assoc J. 2017 May;11(5):E14273.

27. Gormley EA, Lightner DJ, Faraday M, Vasavada SP, American Urological Association, Society of Urodynamics, Female Pelvic Medicine. Diagnosis and treatment of overactive bladder (non-neurogenic) in adults: AUA/SUFU guideline amendment. J Urol. 2015 May;193(5):1572-80.

28. Nambiar AK, Bosch R, Cruz F, Lemack GE, Thiruchelvam N, Tubaro A, et al. EAU Guidelines on Assessment and Nonsurgical Management of Urinary Incontinence. Eur Urol. 2018 Apr 1;73(4):596-609.

29. Rai BP, Cody JD, Alhasso A, Stewart L. Anticholinergic drugs versus non-drug active therapies for non-neurogenic overactive bladder syndrome in adults. Cochrane Database Syst Rev [Internet]. 2012 [cited 2019 Apr 1];(12). Available from:

https://www.cochranelibrary.com/cdsr/doi/10.1002/14651858.CD003193.pub4/full

30. Thompson IM, Lauvetz R. Oxybutynin in bladder spasm, neurogenic bladder, and enuresis. Urology. 1976 Nov;8(5):452-4.

31. Chapple CR, Khullar V, Gabriel Z, Muston D, Bitoun CE, Weinstein D. The effects of antimuscarinic treatments in overactive bladder: an update of a systematic review and meta-analysis. Eur Urol. 2008 Sep;54(3):543-62.

32. Hay-Smith J, Herbison P, Ellis G, Moore K. Anticholinergic drugs versus placebo for overactive bladder syndrome in adults. Cochrane Database Syst Rev. 2002;(3):CD003781.

33. Madhuvrata P, Cody JD, Ellis G, Herbison GP, Hay-Smith EJC. Which anticholinergic drug for overactive bladder symptoms in adults. Cochrane Database Syst Rev. 2012 Jan 18;1:CD005429.

34. Herbison P, McKenzie JE. Which anticholinergic is best for people with overactive bladders? A network meta-analysis. Neurourol Urodyn. 2019 Feb;38(2):525-34. 
35. Tadrous M, Elterman D, Khuu W, Mamdani MM, Juurlink DN, Gomes T. Publicly funded overactive bladder drug treatment patterns in Ontario over 15 years: An ecological study. Can Urol Assoc J J Assoc Urol Can. 2018 Mar;12(3):E142-5.

36. Minhas R, Tadrous M, Elterman D, Gomes T. Trends in the use of older overactive bladder agents and uptake of fesoterodine and mirabegron in Canada. Neurourol Urodyn. 2018 Jun;37(5):1693-700.

37. Veenboer PW, Bosch JLHR. Long-term adherence to antimuscarinic therapy in everyday practice: a systematic review. J Urol. 2014 Apr;191(4):1003-8.

38. Glavind K, Chancellor M. Antimuscarinics for the treatment of overactive bladder: understanding the role of muscarinic subtype selectivity. Int Urogynecology J. 2011 Aug 1;22(8):907-17.

39. Callegari E, Malhotra B, Bungay PJ, Webster R, Fenner KS, Kempshall S, et al. A comprehensive non-clinical evaluation of the CNS penetration potential of antimuscarinic agents for the treatment of overactive bladder. Br J Clin Pharmacol. 2011 Aug;72(2):235-46.

40. Naples JG, Marcum ZA, Perera S, Gray SL, Newman AB, Simonsick EM, et al. Concordance Between Anticholinergic Burden Scales. J Am Geriatr Soc. 2015 Oct;63(10):2120-4.

41. Buser N, Ivic S, Kessler TM, Kessels AGH, Bachmann LM. Efficacy and Adverse Events of Antimuscarinics for Treating Overactive Bladder: Network Metaanalyses. Eur Urol. 2012 Dec 1;62(6):1040-60.

42. Vouri SM, Kebodeaux CD, Stranges PM, Teshome BF. Adverse events and treatment discontinuations of antimuscarinics for the treatment of overactive bladder in older adults: A systematic review and meta-analysis. Arch Gerontol Geriatr. 2017 Apr;69:77-96.

43. Ikeda K, Kobayashi S, Suzuki M, Miyata K, Takeuchi M, Yamada T, et al. M(3) receptor antagonism by the novel antimuscarinic agent solifenacin in the urinary bladder and salivary gland. Naunyn Schmiedebergs Arch Pharmacol. 2002 Aug;366(2):97-103.

44. Kay GG, Granville LJ. Antimuscarinic agents: implications and concerns in the management of overactive bladder in the elderly. Clin Ther. 2005 Jan;27(1):12738; quiz 139-40.

45. Staskin D, Kay G, Tannenbaum C, Goldman HB, Bhashi K, Ling J, et al. Trospium chloride has no effect on memory testing and is assay undetectable in the central nervous system of older patients with overactive bladder. Int J Clin Pract. 2010;64(9):1294-300.

46. Maman K, Aballea S, Nazir J, Desroziers K, Neine M-E, Siddiqui E, et al. Comparative efficacy and safety of medical treatments for the management of 
overactive bladder: a systematic literature review and mixed treatment comparison. Eur Urol. 2014 Apr;65(4):755-65.

47. Kelleher C, Hakimi Z, Zur R, Siddiqui E, Maman K, Aballéa S, et al. Efficacy and Tolerability of Mirabegron Compared with Antimuscarinic Monotherapy or Combination Therapies for Overactive Bladder: A Systematic Review and Network Meta-analysis. Eur Urol. 2018 Sep 1;74(3):324-33.

48. Alexandre EC, Kiguti LR, Calmasini FB, Silva FH, da Silva KP, Ferreira R, et al. Mirabegron relaxes urethral smooth muscle by a dual mechanism involving $\beta 3$ adrenoceptor activation and $\alpha 1$-adrenoceptor blockade. Br J Pharmacol. 2016 Feb;173(3):415-28.

49. Herschorn S, Barkin J, Castro-Diaz D, Frankel JM, Espuna-Pons M, Gousse AE, et al. A phase III, randomized, double-blind, parallel-group, placebo-controlled, multicentre study to assess the efficacy and safety of the beta3 adrenoceptor agonist, mirabegron, in patients with symptoms of overactive bladder.[Erratum appears in Urology. 2013 Dec;82(6):1457]. Urology. 2013;82(2):313-20.

50. Yamaguchi O, Marui E, Kakizaki H, Homma Y, Igawa Y, Takeda M, et al. Phase III, randomised, double-blind, placebo-controlled study of the beta3-adrenoceptor agonist mirabegron, 50mg once daily, in Japanese patients with overactive bladder. BJU Int. 2014;113(6):951-60.

51. Nitti VW, Khullar V, van Kerrebroeck P, Herschorn S, Cambronero J, Angulo JC, et al. Mirabegron for the treatment of overactive bladder: a prespecified pooled efficacy analysis and pooled safety analysis of three randomised, double-blind, placebo-controlled, phase III studies. Int J Clin Pract. 2013 Jul;67(7):619-32.

52. Cui Y, Zong H, Yang C, Yan H, Zhang Y. The efficacy and safety of mirabegron in treating OAB: a systematic review and meta-analysis of phase III trials. Int Urol Nephrol. 2014 Jan;46(1):275-84.

53. Wang J, Zhou Z, Cui Y, Li Y, Yuan H, Gao Z, et al. Meta-analysis of the efficacy and safety of mirabegron and solifenacin monotherapy for overactive bladder. Neurourol Urodyn. 2019 Jan;38(1):22-30.

54. Chapple CR, Cardozo L, Nitti VW, Siddiqui E, Michel MC. Mirabegron in overactive bladder: A review of efficacy, safety, and tolerability. Neurourol Urodyn. 2014;33(1):17-30.

55. Yeowell G, Smith P, Nazir J, Hakimi Z, Siddiqui E, Fatoye F. Real-world persistence and adherence to oral antimuscarinics and mirabegron in patients with overactive bladder $(\mathrm{OAB})$ : a systematic literature review. BMJ Open [Internet]. 2018 Nov 21 [cited 2019 Apr 2];8(11). Available from: https://www.ncbi.nlm.nih.gov/pmc/articles/PMC6252764/

56. Gauthier C, Leblais V, Kobzik L, Trochu JN, Khandoudi N, Bril A, et al. The negative inotropic effect of beta3-adrenoceptor stimulation is mediated by 
activation of a nitric oxide synthase pathway in human ventricle. J Clin Invest. 1998 Oct 1;102(7):1377-84.

57. Rosa GM, Ferrero S, Nitti VW, Wagg A, Saleem T, Chapple CR. Cardiovascular Safety of $\beta 3$-adrenoceptor Agonists for the Treatment of Patients with Overactive Bladder Syndrome. Eur Urol. 2016 Feb;69(2):311-23.

58. Chapple CR, Kaplan SA, Mitcheson D, Klecka J, Cummings J, Drogendijk T, et al. Randomized double-blind, active-controlled phase 3 study to assess 12-month safety and efficacy of mirabegron, a beta(3)-adrenoceptor agonist, in overactive bladder. Eur Urol. 2013;63(2):296-305.

59. Tadrous M, Matta R, Greaves S, Herschorn S, Mamdani M, Juurlink DN, et al. Mirabegron and the Risk of Arrhythmias: A population-based cohort study. JAMA Intern Med. In Press.

60. Batista JE, Kolbl H, Herschorn S, Rechberger T, Cambronero J, Halaska M, et al. The efficacy and safety of mirabegron compared with solifenacin in overactive bladder patients dissatisfied with previous antimuscarinic treatment due to lack of efficacy: Results of a noninferiority, randomized, phase IIIb trial. Ther Adv Urol. 2015;7(4):167-79.

61. Tubaro A, Batista JE, Nitti VW, Herschorn S, Chapple CR, Blauwet MB, et al. Efficacy and safety of daily mirabegron $50 \mathrm{mg}$ in male patients with overactive bladder: a critical analysis of five phase III studies. Ther Adv Urol. 2017 May 10;9(6):137-54.

62. Wagg A, Staskin D, Engel E, Herschorn S, Kristy RM, Schermer CR. A Phase 4, double-blind, randomized, placebo-controlled, parallel group, multi-centre study to evaluate the efficacy, safety, and tolerability of mirabegron in older adult patients with overactive bladder syndrome (PILLAR). Neurourol Urodyn [Internet]. 2018 [cited 2019 Mar 21]; Available from: https://www.ics.org/2018/abstract/268

63. Yoshida M, Kato D, Nishimura T, Van Schyndle J, Uno S, Kimura T. Anticholinergic burden in the Japanese elderly population: Use of antimuscarinic medications for overactive bladder patients. Int J Urol Off J Jpn Urol Assoc. 2018;25(10):855-62.

64. Carnahan RM, Lund BC, Perry PJ, Pollock BG. A critical appraisal of the utility of the serum anticholinergic activity assay in research and clinical practice. Psychopharmacol Bull. 2002;36(2):24-39.

65. Thomas C, Hestermann U, Kopitz J, Plaschke K, Oster P, Driessen M, et al. Serum anticholinergic activity and cerebral cholinergic dysfunction: an EEG study in frail elderly with and without delirium. BMC Neurosci. 2008 Sep 15;9:86.

66. Mulsant BH, Pollock BG, Kirshner M, Shen C, Dodge H, Ganguli M. Serum anticholinergic activity in a community-based sample of older adults: relationship with cognitive performance. Arch Gen Psychiatry. 2003 Feb;60(2):198-203. 
67. Boustani M, Campbell N, Munger S, Maidment I, Fox C. Impact of anticholinergics on the aging brain: a review and practical application. Aging Health. 2008 Jun 1;4(3):311-20.

68. Campbell NL, Boustani MA, Lane KA, Gao S, Hendrie H, Khan BA, et al. Use of anticholinergics and the risk of cognitive impairment in an African American population. Neurology. 2010 Jul 13;75(2):152-9.

69. Rudolph JL, Salow MJ, Angelini MC, McGlinchey RE. The anticholinergic risk scale and anticholinergic adverse effects in older persons. Arch Intern Med. 2008 Mar 10;168(5):508-13.

70. Chew ML, Mulsant BH, Pollock BG, Lehman ME, Greenspan A, Mahmoud RA, et al. Anticholinergic activity of 107 medications commonly used by older adults. J Am Geriatr Soc. 2008 Jul;56(7):1333-41.

71. Carnahan RM, Lund BC, Perry PJ, Pollock BG, Culp KR. The Anticholinergic Drug Scale as a measure of drug-related anticholinergic burden: associations with serum anticholinergic activity. J Clin Pharmacol. 2006 Dec;46(12):1481-6.

72. Ehrt U, Broich K, Larsen JP, Ballard C, Aarsland D. Use of drugs with anticholinergic effect and impact on cognition in Parkinson's disease: a cohort study. J Neurol Neurosurg Psychiatry. 2010 Feb 1;81(2):160-5.

73. Sittironnarit G, Ames D, Bush AI, Faux N, Flicker L, Foster J, et al. Effects of anticholinergic drugs on cognitive function in older Australians: results from the AIBL study. Dement Geriatr Cogn Disord. 2011;31(3):173-8.

74. Han L, Agostini JV, Allore HG. Cumulative Anticholinergic Exposure Is Associated with Poor Memory and Executive Function in Older Men. J Am Geriatr Soc. 2008 Dec;56(12):2203-10.

75. Durán CE, Azermai M, Vander Stichele RH. Systematic review of anticholinergic risk scales in older adults. Eur J Clin Pharmacol. 2013 Jul 1;69(7):1485-96.

76. Plassman BL, Langa KM, Fisher GG, Heeringa SG, Weir DR, Ofstedal MB, et al. Prevalence of Dementia in the United States: The Aging, Demographics, and Memory Study. Neuroepidemiology. 2007 Nov;29(1-2):125-32.

77. Canada PHA of. Dementia in Canada, including Alzheimer's Disease: Highlights from the Canadian Chronic Disease Surveillance System [Internet]. aem. 2017 [cited 2019 Mar 22]. Available from: https://www.canada.ca/en/publichealth/services/publications/diseases-conditions/dementia-highlights-canadianchronic-disease-surveillance.html

78. Prince M, Bryce R, Albanese E, Wimo A, Ribeiro W, Ferri CP. The global prevalence of dementia: a systematic review and metaanalysis. Alzheimers Dement J Alzheimers Assoc. 2013 Jan;9(1):63-75.e2. 
79. Alzheimer Society of Canada. Prevalence and monetary costs of dementia in Canada. [Internet]. Alzheimer Society of Canada; 2016 [cited 2019 Mar 22]. Available from: https://alzheimer.ca/sites/default/files/files/national/statistics/prevalenceandcostsof dementia_en.pdf

80. Sperling RA, Aisen PS, Beckett LA, Bennett DA, Craft S, Fagan AM, et al. Toward defining the preclinical stages of Alzheimer's disease: recommendations from the National Institute on Aging-Alzheimer's Association workgroups on diagnostic guidelines for Alzheimer's disease. Alzheimers Dement J Alzheimers Assoc. 2011 May;7(3):280-92.

81. Albert MS, DeKosky ST, Dickson D, Dubois B, Feldman HH, Fox NC, et al. The diagnosis of mild cognitive impairment due to Alzheimer's disease: recommendations from the National Institute on Aging-Alzheimer's Association workgroups on diagnostic guidelines for Alzheimer's disease. Alzheimers Dement J Alzheimers Assoc. 2011 May;7(3):270-9.

82. McKhann GM, Knopman DS, Chertkow H, Hyman BT, Jack CR, Kawas CH, et al. The diagnosis of dementia due to Alzheimer's disease: Recommendations from the National Institute on Aging-Alzheimer's Association workgroups on diagnostic guidelines for Alzheimer's disease. Alzheimers Dement J Alzheimers Assoc. 2011 May;7(3):263-9.

83. ICD-11 - Dementia [Internet]. [cited 2019 Apr 6]. Available from: https://icd.who.int/browse11/1$\mathrm{m} / \mathrm{en} \# / \mathrm{http} \% 3 \mathrm{a} \% 2 \mathrm{f} \% 2 \mathrm{fid}$. who.int $\% 2$ ficd$\% 2$ fentity\%2f546689346

84. Knopman DS, DeKosky ST, Cummings JL, Chui H, Corey-Bloom J, Relkin N, et al. Practice parameter: diagnosis of dementia (an evidence-based review). Report of the Quality Standards Subcommittee of the American Academy of Neurology. Neurology. 2001 May 8;56(9):1143-53.

85. Dorszewska J, Prendecki M, Oczkowska A, Dezor M, Kozubski W. Molecular Basis of Familial and Sporadic Alzheimer's Disease. Curr Alzheimer Res. 2016;13(9):952-63.

86. Masters CL, Bateman R, Blennow K, Rowe CC, Sperling RA, Cummings JL. Alzheimer's disease. Nat Rev Dis Primer. 2015 Oct 15;1:15056.

87. Jack CR, Knopman DS, Jagust WJ, Petersen RC, Weiner MW, Aisen PS, et al. Tracking pathophysiological processes in Alzheimer's disease: an updated hypothetical model of dynamic biomarkers. Lancet Neurol. 2013 Feb;12(2):20716.

88. Hardy J, Selkoe DJ. The Amyloid Hypothesis of Alzheimer's Disease: Progress and Problems on the Road to Therapeutics. Science. 2002 Jul 19;297(5580):353-6. 
89. Iturria-Medina Y, Sotero RC, Toussaint PJ, Mateos-Pérez JM, Evans AC. Early role of vascular dysregulation on late-onset Alzheimer's disease based on multifactorial data-driven analysis. Nat Commun [Internet]. 2016 Jun 21 [cited 2019 Mar 22];7. Available from:

https://www.ncbi.nlm.nih.gov/pmc/articles/PMC4919512/

90. Brun A, Englund E. Regional pattern of degeneration in Alzheimer's disease: neuronal loss and histopathological grading. Histopathology. 1981 Sep;5(5):54964.

91. Karimi S, Dharia SP, Flora DS, Slattum PW. Anticholinergic burden: clinical implications for seniors and strategies for clinicians. Consult Pharm J Am Soc Consult Pharm. 2012 Aug;27(8):564-82.

92. van Assema DME, Lubberink M, Boellaard R, Schuit RC, Windhorst AD, Scheltens P, et al. P-glycoprotein function at the blood-brain barrier: effects of age and gender. Mol Imaging Biol MIB Off Publ Acad Mol Imaging. 2012 Dec;14(6):771-6.

93. Parasca A, Doogue MP, Woodman RJ, Mangoni AA. Hypoalbuminaemia and impaired renal function are associated with increased anticholinergic drug prescribing. Int J Clin Pract. 2009 Jul;63(7):1110-4.

94. Sunderland T, Tariot PN, Cohen RM, Weingartner H, Mueller EA, Murphy DL. Anticholinergic sensitivity in patients with dementia of the Alzheimer type and age-matched controls. A dose-response study. Arch Gen Psychiatry. 1987 May;44(5):418-26.

95. Paquette A, Gou P, Tannenbaum C. Systematic review and meta-analysis: do clinical trials testing antimuscarinic agents for overactive bladder adequately measure central nervous system adverse events? J Am Geriatr Soc. 2011 Jul;59(7):1332-9.

96. Katz IR, Sands LP, Bilker W, DiFilippo S, Boyce A, D’Angelo K. Identification of medications that cause cognitive impairment in older people: the case of oxybutynin chloride. J Am Geriatr Soc. 1998 Jan;46(1):8-13.

97. Kay G, Crook T, Rekeda L, Lima R, Ebinger U, Arguinzoniz M, et al. Differential effects of the antimuscarinic agents darifenacin and oxybutynin ER on memory in older subjects. Eur Urol. 2006 Aug;50(2):317-26.

98. Lackner TE, Wyman JF, McCarthy TC, Monigold M, Davey C. Randomized, placebo-controlled trial of the cognitive effect, safety, and tolerability of oral extended-release oxybutynin in cognitively impaired nursing home residents with urge urinary incontinence. J Am Geriatr Soc. 2008 May;56(5):862-70.

99. Lipton RB, Kolodner K, Wesnes K. Assessment of cognitive function of the elderly population: effects of darifenacin. J Urol. 2005 Feb;173(2):493-8. 
100. Kay GG, Maruff P, Scholfield D, Malhotra B, Whelan L, Darekar A, et al. Evaluation of Cognitive Function in Healthy Older Subjects Treated with Fesoterodine. Postgrad Med. 2012 May 1;124(3):7-15.

101. Wagg A, Khullar V, Marschall-Kehrel D, Michel MC, Oelke M, Darekar A, et al. Flexible-dose fesoterodine in elderly adults with overactive bladder: results of the randomized, double-blind, placebo-controlled study of fesoterodine in an aging population trial. J Am Geriatr Soc. 2013 Feb;61(2):185-93.

102. Wesnes KA, Edgar C, Tretter RN, Bolodeoku J. Exploratory pilot study assessing the risk of cognitive impairment or sedation in the elderly following single doses of solifenacin 10 mg. Expert Opin Drug Saf. 2009 Nov 1;8(6):615-26.

103. Wagg A, Dale M, Tretter R, Stow B, Compion G. Randomised, Multicentre, Placebo-controlled, Double-blind Crossover Study Investigating the Effect of Solifenacin and Oxybutynin in Elderly People with Mild Cognitive Impairment: The SENIOR Study. Eur Urol. 2013 Jul 1;64(1):74-81.

104. Giramonti KM, Kogan BA, Halpern LF. The effects of anticholinergic drugs on attention span and short-term memory skills in children. Neurourol Urodyn. 2008;27(4):315-8.

105. Womack KB, Heilman KM. Tolterodine and Memory: Dry but Forgetful. Arch Neurol. 2003 May 1;60(5):771-3.

106. Todorova A, Vonderheid-Guth B, Dimpfel W. Effects of Tolterodine, Trospium Chloride, and Oxybutynin on the Central Nervous System. J Clin Pharmacol. 2001;41(6):636-44.

107. Sakakibara R, Uchiyama T, Yamanishi T, Kishi M. Dementia and lower urinary dysfunction: With a reference to anticholinergic use in elderly population. Int $\mathbf{J}$ Urol. 2008 Sep 1;15(9):778-88.

108. Suskind AM, Quanstrom K, Zhao S, Bridge M, Walter LC, Neuhaus J, et al. Overactive bladder is strongly associated with frailty in older individuals. Urology. 2017 Aug;106:26-31.

109. Thom DH, Haan MN, Van Den Eeden SK. Medically recognized urinary incontinence and risks of hospitalization, nursing home admission and mortality. Age Ageing. 1997 Sep;26(5):367-74.

110. Henriksson L, Andersson K-E, Ulmsten U. The Urethral Pressure Profiles in Continent and Stress-Incontinent Women. Scand J Urol Nephrol. 1979 Jan 1;13(1):5-10.

111. Nygaard I, Barber MD, Burgio KL, Kenton K, Meikle S, Schaffer J, et al. Prevalence of symptomatic pelvic floor disorders in US women. JAMA. 2008 Sep 17;300(11):1311-6. 
112. Danforth KN, Townsend MK, Lifford K, Curhan GC, Resnick NM, Grodstein F. Risk factors for urinary incontinence among middle-aged women. Am J Obstet Gynecol. 2006 Feb;194(2):339-45.

113. Yamaguchi C, Sakakibara R, Uchiyama T, Yamamoto T, Ito T, Liu Z, et al. Overactive bladder in diabetes: a peripheral or central mechanism? Neurourol Urodyn. 2007;26(6):807-13.

114. Palmer MH, Busby-Whitehead J. Relationship Between Heart Failure and Overactive Bladder. Curr Bladder Dysfunct Rep. 2010 Mar 1;5(1):18-22.

115. Green AR, Segal J, Tian J, Oh E, Roth DL, Hilson L, et al. Use of Bladder Antimuscarinics in Older Adults with Impaired Cognition. J Am Geriatr Soc. 2017 Feb;65(2):390-4.

116. Vouri SM, Schootman M, Strope SA, Birge SJ, Olsen MA. Differential Prescribing of Antimuscarinic Agents in Older Adults with Cognitive Impairment. Drugs Aging. 2018;35(4):321-31.

117. Ancelin ML, Artero S, Portet F, Dupuy A-M, Touchon J, Ritchie K. Nondegenerative mild cognitive impairment in elderly people and use of anticholinergic drugs: longitudinal cohort study. BMJ. $2006 \mathrm{Feb}$ 25;332(7539):455-9.

118. Carrière I, Fourrier-Reglat A, Dartigues J-F, Rouaud O, Pasquier F, Ritchie K, et al. Drugs with anticholinergic properties, cognitive decline, and dementia in an elderly general population: the 3-city study. Arch Intern Med. 2009 Jul;169(14):1317-24.

119. Gray SL, Anderson ML, Dublin S, Hanlon JT, Hubbard R, Walker R, et al. Cumulative Use of Strong Anticholinergics and Incident Dementia: A Prospective Cohort Study. JAMA Intern Med. 2015 Mar 1;175(3):401-7.

120. Perry EK, Kilford L, Lees AJ, Burn DJ, Perry RH. Increased Alzheimer pathology in Parkinson's disease related to antimuscarinic drugs. Ann Neurol. 2003 Aug;54(2):235-8.

121. Morrow SA, Rosehart H, Sener A, Welk B. Anti-cholinergic medications for bladder dysfunction worsen cognition in persons with multiple sclerosis. J Neurol Sci. 2018 Feb 15;385:39-44.

122. Richardson K, Fox C, Maidment I, Steel N, Loke YK, Arthur A, et al. Anticholinergic drugs and risk of dementia: case-control study. BMJ. 2018 Apr 25;361:k1315.

123. Moga DC, Abner EL, Wu Q, Jicha GA. Bladder antimuscarinics and cognitive decline in elderly patients. Alzheimers Dement Transl Res Clin Interv. 2017 Feb 9;3(1):139-48. 
124. Wacholder S, Silverman DT, McLaughlin JK, Mandel JS. Selection of controls in case-control studies. II. Types of controls. Am J Epidemiol. 1992 May 1;135(9):1029-41.

125. Austin PC, Anderson GM, Cigsar C, Gruneir A. Comparing the cohort design and the nested case-control design in the presence of both time-invariant and timedependent treatment and competing risks: bias and precision. Pharmacoepidemiol Drug Saf. 2012;21(7):714-24.

126. Essebag V, Platt RW, Abrahamowicz M, Pilote L. Comparison of nested casecontrol and survival analysis methodologies for analysis of time-dependent exposure. BMC Med Res Methodol. 2005 Jan 25;5:5.

127. Juurlink DN, Preyra C, Croxford R, Chong A, Austin P, Tu J, et al. Canadian Institute for Health Information Discharge Abstract Database: A Validation Study [Internet]. 2006 [cited 2019 Feb 6]. Available from:

https://www.ices.on.ca/Publications/Atlases-and-Reports/2006/Canadian-Institutefor-Health-Information

128. Levy AR, O’Brien BJ, Sellors C, Grootendorst P, Willison D. Coding accuracy of administrative drug claims in the Ontario Drug Benefit database. Can J Clin Pharmacol J Can Pharmacol Clin. 2003;10(2):67-71.

129. Hux JE, Ivis F, Flintoft V, Bica A. Diabetes in Ontario: determination of prevalence and incidence using a validated administrative data algorithm. Diabetes Care. 2002 Mar;25(3):512-6.

130. Tu JV, Naylor CD, Austin P. Temporal changes in the outcomes of acute myocardial infarction in Ontario, 1992-1996. Can Med Assoc J. 1999 Nov 16;161(10):1257-61.

131. Schultz SE, Rothwell DM, Chen Z, Tu K. Identifying cases of congestive heart failure from administrative data: a validation study using primary care patient records. Chronic Dis Inj Can. 2013 Jun;33(3):160-6.

132. Tu K, Campbell NR, Chen Z-L, Cauch-Dudek KJ, McAlister FA. Accuracy of administrative databases in identifying patients with hypertension. Open Med. 2007 Apr 14;1(1):e18-26.

133. Jaakkimainen RL, Bronskill SE, Tierney MC, Herrmann N, Green D, Young J, et al. Identification of Physician-Diagnosed Alzheimer's Disease and Related Dementias in Population-Based Administrative Data: A Validation Study Using Family Physicians' Electronic Medical Records. J Alzheimers Dis JAD. 2016 Aug 10;54(1):337-49.

134. Harada CN, Natelson Love MC, Triebel K. Normal Cognitive Aging. Clin Geriatr Med. 2013 Nov;29(4):737-52. 
135. Chiang C-H, Wu M-P, Ho C-H, Weng S-F, Huang C-C, Hsieh W-T, et al. Lower Urinary Tract Symptoms Are Associated with Increased Risk of Dementia among the Elderly: A Nationwide Study. BioMed Res Int [Internet]. 2015 [cited 2017 Nov 5];2015. Available from:

https://www.ncbi.nlm.nih.gov/pmc/articles/PMC4531168/

136. Cherbuin N, Kim S, Anstey KJ. Dementia risk estimates associated with measures of depression: a systematic review and meta-analysis. BMJ Open. 2015 Dec 1;5(12):e008853.

137. Kivipelto M, Ngandu T, Fratiglioni L, Viitanen M, Kåreholt I, Winblad B, et al. Obesity and Vascular Risk Factors at Midlife and the Risk of Dementia and Alzheimer Disease. Arch Neurol. 2005 Oct 1;62(10):1556-60.

138. Apostolidis A, Wagg A, Rahnam---a'i MS, Panicker JN, Vrijens D, Gontard A von. Is there "brain OAB" and how can we recognize it? International Consultation on Incontinence-Research Society (ICI-RS) 2017. Neurourol Urodyn. 2018;37(S4):S38-45.

139. Rosenbaum PR. Optimal Matching for Observational Studies. J Am Stat Assoc. 1989 Dec 1;84(408):1024-32.

140. Bergstralh EJ, Kosanke JL. Computerized Matching of Cases to Controls. Mayo Foundation; 1995 Apr. Report No.: 56.

141. Yao S, Till C, Kristal AR, Goodman PJ, Hsing AW, Tangen CM, et al. Serum estrogen levels and prostate cancer risk in the prostate cancer prevention trial: a nested case-control study. Cancer Causes Control. 2011 Aug;22(8):1121-31.

142. Kemppainen KJ, Tammela TLJ, Auvinen A, Murtola TJ. The association between antihypertensive drug use and incidence of prostate cancer in Finland: a population-based case-control study. Cancer Causes Control. 2011 Jul 19;22(10):1445.

143. Pearce N. Analysis of matched case-control studies. BMJ. 2016 Feb 25;352:i969.

144. Kuo C-L, Duan Y, Grady J. Unconditional or Conditional Logistic Regression Model for Age-Matched Case-Control Data? Front Public Health [Internet]. 2018 Mar 2 [cited 2019 Jun 9];6. Available from: https://www.ncbi.nlm.nih.gov/pmc/articles/PMC5840200/

145. Tamim H, Monfared AAT, LeLorier J. Application of lag-time into exposure definitions to control for protopathic bias. Pharmacoepidemiol Drug Saf. 2007 Mar;16(3):250-8.

146. Risacher SL, McDonald BC, Tallman EF, West JD, Farlow MR, Unverzagt FW, et al. Association Between Anticholinergic Medication Use and Cognition, Brain Metabolism, and Brain Atrophy in Cognitively Normal Older Adults. JAMA Neurol. 2016 Jun 1;73(6):721-32. 
147. Dupont WD. Power calculations for matched case-control studies. Biometrics. 1988 Dec;44(4):1157-68.

148. Sinha S, Mukherjee B. A score test for determining sample size in matched casecontrol studies with categorical exposure. Biom J Biom Z. 2006 Feb;48(1):35-53.

149. Parker RA, Bregman DJ. Sample size for individually matched case-control studies. Biometrics. 1986 Dec;42(4):919-26.

150. Cerasuolo JO, Cipriano LE, Sposato LA, Kapral MK, Fang J, Gill SS, et al. Population-based stroke and dementia incidence trends: Age and sex variations. Alzheimers Dement J Alzheimers Assoc. 2017 Oct;13(10):1081-8.

151. Nunes MS with contributions from T, Heuer C, Marshall J, Sanchez J, Thornton R, Reiczigel J, et al. epiR: Tools for the Analysis of Epidemiological Data [Internet]. 2018 [cited 2019 Apr 1]. Available from: https://CRAN.Rproject.org/package $=$ epiR

152. Duan Y, Grady JJ, Albertsen PC, Helen Wu Z. Tamsulosin and the risk of dementia in older men with benign prostatic hyperplasia. Pharmacoepidemiol Drug Saf. 2018 Mar;27(3):340-8.

153. Nikolic K, Filipic S, Smoliński A, Kaliszan R, Agbaba D. Partial least square and hierarchical clustering in ADMET modeling: prediction of blood-brain barrier permeation of $\alpha$-adrenergic and imidazoline receptor ligands. J Pharm Pharm Sci Publ Can Soc Pharm Sci Soc Can Sci Pharm. 2013;16(4):622-47.

154. Frankel JK, Duan Y, Albertsen PC. Is Tamsulosin Linked to Dementia in the Elderly? Curr Urol Rep. 2018 Jul 3;19(9):69.

155. Tae BS, Jeon BJ, Choi H, Cheon J, Park JY, Bae JH. Alpha-blocker and risk of dementia in patients with benign prostate hyperplasia: A nationwide populationbased study using the National Health Insurance Service database. J Urol. 2019 Mar 6;101097JU0000000000000209.

156. Pearce N. Classification of epidemiological study designs. Int J Epidemiol. 2012 Apr 1;41(2):393-7.

157. Rothman KJ, Greenland S, Lash TL. Case-control studies. In: Encyclopedia of Quantitative Risk Analysis and Assessment. 1st ed. 2008.

158. Rothman KJ, Greenland S, Lash TL. Modern epidemiology. 3rd ed. Philadelphia: Wolters Kluwer/Lippincott Williams \& Wilkins; 2008. 758 p.

159. Vandenbroucke JP, Pearce N. Case-control studies: basic concepts. Int J Epidemiol. 2012 Oct 1;41(5):1480-9.

160. Cole P, MacMahon B. Attributable risk percent in case-control studies. Br J Prev Soc Med. 1971 Nov;25(4):242-4. 
161. Deary IJ, Corley J, Gow AJ, Harris SE, Houlihan LM, Marioni RE, et al. Ageassociated cognitive decline. Br Med Bull. 2009;92:135-52.

162. da Silva J, Gonçalves-Pereira M, Xavier M, Mukaetova-Ladinska EB. Affective disorders and risk of developing dementia: systematic review. Br J Psychiatry J Ment Sci. 2013 Mar;202(3):177-86.

163. Ribe AR, Laursen TM, Charles M, Katon W, Fenger-Grøn M, Davydow D, et al. Long-term Risk of Dementia in Persons With Schizophrenia: A Danish Population-Based Cohort Study. JAMA Psychiatry. 2015 Nov 1;72(11):1095-101.

164. Berger AK, Fratiglioni L, Forsell Y, Winblad B, Bäckman L. The occurrence of depressive symptoms in the preclinical phase of AD: a population-based study. Neurology. 1999 Dec 10;53(9):1998-2002.

165. Javaherian K, Newman BM, Weng H, Hassenstab J, Xiong C, Coble D, et al. Examining the Complicated Relationship Between Depressive Symptoms and Cognitive Impairment in Preclinical Alzheimer Disease. Alzheimer Dis Assoc Disord. 2019 Mar;33(1):15-20.

166. Quan H, Li B, Duncan Saunders L, Parsons GA, Nilsson CI, Alibhai A, et al. Assessing Validity of ICD-9-CM and ICD-10 Administrative Data in Recording Clinical Conditions in a Unique Dually Coded Database. Health Serv Res. 2008 Aug;43(4):1424-41.

167. Greco A, Cascavilla L, Paris F, Errico M, Orsitto G, D'Alessandro V, et al. Undercoding of Alzheimer's disease and related dementias in hospitalized elderly patients in Italy. Am J Alzheimers Dis Other Demen. 2005 Jun;20(3):167-70.

168. Čolović MB, Krstić DZ, Lazarević-Pašti TD, Bondžić AM, Vasić VM. Acetylcholinesterase Inhibitors: Pharmacology and Toxicology. Curr Neuropharmacol. 2013 May;11(3):315-35.

169. Langa KM, Levine DA. The Diagnosis and Management of Mild Cognitive Impairment: A Clinical Review. JAMA. 2014 Dec 17;312(23):2551-61.

170. Williamson T, Green ME, Birtwhistle R, Khan S, Garies S, Wong ST, et al. Validating the 8 CPCSSN Case Definitions for Chronic Disease Surveillance in a Primary Care Database of Electronic Health Records. Ann Fam Med. 2014 Jul;12(4):367-72.

171. Rudy D, Cline K, Harris R, Goldberg K, Dmochowski R. Time to onset of improvement in symptoms of overactive bladder using antimuscarinic treatment. BJU Int. 2006 Mar;97(3):540-6.

172. Cai X, Campbell N, Khan B, Callahan C, Boustani M. Long-term anticholinergic use and the aging brain. Alzheimers Dement J Alzheimers Assoc. $2013 \mathrm{Jul}$ 1;9(4):377-85. 
173. Ivanova JI, Hayes-Larson E, Sorg RA, Birnbaum HG, Berner T. Healthcare resource use and costs of privately insured patients who switch, discontinue, or persist on anti-muscarinic therapy for overactive bladder. J Med Econ. 2014 Oct 1;17(10):741-50.

174. D’Souza AO, Smith MJ, Miller L-A, Doyle J, Ariely R. Persistence, adherence, and switch rates among extended-release and immediate-release overactive bladder medications in a regional managed care plan. J Manag Care Pharm JMCP. 2008 Apr;14(3):291-301.

175. Tadrous M, Khuu W, Elterman D, Singh S, Fernandes K, Martins D, et al. Treatments for Overactive Bladder: FINAL PHARMACOEPIDEMIOLOGY REPORT [Internet]. Ontario Drug Policy Research Network; 2016 Mar [cited 2017 Aug 17]. Available from: http://odprn.ca/wp-content/uploads/2016/03/OABFinal-Pharmacoepidemiology-Report-Censored_March3-2016.docx.pdf

176. Chancellor MB, Migliaccio-Walle K, Bramley TJ, Chaudhari SL, Corbell C, Globe D. Long-term patterns of use and treatment failure with anticholinergic agents for overactive bladder. Clin Ther. 2013 Nov;35(11):1744-51.

177. Sexton CC, Notte SM, Maroulis C, Dmochowski RR, Cardozo L, Subramanian D, et al. Persistence and adherence in the treatment of overactive bladder syndrome with anticholinergic therapy: a systematic review of the literature. Int J Clin Pract. 2011 May;65(5):567-85.

178. Rothman KJ, Greenland S, Lash TL. Control selection. In: Modern Epidemiology. 3rd ed. Philadelphia: Wolters Kluwer/Lippincott Williams \& Wilkins; 2008. p. $116-7$.

179. Austin PC. Balance diagnostics for comparing the distribution of baseline covariates between treatment groups in propensity-score matched samples. Stat Med. 2009 Nov 10;28(25):3083-107.

180. Ngo LH, Inouye SK, Jones RN, Travison TG, Libermann TA, Dillon ST, et al. Methodologic considerations in the design and analysis of nested case-control studies: association between cytokines and postoperative delirium. BMC Med Res Methodol. 2017 Jun 6;17(1):88.

181. Pike MC, Hill AP, Smith PG. Bias and efficiency in logistic analyses of stratified case-control studies. Int J Epidemiol. 1980 Mar;9(1):89-95.

182. Ray WA. Evaluating Medication Effects Outside of Clinical Trials: New-User Designs. Am J Epidemiol. 2003 Nov 1;158(9):915-20.

183. Haut ER, Pronovost PJ. Surveillance Bias in Outcomes Reporting. JAMA. 2011 Jun 15;305(23):2462-3.

184. Mozessohn L, Earle C, Spaner D, Cheng SY, Kumar M, Buckstein R. The Association of Dyslipidemia With Chronic Lymphocytic Leukemia: A Population- 
Based Study. JNCI J Natl Cancer Inst [Internet]. 2017 Mar 1 [cited 2019 Feb 21];109(3). Available from: https://academic-oupcom.myaccess.library.utoronto.ca/jnci/article/109/3/djw226/2905648

185. Tu K, Wang M, Young J, Green D, Ivers NM, Butt D, et al. Validity of administrative data for identifying patients who have had a stroke or transient ischemic attack using EMRALD as a reference standard. Can J Cardiol. 2013 Nov;29(11):1388-94.

186. Butt DA, Tu K, Young J, Green D, Wang M, Ivers N, et al. A validation study of administrative data algorithms to identify patients with Parkinsonism with prevalence and incidence trends. Neuroepidemiology. 2014;43(1):28-37.

187. Tu K, Wang M, Jaakkimainen RL, Butt D, Ivers NM, Young J, et al. Assessing the validity of using administrative data to identify patients with epilepsy. Epilepsia. 2014 Feb 1;55(2):335-43.

188. Welk B, Loh E, Shariff SZ, Liu K, Siddiqi F. An administrative data algorithm to identify traumatic spinal cord injured patients: a validation study. Spinal Cord. 2014 Jan;52(1):34-8. 


\section{Appendices}

\section{Appendices}

\subsection{Drug Identification List}

\begin{tabular}{|c|c|}
\hline Drug & DIN \\
\hline \multicolumn{2}{|c|}{ Overactive bladder drugs } \\
\hline Darifenacin & 02273217,02273225 \\
\hline Solifenacin & $\begin{array}{l}02277263,02277271,02397900 \\
02397919,02399032,02399040,02417723,02417731,02422239,02422247,02423308,02423316,02424339, \\
02424347,02428938, \\
02437988,02437996,02443171,02443198,02446375,02446383\end{array}$ \\
\hline Trospium & 02275066 \\
\hline Fesoterodine & 02380021,02380048 \\
\hline Mirabegron & 02402874,02402882 \\
\hline \multicolumn{2}{|c|}{ Cholinesterase Inhibitors } \\
\hline Donepezil & $\begin{array}{l}02232043,02232044,02269457,02269465,02322331,02322358,02328666,02328682,02340607,02340615, \\
02359472,02359480,02362260,02362279,02367688,02367696,02381508,02381516,02397595,02397609, \\
\text { 02397617, 02397625, 02400561, 02400588, 02402092, 02402106, 02402645, 02402653, 02404419, 02404427, } \\
\text { 02412853, 02412861, 02412918, 02412934, 02416417, 02416425, 02416948, 02416956, 02419866, 02419874, } \\
\text { 02420597, 02420600, 02425343, 02425351, 02426943, 02426951, 02428482, 02428490, 02432684, 02432692, } \\
\text { 02439557, 02439565, 02446669, 02446677, 82232044, 99400856, 99401081, 99401082 }\end{array}$ \\
\hline Memantine & $\begin{array}{l}02244298,02244299,02244300,02244302,02266717,02266725,02266733,02270773,02270781,02270803, \\
02293021,02293048,02293056,02295229,02295237,02295245,02316943,02316951,02316978,02333376,\end{array}$ \\
\hline
\end{tabular}




\begin{tabular}{|c|c|}
\hline & $\begin{array}{l}\text { 02333384, 02333392, 02339439, 02339447, 02339455, 02377950, 02377969, 02377977, 02398370, 02398389, } \\
\text { 02398397, 02416573, 02416581, 02416603, 02420821, 02420848, 02420856, 02425157, 02425165, 02425173, } \\
\text { 02443015, 02443023, 02443031, 82244299, 82244300, 02349116, 02260638, 02320908, 02321130, 02324059, } \\
\text { 02324067, 02344807, 02348950, 02366487, 02375532, 02382830, 02409887, 02409895, 02421364, 02430371, } \\
\text { 02443082, 02446049 }\end{array}$ \\
\hline Rivastigmine & $\begin{array}{l}\text { 02305984, 02305992, 02306018, 02306026, 02306034, 02306042, 02306050, 02306069, 02307685, 02307693, } \\
02307707,02307715,02308169,02308177,02308185,02308193,02308622,02308630,02308649,02308657, \\
02311283,02311291,02311305,02311313,02312492,02312506,02312514,02312522,02332809,02332825, \\
02336715,02336723,02336731,02336758,02375729,02375737,02375745,02375753,02406985,02406993, \\
02407000,02407019,02416999,02417006,02417014,02417022,02423413,02423421,02426293,02426307, \\
02242115,02242116,02242117,02242118,02245240,02302845,02302853,02324563,02324571,02324598, \\
02324601,02332817,02332833,02401614,02401622,02401630,02401649,02427567,02427575,02427583, \\
02427591,02432803,82242115,82242116\end{array}$ \\
\hline \multicolumn{2}{|l|}{ Statin drugs } \\
\hline Atorvastatin calcium & $\begin{array}{l}\text { 02230711, 02230713, 02230714, 02243097, 02288346, 02288354, 02288362, 02288370, 02295261, 02295288, } \\
\text { 02295296, 02295318, 02302675, 02302683, 02302691, 02302713, 02310899, 02310902, 02310910, 02310929, } \\
\text { 02313448, 02313456, 02313464, 02313472, 02313707, 02313715, 02313723, 02313758, 02324946, 02324954, } \\
\text { 02324962, 02324970, 02348713, 02348748, 02350297, 02350319, 02350327, 02350335, 02373203, 02373211, } \\
02373238,02373246,02391058,02391066,02391074,02391082,02392933,02392941,02392968,0239297, \\
\text { 02399377, 02399385, 02399393, 02399407, 02407256, 02407264, 02407272, 02407280, 02417952, 02454017, } \\
02454025,02454041\end{array}$ \\
\hline Cerivastatin sodium & $02237325,02237326,02241466$ \\
\hline Fluvastatin & $02250527,02061562,02061570,02299224,02299232,02400235,02400243$ \\
\hline Lovastatin & $\begin{array}{l}\text { 00795852, 00795860, 02220172, 02220180, 02243127, 02243129, 02245822, 02245823, 02246013, 02246014, } \\
\text { 02246542, 02246543, 02247056, 02247057, 02248572, 02248573, 02267969, 02267977, 02353229, }\end{array}$ \\
\hline Pravastatin & $\begin{array}{l}\text { 02237373, 02237374, 02237375, 00893749, 00893757, 02222051, 02243506, 02243507, 02243508, 02244350, } \\
\text { 02244351, 02244352, 02246930, 02246931, 02246932, 02247008, 02247009, 02247010, 02247655, 0224765, } \\
\text { 02247657, 02247856, 02247857, 02247858, 02248182, 02248183, 02248184, 02257092, 02257106, 02257114, } \\
\text { 02284421, 02284448, 02284456, 02317451, 02317478, 02317486, 02330954, 02330962, 02330970, 02332191, } \\
\text { 02332205, 02332213 }\end{array}$ \\
\hline Rosuvastatin calcium & $\begin{array}{l}\text { 02247162, 02247163, 02247164, 02265540, 02337975, 02337983, 02337991, 02338009, 02338726, 02338734, } \\
\text { 02338742, 02338750, 02339765, 02339773, 02339781, 02339803, 02354608, 02354616, 02354624, 02354632, } \\
\text { 02378523, 02378531, 02378558, 02378566, 02381265, 02381273, 02381281, 02381303, 02382644, 02382652, } \\
\text { 02382660, 02382679, 02391252, 02391260, 02391279, 02391287, 02397781, 02397803, 02397811, 02397838, }\end{array}$ \\
\hline
\end{tabular}




\begin{tabular}{|l|l|}
\hline & $02399164,02399172,02405628,02405636,02405644,02405652,02413051,02413078,02413086,02413108$, \\
& $02442574,02442582,02442590,02442604$ \\
\hline Simvastatin & $00884324,00884332,00884340,00884359,02240332,02246582,02246583,02246584,02246585,02246737$, \\
& $02247011,02247012,02247013,02247014,02247015,02247067,02247068,02247069,02247070,02247071$, \\
& $02247827,02247828,02247830,02247831,02247833,02248103,02248104,02248105,02248106,02248107$, \\
& $02250144,02250152,02250160,02250179,02250187,02252619,02252635,02252643,02252651,02252678$, \\
& $02265885,02265893,02265907,02269252,02269260,02269279,02269287,02269295,02281546,02281554$, \\
& $02284758,02284766,02300915,02300923,02300931,02329131,02329158,02329166,02329174,02329182$, \\
& $02331020,02331039,02331047,02331055,02331063,02331985,02331993,02332000,02372932,02372940$, \\
& $02372959,02372967,02372975,02375036,02375044,02375052,02375060,02375079,02375591,02375605$, \\
& $02375613,02375621,02375648,02378884,02378892,02378906,02378914,02405148,02405156,02405164$, \\
& 02405172,02405180 \\
\hline
\end{tabular}




\subsection{Strong anticholinergic drug list}

\begin{tabular}{|c|c|c|}
\hline ACLIDINIUM \& FORMOTEROL FUMARATE & CLOMIPRAMINE & MECLIZINE HCL \\
\hline ACLIDINIUM BROMIDE & CLOMIPRAMINE HCL & MECLIZINE HCL \& NIACIN \\
\hline $\begin{array}{l}\text { AMITRIPTYLINE \& BUPIVACAINE HCL \& CLONIDINE } \\
\text { HCL \& GABAPENTIN }\end{array}$ & CLOZAPINE & NORTRIPTYLINE \\
\hline AMITRIPTYLINE HCL \& PERPHENAZINE & CYPROHEPTADINE HCL & OLANZAPINE \\
\hline AMOXAPINE & DESIPRAMINE HCL & ORPHENADRINE CITRATE \\
\hline ATROPINE SULFATE & DEXCHLORPHENIRAMINE MALEATE & ORPHENADRINE HCL \\
\hline $\begin{array}{l}\text { ATROPINE SULFATE \& HYOSCYAMINE SULFATE \& } \\
\text { PHENOBARBITAL \& SCOPOLAMINE HBR }\end{array}$ & DIMENHYDRINATE & PROPANTHELINE BROMIDE \\
\hline $\begin{array}{l}\text { ATROPINE SULFATE \& HYOSCYAMINE SULFATE \& } \\
\text { SCOPOLAMINE HBR }\end{array}$ & DIPHENHYDRAMINE HCL & PROTRIPTYLINE HCL \\
\hline AZATADINE MALEATE & DOXEPIN HCL & SCOPOLAMINE \\
\hline $\begin{array}{l}\text { AZATADINE MALEATE \& PSEUDOEPHEDRINE } \\
\text { SULFATE }\end{array}$ & $\begin{array}{l}\text { DOXYLAMINE SUCCINATE \& } \\
\text { PYRIDOXINE HCL }\end{array}$ & $\begin{array}{l}\text { SCOPOLAMINE BUTYL HYDROXIDE } \\
\text { BROMIDE }\end{array}$ \\
\hline CHLORDIAZEPOXIDE HCL \& CLIDINIUM HCL & $\begin{array}{l}\text { GLYCOPYRROLATE BROMIDE \& } \\
\text { INDACATEROL MALEATE }\end{array}$ & TRIHEXYPHENIDYL HCL \\
\hline CHLORPHENIRAMINE MALEATE & $\begin{array}{l}\text { HYDROCODONE BITARTRATE \& } \\
\text { PHENYLTOLOXAMINE CHLORIDE }\end{array}$ & TRIMIPRAMINE \\
\hline CHLORPHENIRAMINE MALEATE \& EPINEPHRINE & HYDROXYZINE HCL & TRIMIPRAMINE MALEATE \\
\hline CHLORPROMAZINE & HYOSCYAMINE SULFATE & UMECLIDINIUM BROMIDE \\
\hline CHLORPROMAZINE HCL & IMIPRAMINE HCL & $\begin{array}{l}\text { UMECLIDINIUM BROMIDE \& } \\
\text { VILANTEROL TRIPHENYLACETATE }\end{array}$ \\
\hline CHLORPROTHIXENE & CLEMASTINE FUMARATE & \\
\hline
\end{tabular}




\subsection{Cardiovascular, psychological, and neurological covariates and their derivation}

\begin{tabular}{|c|c|c|c|c|c|c|}
\hline Diagnosis & Algorithm & Validation & CIHI DAD/SD & NACRS & OHIP & \\
\hline & & & ICD-9 & ICD-10 & $\begin{array}{l}\text { Diagnosis } \\
\text { code }\end{array}$ & Fee Code \\
\hline Diabetes mellitus & $\begin{array}{l}\text { ICES Derived Cohort } \\
\text { Prevalent case preceding } \\
\text { index date within } 3 \text { years }\end{array}$ & $\begin{array}{l}\text { Sens } 86 \% \\
\text { Spec } 97 \% \\
\text { PPV } 80 \%(129)\end{array}$ & & & & \\
\hline Dyslipidemia & $\begin{array}{l}\text { Diagnosis preceding the } \\
\text { index date within } 3 \text { years } \\
\quad \text { OR } \\
\text { Dyslipidemic agent } \\
\text { prescription for at least } 180 \\
\text { days cumulative supply } \\
\text { preceding the index date } \\
\text { within } 3 \text { years (See Statin } \\
\text { list in Appendix } 6.1 \text { ) }\end{array}$ & $\begin{array}{l}\text { Non-validated } \\
\text { algorithm used in } \\
\text { previous study } \\
\text { (184) }\end{array}$ & $\begin{array}{l}2720-2726, \\
2729\end{array}$ & $\begin{array}{l}\text { E780-E785, E788 } \\
\text { E789, E881, H026 }\end{array}$ & 272 & \\
\hline Hypertension & $\begin{array}{l}\text { ICES Derived Cohort } \\
\text { Prevalent case preceding } \\
\text { index date within } 3 \text { years }\end{array}$ & $\begin{array}{l}\text { Sens } 72 \% \\
\text { Spec } 95 \% \\
\text { PPV } 87 \%(132)\end{array}$ & $\begin{array}{l}401,402,403 \\
404,405\end{array}$ & $\mathrm{I} 10, \mathrm{I} 11, \mathrm{I} 12, \mathrm{I} 13, \mathrm{I} 15$ & $\begin{array}{l}401,402, \\
403\end{array}$ & \\
\hline Stroke/TIA & $\begin{array}{l}\text { CIHI or NACRS or SDS or } \\
1 \text { OHIP } \\
\text { Prevalent case preceding } \\
\text { index date within } 3 \text { years }\end{array}$ & $\begin{array}{l}\text { Sens } 76 \% \\
\text { Spec } 98 \% \\
\text { PPV 39\% } \\
\text { NPV } 99 \%(185)\end{array}$ & $430-438$ & $\begin{array}{l}\text { I60, I61, I62 } \\
\text { I63, I64, G46, G45 } \\
\text { (excluding G45.4), } \\
\text { H34.1 }\end{array}$ & $432-436$ & \\
\hline $\begin{array}{l}\text { Congestive heart } \\
\text { disease, heart } \\
\text { failure }\end{array}$ & $\begin{array}{l}\text { ICES Derived Cohort } \\
\text { Prevalent case preceding } \\
\text { index date within } 3 \text { years }\end{array}$ & $\begin{array}{l}\text { Sens } 85 \% \\
\text { Spec } 97 \% \\
\text { PPV } 56 \%(131)\end{array}$ & 428 & I500, I50, I509 & 428 & Q050 \\
\hline $\begin{array}{l}\text { Peripheral arterial } \\
\text { disease/ } \\
\text { Atherosclerotic } \\
\text { disease }\end{array}$ & $\begin{array}{l}\text { Diagnosis preceding the } \\
\text { index date within } 3 \text { years }\end{array}$ & None & 4140,440 & $\mathrm{I} 251, \mathrm{I} 70$ & 440 & \\
\hline
\end{tabular}




\begin{tabular}{|c|c|c|c|c|c|c|}
\hline Atrial Fibrillation & $\begin{array}{l}\text { Hospitalization OR ED visit } \\
\text { OR } 4 \text { OHIP billing codes in } \\
1 \text { year within } 3 \text { years prior } \\
\text { to index date }\end{array}$ & None & $427.31,427.32$ & I48 & 427 & \\
\hline $\begin{array}{l}\text { Acute myocardial } \\
\text { infarction }\end{array}$ & $\begin{array}{l}\text { ICES derived cohort } \\
\text { Prevalent case preceding } \\
\text { index date within } 3 \text { years }\end{array}$ & $\begin{array}{l}\text { True diagnosis } \\
\text { was AMI in } 94 \% \\
\text { or more of } \\
\text { patients(130) }\end{array}$ & 410 & $\mathrm{I} 21$ & 410,413 & \\
\hline $\begin{array}{l}\text { Other Coronary } \\
\text { disease (composite) }\end{array}$ & $\begin{array}{l}\text { Diagnosis or procedure } \\
\text { preceding the index date } \\
\text { within } 3 \text { years }\end{array}$ & None & $\begin{array}{l}4110,4120 \\
4130,4140 \\
4148,4149\end{array}$ & $\begin{array}{l}\text { I20, I240, I248, I249, } \\
\text { I251, I252, I255, I256, } \\
\text { I258, I259 } \\
\text { Procedure code (CCI): } \\
\text { Coronary angiography } \\
\text { or artery bypass } \\
\text { grafting 4802, 4803, } \\
\text { 4809, 1IJ50, 1IJ57. } \\
\text { 1.IJ.76xx }\end{array}$ & 412 & $\begin{array}{l}\text { Coronary angiography, } \\
\text { angioplasty, or artery } \\
\text { bypass grafting } \\
\text { G263, G297, Z440, } \\
\text { Z442, } \\
\text { G262, G298, Z434, } \\
\text { R742, R743 }\end{array}$ \\
\hline $\begin{array}{l}\text { Pulmonary } \\
\text { Emboism or Deep } \\
\text { Vein Thrombosis } \\
\end{array}$ & $\begin{array}{l}\text { Diagnosis preceding the } \\
\text { index date within } 3 \text { years }\end{array}$ & None & $\begin{array}{l}415(\mathrm{PE}) \\
451 \\
453\end{array}$ & $\begin{array}{l}\text { I80 (VTE) } \\
\text { I82 (VTE) } \\
\text { I26 (PE) } \\
\end{array}$ & $\begin{array}{l}415(\mathrm{PE}) \\
451 \\
(\mathrm{DVT}) \\
\end{array}$ & \\
\hline Mood disorder & $\begin{array}{l}\text { Diagnosis preceding the } \\
\text { index date within } 3 \text { years }\end{array}$ & None & 296 & $\begin{array}{l}\text { F30, F31, F32, F33, } \\
\text { F34, F38, F39, F53.0 }\end{array}$ & 296 & $\begin{array}{l}\text { 296.x, 300.4x, 301.13 or } \\
\text { provisional diagnosis } 6\end{array}$ \\
\hline Anxiety disorder & $\begin{array}{l}\text { Diagnosis preceding the } \\
\text { index date within } 3 \text { years }\end{array}$ & None & 300 & $\begin{array}{l}\text { F40: Phobic anxiety } \\
\text { disorders } \\
\text { F41: Other anxiety } \\
\text { disorders } \\
\text { F42: Obsessive- } \\
\text { compulsive disorder } \\
\text { F43: Reaction to } \\
\text { severe stress and } \\
\text { adjustment disorders } \\
\text { F48.8: Other specified } \\
\text { neurotic disorders } \\
\text { F48.9: Neurotic } \\
\text { disorder, unspecified }\end{array}$ & 300 & $\begin{array}{l}300,300.0 x, 300.2 x, \\
300.3 x, 308.3 x, 309.0 x, \\
309.24,309.28,309.3 x \\
309.4 x, 309.8 x, 309.9 x \\
\text { or provisional diagnosis } \\
7,15\end{array}$ \\
\hline
\end{tabular}




\begin{tabular}{|c|c|c|c|c|c|c|}
\hline $\begin{array}{l}\text { Schizophrenia } \\
\text { (includes } \\
\text { psychoses, } \\
\text { agitation, and } \\
\text { related disorders) }\end{array}$ & $\begin{array}{l}\text { Diagnosis preceding the } \\
\text { index date within } 3 \text { years }\end{array}$ & None & $\begin{array}{l}292,2930 \\
2938,294, \\
295,2971 \\
2973,2978 \\
2979,299\end{array}$ & $\begin{array}{l}\text { F04, F050, F058, } \\
\text { F059, F060-F066 } \\
\text { F20: (excluding } \\
\text { F20.4), F22, } \\
\text { F23, F24, F25, F28, } \\
\text { F29, F53.1 }\end{array}$ & $\begin{array}{l}295,297, \\
298\end{array}$ & $\begin{array}{l}\text { 295.x, 297.x, 298.x or } \\
\text { provisional diagnosis } 5\end{array}$ \\
\hline Alcohol abuse & $\begin{array}{l}\text { Diagnosis preceding the } \\
\text { index date within } 3 \text { years }\end{array}$ & None & $\begin{array}{l}\text { V113, 291, } \\
3030,3039, \\
3050,3575, \\
4255,5353, \\
5710,5711, \\
5713,7903, \\
9800\end{array}$ & $\begin{array}{l}\text { F10, G312, G721, } \\
\text { I426, K292, K700, } \\
\text { K701, K702, K703 } \\
\text { K704, K709, K860, } \\
\text { T510, Z502, Z714, } \\
\text { Z8640 }\end{array}$ & 291,303 & $\begin{array}{l}\text { 291.x (excluding } \\
291.82), 303.0\end{array}$ \\
\hline $\begin{array}{l}\text { Parkinson's } \\
\text { disease }\end{array}$ & $\begin{array}{l}\text { Hospitalization OR } 2 \\
\text { physician claims at least } 30 \\
\text { days apart in a 1-year period } \\
\text { preceding the index date } \\
\text { within } 3 \text { years }\end{array}$ & $\begin{array}{l}\text { Sens } 72 \% \\
\text { Spec } 100 \% \\
\text { PPV } 74 \% \\
\text { NPV } 100 \%(186)\end{array}$ & $3320-3321$ & $\begin{array}{l}\text { G20, G211, G212, } \\
\text { G213, G214, G218, } \\
\text { G219, G22, F02.3 }\end{array}$ & 332 & \\
\hline $\begin{array}{l}\text { Seizure disorder or } \\
\text { Epilepsy }\end{array}$ & $\begin{array}{l}\text { Hospitalization OR } 3 \\
\text { physician claims at least } 30 \\
\text { days apart in a } 2 \text {-year period } \\
\text { preceding the index date } \\
\text { within } 3 \text { years }\end{array}$ & $\begin{array}{l}\text { Sens } 74 \% \\
\text { Spec } 100 \% \\
\text { PPV } 80 \% \\
\text { NPV } 100 \%(187)\end{array}$ & 7803,345 & $\begin{array}{l}\text { R560, R568, G40, } \\
\text { G41 }\end{array}$ & 345 & \\
\hline Spinal cord injury & $\begin{array}{l}1 \text { record in CIHI-DAD or } \\
\text { NRS - } \\
\text { look back as far as possible } \\
\text { to identify prevalent cases }\end{array}$ & $\begin{array}{l}\text { Sens } 94 \% \\
\text { Spec } 97 \% \\
\text { PPV 96\% } \\
\text { NPV 95\%(188) }\end{array}$ & $\begin{array}{l}806 \\
907.2 \\
952\end{array}$ & $\begin{array}{l}\text { NRS RCG codes } \\
04.21 \times, 04.2 \times x, 14.1 \text {, } \\
14.3 \\
\text { CIHI-DAD S14.1, } \\
\text { S24.0, S24.1, S34.0, } \\
\text { S34.1, S34.3, T06.0, } \\
\text { T06.1 }\end{array}$ & E383A & \\
\hline
\end{tabular}


6.4 Baseline characteristics of unmatched cases and controls in sensitivity analysis

\begin{tabular}{|l|r|r|r|r|r|}
\hline Variable & & Control (n=37,119) & Cases (n=11,258) & Total (n=48,377) & StDiff \\
\hline Age (years) & Median (IQR) & $77(71-83)$ & $83(77-88)$ & $78(72-84)$ & 0.69 \\
\hline Age Group (years), n(\%) & $65-70$ & $8,308(22.4 \%)$ & $873(7.8 \%)$ & $9,181(19.0 \%)$ & 0.42 \\
\hline & $71-75$ & $8,502(22.9 \%)$ & $1,312(11.7 \%)$ & $9,814(20.3 \%)$ & 0.3 \\
\hline & $76-80$ & $8,060(21.7 \%)$ & $2,106(18.7 \%)$ & $10,166(21.0 \%)$ & 0.07 \\
\hline & $81-85$ & $6,593(17.8 \%)$ & $2,925(26.0 \%)$ & $9,518(19.7 \%)$ & 0.2 \\
\hline & $86-90$ & $3,966(10.7 \%)$ & $2,579(22.9 \%)$ & $6,545(13.5 \%)$ & 0.33 \\
\hline Sex (female), n,(\%) & $\geq 91$ & $1,690(4.6 \%)$ & $1,463(13.0 \%)$ & $3,153(6.5 \%)$ & 0.3 \\
\hline Stroke/TIA in previous 3 years, n(\%) & & $26,203(70.6 \%)$ & $7,727(68.6 \%)$ & $33,930(70.1 \%)$ & 0.04 \\
\hline
\end{tabular}




\subsection{Baseline characteristics of matched cases and controls in sensitivity analysis}

\begin{tabular}{|c|c|c|c|c|c|}
\hline Variable & & Control $(n=29,881)$ & Cases $(n=11,392)$ & Total $(n=41,273)$ & StDiff* \\
\hline \multicolumn{6}{|l|}{ Demographics } \\
\hline Age & Median (IQR) & $79(74-84)$ & $83(77-88)$ & $80(75-85)$ & 0.08 \\
\hline Sex (female), n, $(\%)$ & & $19,678(68.1 \%)$ & $7,703(68.7 \%)$ & $27,381(68.3 \%)$ & 0.07 \\
\hline \multirow[t]{8}{*}{ Year of diagnosis, $\mathrm{n},(\%)$} & 2010 & $3,225(11.2 \%)$ & $1,316(11.7 \%)$ & $4,541(11.3 \%)$ & 0.05 \\
\hline & 2011 & $3,783(13.1 \%)$ & $1,555(13.9 \%)$ & $5,338(13.3 \%)$ & 0.04 \\
\hline & 2012 & $3,767(13.0 \%)$ & $1,540(13.7 \%)$ & $5,307(13.2 \%)$ & 0.01 \\
\hline & 2013 & $4,042(14.0 \%)$ & $1,617(14.4 \%)$ & $5,659(14.1 \%)$ & 0.02 \\
\hline & 2014 & $4,213(14.6 \%)$ & $1,622(14.5 \%)$ & $5,835(14.5 \%)$ & 0.05 \\
\hline & 2015 & $4,691(16.2 \%)$ & $1,728(15.4 \%)$ & $6,419(16.0 \%)$ & 0.08 \\
\hline & 2016 & $4,520(15.6 \%)$ & $1,631(14.5 \%)$ & $6,151(15.3 \%)$ & 0.04 \\
\hline & 2017 & $656(2.3 \%)$ & $210(1.9 \%)$ & $866(2.2 \%)$ & 0.07 \\
\hline \multirow[t]{15}{*}{ LHIN, n, (\%) } & Toronto Central & $2,144(7.4 \%)$ & $760(6.8 \%)$ & $2,904(7.2 \%)$ & 0.02 \\
\hline & Erie St. Clair & $2,868(9.9 \%)$ & $977(8.7 \%)$ & $3,845(9.6 \%)$ & 0.04 \\
\hline & South West & $1,646(5.7 \%)$ & $645(5.7 \%)$ & $2,291(5.7 \%)$ & 0 \\
\hline & Waterloo Wellington & $3,868(13.4 \%)$ & $1,452(12.9 \%)$ & $5,320(13.3 \%)$ & 0.02 \\
\hline & Hamilton Niagara & $1,190(4.1 \%)$ & $423(3.8 \%)$ & $1,613(4.0 \%)$ & 0.01 \\
\hline & Central West & $1,576(5.5 \%)$ & $673(6.0 \%)$ & $2,249(5.6 \%)$ & 0.02 \\
\hline & Mississauga Halton & $1,951(6.8 \%)$ & $861(7.7 \%)$ & $2,812(7.0 \%)$ & 0.03 \\
\hline & Central & $3,017(10.4 \%)$ & $1,202(10.7 \%)$ & $4,219(10.5 \%)$ & 0.01 \\
\hline & Central East & $3,259(11.3 \%)$ & $1,325(11.8 \%)$ & $4,584(11.4 \%)$ & 0.01 \\
\hline & South East & $1,534(5.3 \%)$ & $566(5.0 \%)$ & $2,100(5.2 \%)$ & 0.01 \\
\hline & Champlain & $2,215(7.7 \%)$ & $1,075(9.6 \%)$ & $3,290(8.2 \%)$ & 0.06 \\
\hline & North Simcoe Muskoka & $1,546(5.4 \%)$ & $567(5.1 \%)$ & $2,113(5.3 \%)$ & 0.01 \\
\hline & North East & $1,531(5.3 \%)$ & $486(4.3 \%)$ & $2,017(5.0 \%)$ & 0.03 \\
\hline & North West & $531(1.8 \%)$ & $205(1.8 \%)$ & $736(1.8 \%)$ & 0 \\
\hline & Missing & $21(0.1 \%)$ & $<=5(0.0 \%)$ & $23(0.1 \%)$ & 0.02 \\
\hline Rural, n, $(\%)$ & & $4,020(13.9 \%)$ & $1,410(12.6 \%)$ & $5,430(13.5 \%)$ & 0.03 \\
\hline \multirow[t]{5}{*}{ Income quintile, $\mathrm{n},(\%)$} & 1 & $6,309(21.8 \%)$ & $2,634(23.5 \%)$ & $8,943(22.3 \%)$ & 0.04 \\
\hline & 2 & $6,175(21.4 \%)$ & $2,486(22.2 \%)$ & $8,661(21.6 \%)$ & 0.02 \\
\hline & 3 & $5,687(19.7 \%)$ & $2,137(19.0 \%)$ & $7,824(19.5 \%)$ & 0.02 \\
\hline & 4 & $5,451(18.9 \%)$ & $2,018(18.0 \%)$ & $7,469(18.6 \%)$ & 0.02 \\
\hline & 5 & $5,178(17.9 \%)$ & $1,908(17.0 \%)$ & $7,086(17.7 \%)$ & 0.02 \\
\hline
\end{tabular}




\begin{tabular}{|c|c|c|c|c|c|}
\hline & Missing & $97(0.3 \%)$ & $36(0.3 \%)$ & $133(0.3 \%)$ & 0 \\
\hline \multicolumn{6}{|l|}{ Health status and utilization } \\
\hline \multirow[t]{4}{*}{ Charlson index, $\mathrm{n},(\%)$} & 0 & $18,495(64.0 \%)$ & $6,112(54.5 \%)$ & $24,607(61.3 \%)$ & 0.17 \\
\hline & 1 to 2 & $7,252(25.1 \%)$ & $3,238(28.9 \%)$ & $10,490(26.1 \%)$ & 0.07 \\
\hline & 3 to 4 & $2,263(7.8 \%)$ & $1,303(11.6 \%)$ & $3,566(8.9 \%)$ & 0.11 \\
\hline & $>4$ & $887(3.1 \%)$ & $566(5.0 \%)$ & $1,453(3.6 \%)$ & 0.09 \\
\hline Primary care visits & Median (IQR) & $6(3-10)$ & $8(4-13)$ & $6(4-11)$ & 0.25 \\
\hline Hospital admission & $\mathrm{n},(\%)$ & $5,172(17.3 \%)$ & $5,050(44.3 \%)$ & $10,222(24.8 \%)$ & 0.61 \\
\hline Unique drugs dispensed & Median (IQR) & $11(8-16)$ & $13(9-18)$ & $12(8-16)$ & 0.27 \\
\hline Strong anticholinergics & $\mathrm{n},(\%)$ & $2,903(10.0 \%)$ & $1,468(13.1 \%)$ & $4,371(10.9 \%)$ & 0.09 \\
\hline \multicolumn{6}{|c|}{ Cardiovascular risk factors, $n,(\%)$} \\
\hline Hypertension & & $24,292(84.1 \%)$ & $9,738(86.8 \%)$ & $34,030(84.8 \%)$ & 0.03 \\
\hline Diabetes & & $10,708(37.1 \%)$ & $4,469(39.8 \%)$ & $15,177(37.8 \%)$ & 0.07 \\
\hline Dyslipidemia & & $18,087(62.6 \%)$ & $6,808(60.7 \%)$ & $24,895(62.1 \%)$ & 0.01 \\
\hline Atrial fibrillation & & $5,449(18.9 \%)$ & $2,877(25.6 \%)$ & $8,326(20.8 \%)$ & 0.12 \\
\hline Myocardial infarction & & $376(1.3 \%)$ & $231(2.1 \%)$ & $607(1.5 \%)$ & 0.05 \\
\hline Stroke/TIA & & $3,040(10.5 \%)$ & $2,267(20.2 \%)$ & $5,307(13.2 \%)$ & 0.21 \\
\hline Congestive heart disease & & $4,200(14.5 \%)$ & $2,524(22.5 \%)$ & $6,724(16.8 \%)$ & 0.14 \\
\hline Other coronary disease & & $6,564(22.7 \%)$ & $3,001(26.7 \%)$ & $9,565(23.8 \%)$ & 0.06 \\
\hline Peripheral arterial disease & & $2,480(8.6 \%)$ & $1,275(11.4 \%)$ & $3,755(9.4 \%)$ & 0.08 \\
\hline Venous thrombosis & & $1,636(5.7 \%)$ & $839(7.5 \%)$ & $2,475(6.2 \%)$ & 0.07 \\
\hline \multicolumn{6}{|c|}{ Psychological Risk Factors, n,(\%) } \\
\hline Anxiety & & $8,133(28.1 \%)$ & $4,450(39.7 \%)$ & $12,583(31.4 \%)$ & 0.23 \\
\hline Mood Disorder & & $788(2.7 \%)$ & $752(6.7 \%)$ & $1,540(3.8 \%)$ & 0.17 \\
\hline Schizophrenia & & $849(2.9 \%)$ & $1,417(12.6 \%)$ & $2,266(5.6 \%)$ & 0.34 \\
\hline Alcohol Abuse & & $383(1.3 \%)$ & $528(4.7 \%)$ & $911(2.3 \%)$ & 0.19 \\
\hline \multicolumn{6}{|c|}{ Neurological Risk Factors, $n,(\%)$} \\
\hline Parkinson's disease & & $606(2.1 \%)$ & $762(6.8 \%)$ & $1,368(3.4 \%)$ & 0.19 \\
\hline Epilepsy & & $223(0.8 \%)$ & $182(1.6 \%)$ & $405(1.0 \%)$ & 0.08 \\
\hline Spinal Cord Injury & & $70(0.2 \%)$ & $26(0.2 \%)$ & $96(0.2 \%)$ & 0 \\
\hline
\end{tabular}

